\title{
Urbanization, agricultural intensification, and environmental services: \\ A spatial analysis
}

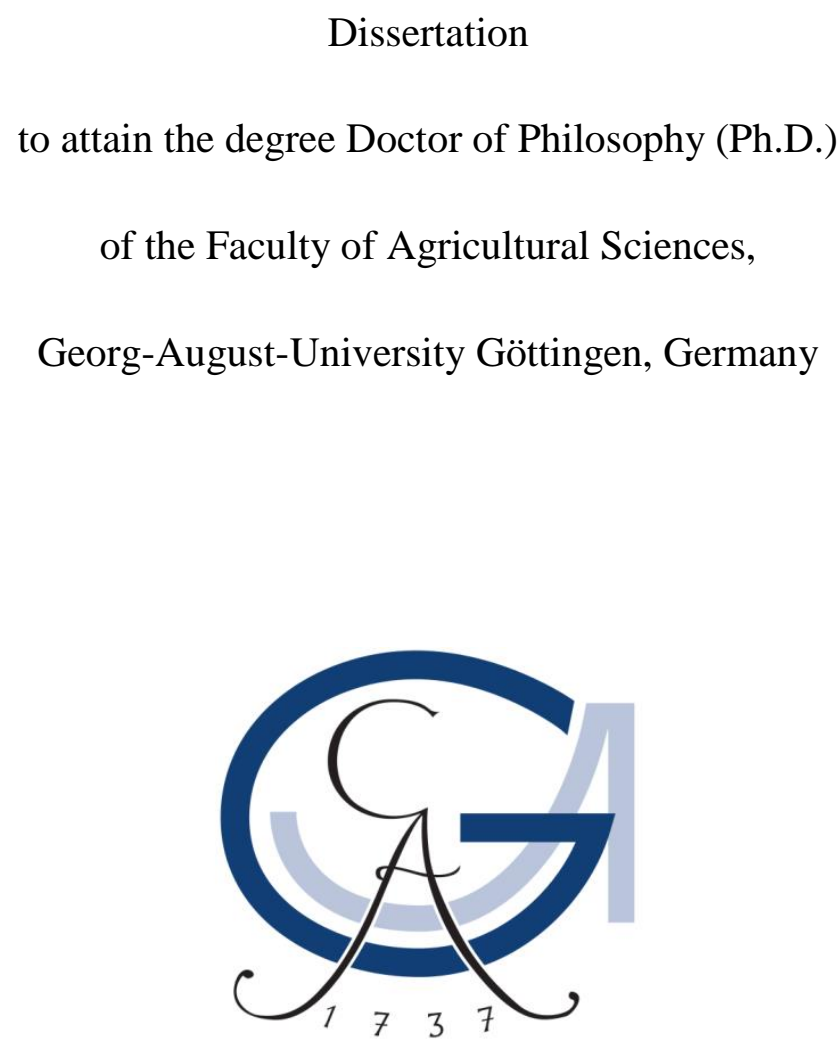

Submitted by

Linda Steinhübel

born on June 13, 1991 in Kirchheimbolanden, Germany

Göttingen, September 2019 
$1^{\text {st }}$ Referee:

Prof. Dr. Stephan von Cramon-Taubadel

$2^{\text {nd }}$ Referee:

Prof. Dr. Thomas Kneib

Date of oral examination: October 25, 2019 


\section{Table of contents}

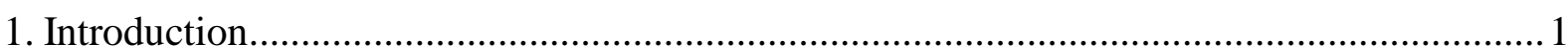

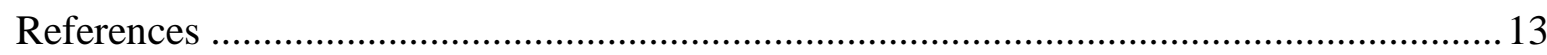

2. Somewhere in between towns, markets, and jobs - Opportunity costs of agricultural

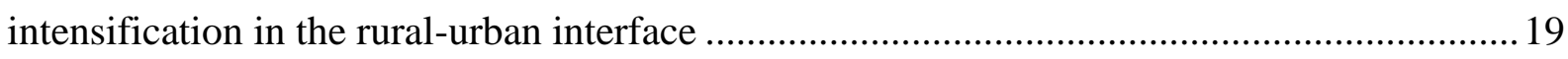

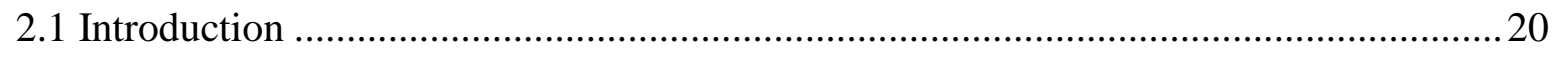

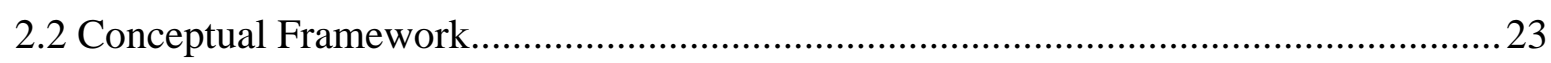

2.3 The Study Area, Survey Design and Data Set......................................................28

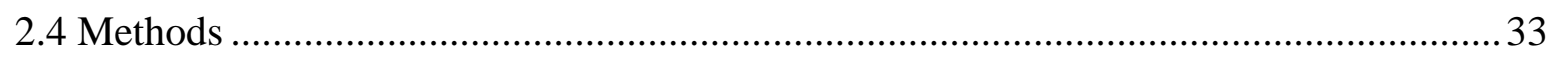

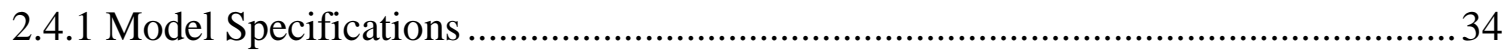

2.4.2 Linking theoretical and empirical Concepts of Location ..................................... 35

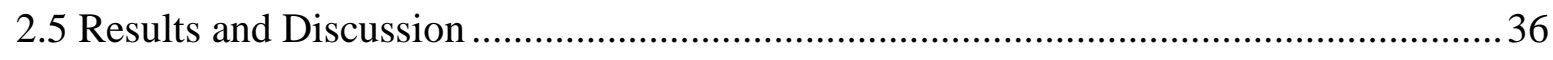

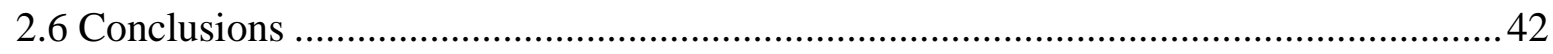

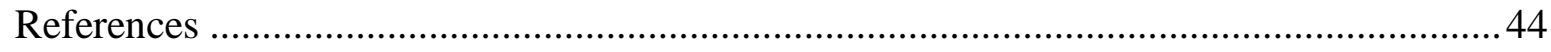

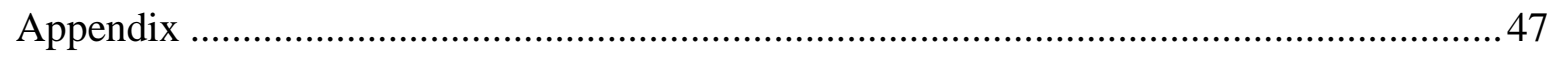

3. Digging deep and running dry - the adoption of borewell technology in the face of climate

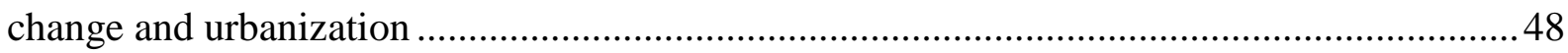

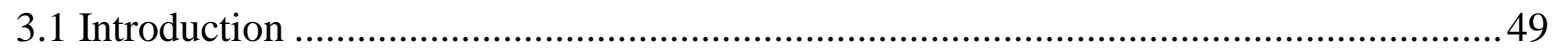

3.2 Background on irrigation in South India and technology adoption.............................51

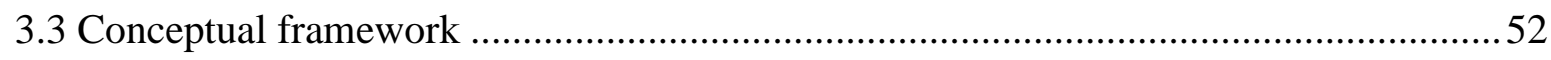

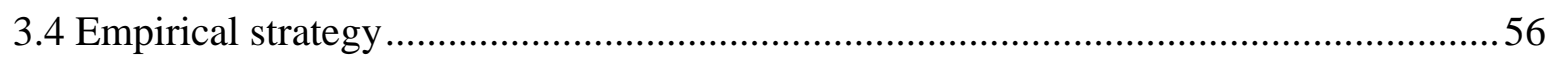

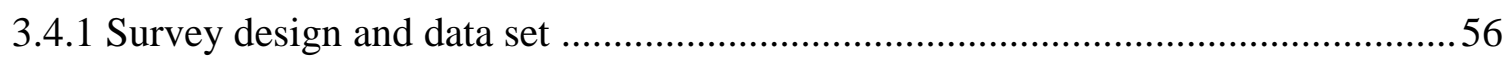

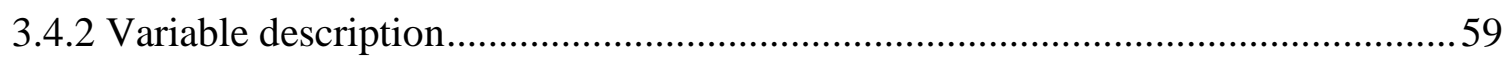

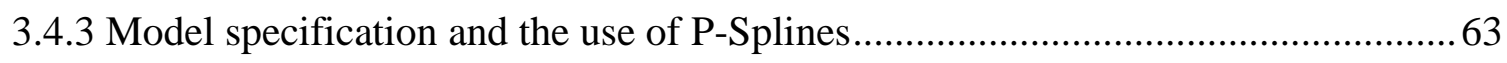

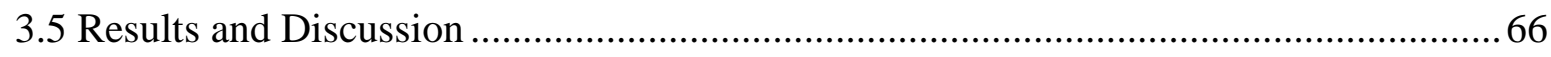

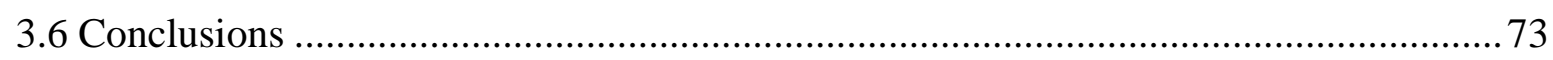

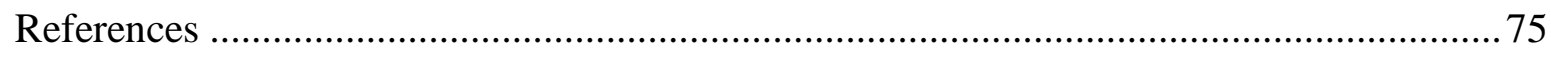

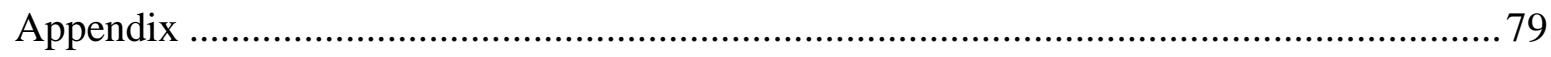


4. Farmers' decision-making and pollination services: A spatial autoregressive analysis ....... 85

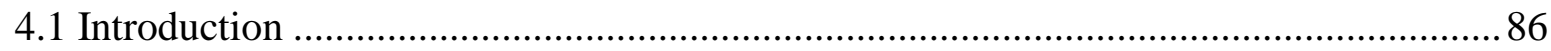

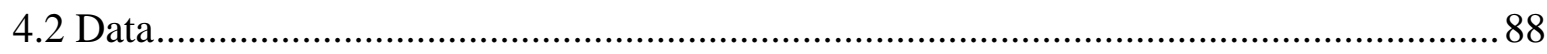

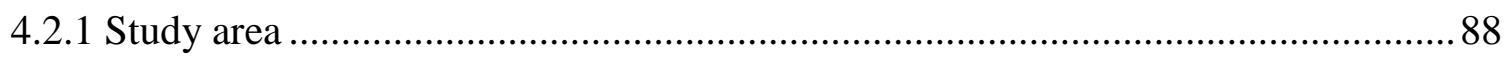

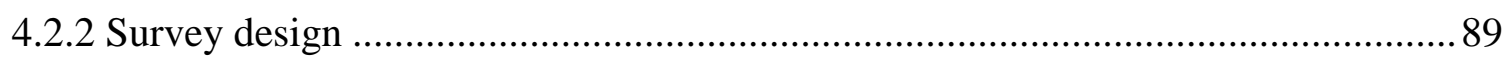

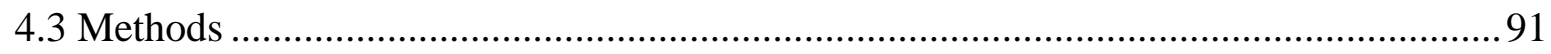

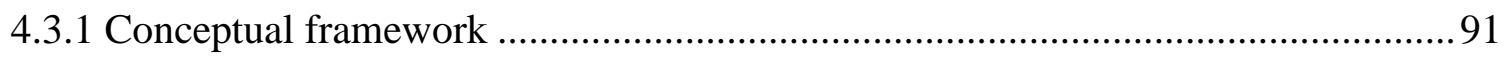

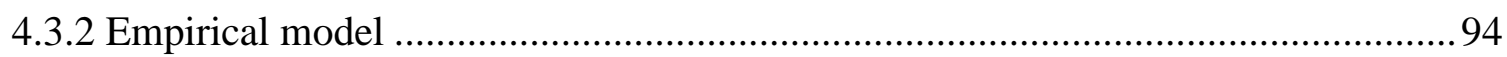

4.3.3 Estimation strategy and interpretation of effects ............................................ 98

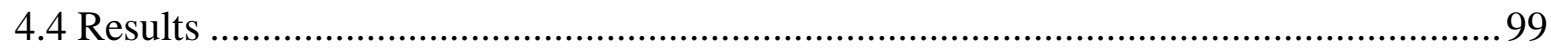

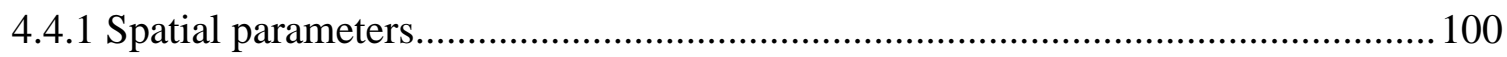

4.4.2 Effects of agricultural management practices on bee abundance and richness ..... 100

4.4.3 Other determinants of bee abundance and richness.......................................... 101

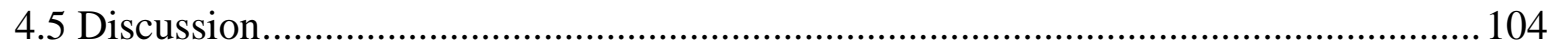

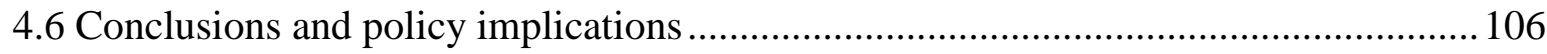

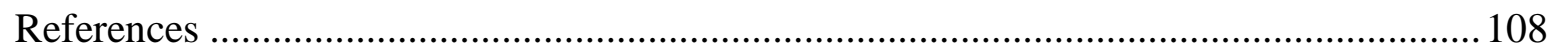

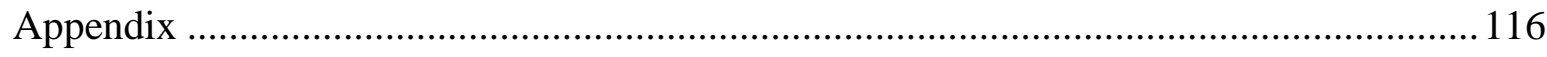

5. Conclusions, limitations, and future research potential ............................................. 121

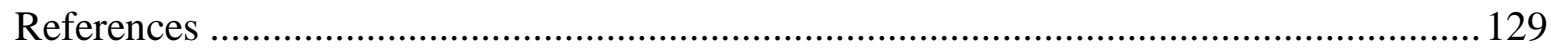

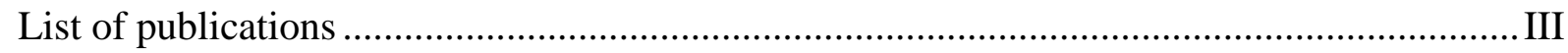

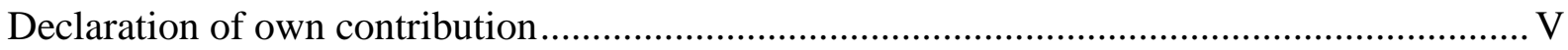

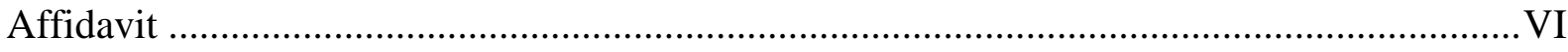




\section{Introduction}

Urbanization is a global trend. The United Nations (UN) Population Division estimates that 6.8 billion people ( 68 percent of the world's population) will live in cities by 2050, 2.5 billion (13 percent) more than in 2018 (United Nations, Department of Economic and Social Affairs, Population Division, 2019). Whereas urbanization was long a phenomenon of the Western world, future urbanization hotspots are mainly located in Africa and Asia. The consequences of such developments for societies, economies, and the environment are diverse and complex, presenting challenges, as well as opportunities for many developing and transition countries located on these continents. Growing urban centers lead to an increase in the demand for living space, food, and other consumables (Boserup, 1965; Pribadi \& Pauleit, 2015). To meet the additional demand, more land is needed for housing (i.e. urban expansion). Retail formats become more efficient and complex, and local industries grow due to additional labor force (Humphrey, 2007; Schipmann \& Qaim, 2011; Christiaensen et al., 2013). The resulting economic growth draws more people and, thus, reinforces urbanization drivers described before. In the literature this is often referred to as urban pull factors (Ellis, 2000; Reardon et al., 2007; Sridhar et al., 2012). Once local markets are connected to national and international markets, economic growth and pull factors are further amplified. Consequently, an increasing share of the urban population will live in so-called mega-cities, urban agglomerations with more than 10 million inhabitants, of which most are located in developing countries (United Nations, Department of Economic and Social Affairs, Population Division, 2019). If such growth and urban expansion occur unmanaged and at a rapid pace, positive economic growth might be outweighed by negative environmental externalities (Elmqvist et al., 2013). Air and water pollution due to unfiltered industrial emissions and traffic, as well as decreased environmental services due to high shares of sealed surfaces, are only two examples (Shah, 2007; Vanderhaegen et al., 2015; Srinivasan et al., 2017). ${ }^{1}$

The dynamics discussed so far primarily address urbanization as such and possible effects on urban population. However, people living in the periphery of urban centers are equally affected by their changing surroundings. 90 percent of the global rural population lives in Asia and Africa depending on agricultural production for their own consumption and/or income generation (Food and Agriculture Organisation of the United Nations, 2013). At the

\footnotetext{
${ }^{1}$ These factors among others are referred to as urban push factors, i.e. they cause people to leave urban centers (Sridhar et al. , 2012).
} 
same time India, China, and Nigeria alone will account for 35 percent of the urban population growth until 2050 (United Nations, Department of Economic and Social Affairs, Population Division, 2019). Consequently, many of these countries will experience significant demographic change with rural population either migrating to urban centers or rural areas turning into urban or peri-urban neighborhoods due to urban expansion. Thus, more and more smallholders will come under the influence of growing urban centers. Understanding how such a development affects agricultural production systems in the periphery of rapidly growing urban centers will be the key to many questions of poverty alleviation and nutrition security in the decades to come. Additionally, effects of natural resource depletion and environmental services have to be considered. Since proximity to urban centers often appear to be associated with agricultural intensification, depletion of natural resources and declining environmental services can be additional effects of urbanization threatening the long-term functioning of ecosystems and agricultural systems depending on them (United Nations, Department of Economic and Social Affairs, Population Division, 2019).

In this context the three studies presented in this dissertation revolve around the following two research questions:

\section{1) How do agricultural management systems and the agricultural decision-making of} smallholders change in the rural-urban interfaces of mega-cities?

\section{2) How do agricultural change and intensification affect environmental services and the stock} of natural resources?

In the literature, a common tool to describe urban effects on agricultural production are transportation costs, which are measured by distance to a city center or market (Dadi et al., 2004; Chamberlin \& Jayne, 2013; Damania et al., 2017; Euler et al., 2017; Vandercasteelen et al., 2017). As early as in 1826, this concept already enters the pioneering theory by von Thünen describing concentric rings of different agricultural production systems around a town. Von Thünen argues that agricultural production intensifies in urban proximity because profit made from the agricultural output has to cover higher land rates close to towns. More recent model extensions do not only consider transportation costs in terms of net output prices (market price minus transportation costs), but they also incorporate input prices and labor costs as functions of the distance to city (Vandercasteelen et al., 2017; Damania et al., 2017). The conclusions derived from these models, however, remain similar to von Thünen's theory. 
Using the adoption of chemical fertilizers and improved seeds as indicators of agricultural intensification in Ethiopia, Vandercasteelen et al. (2017) show that the adoption of these inputs increases with decreasing distance to urban centers ceteris paribus. Similar results are presented by Minten et al. (2013) and Damania et al. (2017) for the adoption of modern inputs in Ethiopia and Nigeria, respectively.

Even though these studies provide important evidence on effects of towns on agricultural management systems, they generally do not differentiate between different types of towns. Exceptions might be studies by Vandercasteelen et al. (2018) and Christiaensen et al. (2013). However, they still assume - as von Thünen did — that urbanization effects are concentric, i.e. the distance but not the direction from a city matters. Thus, they use one-dimensional (univariate) variables such as distance or travel time to a city to describe urbanization effects based on the assumption these proxies are proportional to transportation costs (Damania et al., 2017; Vandercasteelen et al., 2017).

However, considering the trend towards mega-cities, the assumption of concentric or linear urbanization effects might be increasingly difficult to hold in the future. Mega-cities are generally characterized by larger industrial and service sectors than smaller towns (Hall \& Pain, 2009). Therefore, a more diverse set of urban factors influences smallholder decisionmaking closer to mega-cities. An example is off-farm employment. Fafchamps \& Shilpi (2003), Deichmann et al. (2009), and Imai et al. (2015) find that households are very likely to diversify their income when off-farm employment opportunities are available. Consequently, labor might be withdrawn from agriculture production counteracting labor-intensive agricultural intensification. Furthermore, towns are not isolated agglomerations expanding into the empty plain. Taylor et al. (2008) or Marull et al. (2015), for example show that rapid urbanization often occurs in polycentric patterns. In such a setting farm households can choose among several market centers to buy inputs or sell their produce, and the definition of one reference point becomes increasingly difficult. Urbanization effects might be neither concentric nor linear and the measure of distance to an urban center might not be the ideal methodological tool to describe urbanization effects on agricultural systems in the face of rapid urbanization and mega-cities. A possible solution to this problem is to model spatially explicit urbanization effects.

Spatial analysis, including models from spatial statistics and spatial econometrics, is, therefore, the methodological focus of this dissertation. One way to overcome the assumption 
of concentric urbanization effects is to estimate so-called smooth effect surfaces or twodimensional Penalized (P-) Splines based on GPS coordinates (longitude, latitude). P-Splines can be understood as nonlinear effect functions build of piecewise polynomials and a penalty term ensuring the smoothness of the function (Fahrmeir et al., 2013). In the spatial context, treating GPS coordinates as bivariate continuous variables, two-dimensional P-Splines represent effect surfaces. These show how a respective dependent variable (e.g. adoption of a particular input) is affected by the location of the observation unit (e.g. household) in twodimensional space. Therefore, unlike in the case of one-dimensional proxies, no reference point such as a city center or market place has to be defined and nonlinear, as well as nonconcentric effect patterns can be estimated.

Aside from the flexible modeling of urbanization effects, the effect of agricultural intensification on environmental services has an important spatial component as well. Generally, the scales of agricultural decision making (e.g. plot or farm) and environmental services (e.g. pollination or water aquifers) do not coincide, the latter normally having larger boundaries than the former (Kremen et al., 2007). Thus, spatial correlation and endogeneity are likely to lead to estimation bias, if not addressed in the empirical strategy (Hoef et al., 2018). Even though this issue has been repeatedly mentioned in the methodological literature, it has been rather neglected in empirical analyses (Lichstein et al., 2002; Hoef et al., 2018). Therefore, in this dissertation I apply spatial econometric techniques do present a suitable tool to overcome such issues in future research. In addition to controlling for estimation bias, these methods allow for quantifying spillovers from a smaller scale (farmers' decision-making) to a larger scale (environmental services). Therefore, the results are also relevant for the development of policies or programs aiming to protect the functioning of environmental systems.

The empirical analysis is based on primary household data from the rural-urban interface of the mega-city of Bangalore in South India. Bangalore's population almost doubled during the last two decades and is currently estimated at around 12 million (as of 2018) (Directorate of Census Operations Karnataka, 2011; Sharma, 2018). Even though the rapid expansion and growth of Bangalore is largely attributed to industry and service providers-Bangalore is also referred to as the Silicon Valley of India-, the rural-urban interface is still dominated by smallholder farming (Sudhira et al., 2007). The climate of the region is classified as seasonal 
dry savanna. The seasons are defined by a south-west monsoon, normally bringing heavy rains from June to September (Directorate of Census Operations Karnataka, 2011). The agricultural seasons depend on monsoon rain as a perennial irrigation source. Even though modern irrigation technologies are becoming more common, rainfed agricultural management systems are still the norm and have become under increasing pressure due to uncertain and absent monsoon rains in recent years (Srinivasa Rao et al., 2015). Next to staple crops such as ragi (Eleusine coracana) or maize, the area is particularly famous for fruit and vegetable production (Directorate of Census Operations Karnataka, 2011). The proximity to Mysore, known for its silk markets, promotes mulberry and silkworm farming in the Bangalore region. Several satellite towns within a 40-kilometer-radius around Bangalore lead to a polycentric urbanization pattern (Fig. 1). Proximity and improved roads connecting the satellite towns to Bangalore facilitate the growth of these smaller urban centers and create additional marketing and employment opportunities to abutting farm households. As a result, the research area exhibits all the characteristics of the urbanization trend predicted by the UN Population Division and offers an excellent study case for the research questions of this dissertation.

The data collection and research presented in this dissertation is embedded in the framework of the Research Unit 2432 "Social-ecological systems in the Indian rural-urban interface: Functions, scales, and dynamics of transition" funded by the German Research Foundation (DFG). The goal of the research unit is to quantify social, economic, and environmental change and interdependencies induced by urbanization. It follows an interdisciplinary research strategy bringing together scientists from different disciplines (e.g. economics, natural sciences, nutrition science) working in the same defined research area conducting surveys and experiments facilitating interdisciplinary research. Two research transects were defined along the rural-urban interface of Bangalore to represent the spatial variability caused by the urban center (Hoffmann et al., 2017) (Fig. 1). One transect is located north of Bangalore (hereafter referred to as northern transect), the other one extends in the southwest of Bangalore (hereafter southern transect).

The main data source for the empirical analysis presented in this dissertation is a comprehensive socio-economic survey of 1,275 randomly selected households interviewed from December 2016 to May 2017. A subsample of 131 households was revisited between February and March 2018 for another round of interviews. In addition to the second survey, pan trap experiments were installed on plots of these 131 households. The result is a 
combined and interdisciplinary data set that allows for the analysis of effects of agricultural management on pollinator abundance and richness. Furthermore, all interviewed households and sampled plots were geo-referenced (Fig. 1). Thus, advanced methods of spatial statistics and spatial econometrics could be applied.

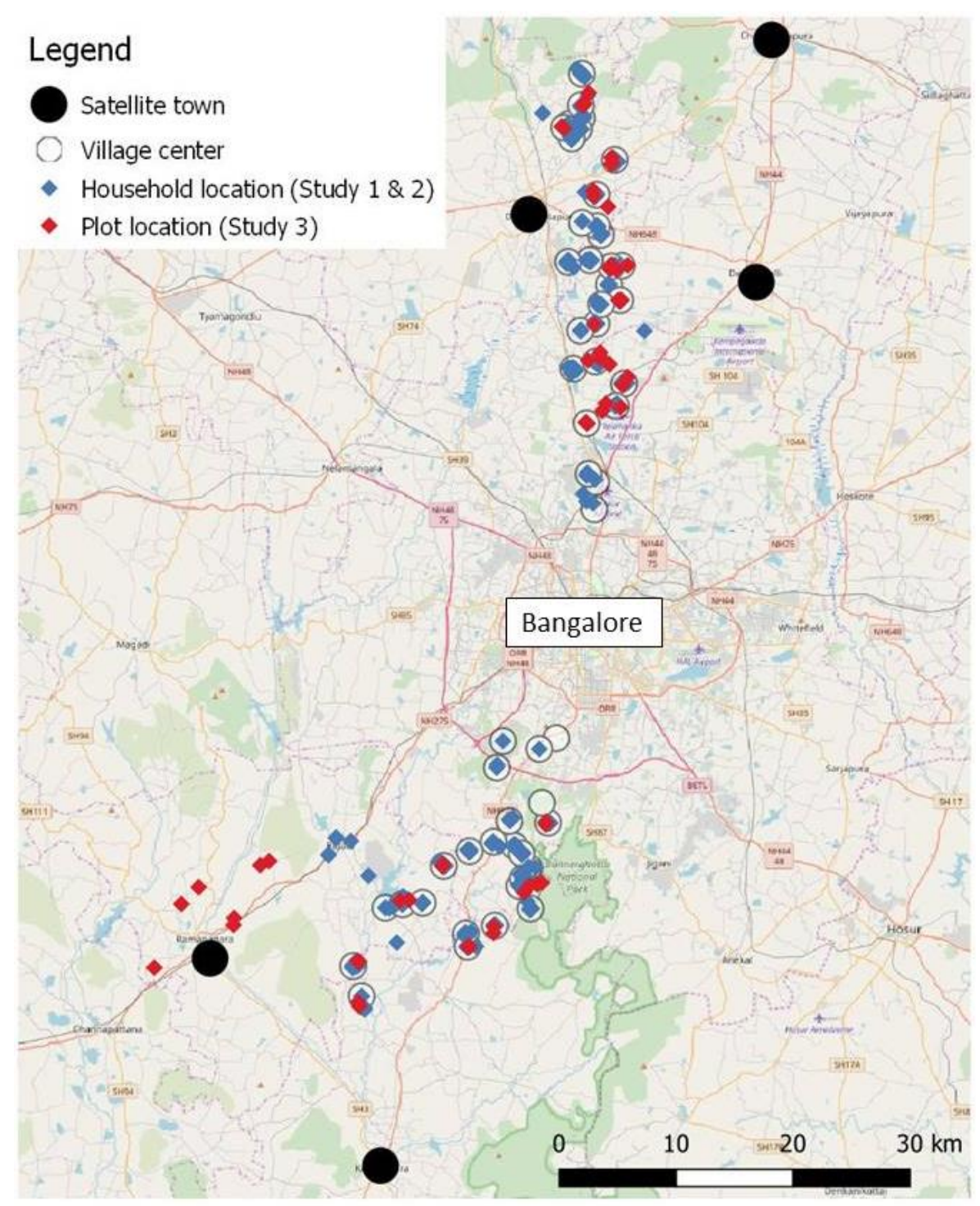

Note: Studies 1 and 2 only refer to farming households. Therefore, not all 1,275 households are plotted. Study 3 only covered villages in the peri-urban and rural strata.

Fig. 1. Overview of study area showing the polycentric setup of the region.

The three studies presented in the dissertation analyze the interaction of urbanization, agricultural management decisions, and environmental services in the rural-urban interface of 
Bangalore, with a particular focus on spatial modeling techniques. The first study is conceptual, aimed at developing theoretical, as well as empirical strategies, to represent nonlinear and nonconcentric urbanization effects on farmers' management decisions. The second study looks at farmers' decision behavior to adopt borewell technology under the influence of urbanization and weather variability. The third study combines economic and ecological data and analyzes the effect of agricultural intensification on pollinator abundance and richness in the rural-urban interface of Bangalore.

The first study (Chapter 2) "Somewhere in between towns, markets, and jobs - Opportunity costs of agricultural intensification in the rural-urban interface" was written in collaboration with Prof. Dr. Stephan von Cramon-Taubadel. It is currently under review at The Journal of Development Studies. The study investigates how polycentric urbanization affects farmers' decision-making to intensify their agricultural management systems. The general hypothesis is that urbanization effects on agricultural intensification are nonconcentric and nonlinear. When satellite towns channel urbanization effects from a larger urban center into the hinterlands, the influence of the urban center is no longer uniformly distributed. Furthermore, large urban centers offer a variety of off-farm employment opportunities for skilled, as well as unskilled labor (Deichmann et al., 2009). The consequence is a competition for labor between the off-farm sector and agricultural production; especially intensified management systems are generally associated with a higher labor demand (Haggblade et al., 2010). Therefore, the degree of agricultural intensification will likely depend on the relation between the access to agricultural input and output markets and access to off-farm employment.

Previous studies model urbanization effects on agricultural management systems by using measures such as households' distance to the next urban center (Damania et al., 2017; Vandercasteelen et al., 2017; Vandercasteelen et al., 2018). They argue that net input costs decrease and net output prices increase with proximity to a city due to lower transportation costs. Comparable to the theory by von Thünen (1826), they assume concentric rings of monotonically decreasing agricultural intensification around an urban center. In a polycentric urbanization set-up, one could argue that every satellite town has its own cone of agricultural intensification (Vandercasteelen et al., 2018). However, this still implies that households can only access one city since the concept relies on the definition of transportation costs as the distance to one urban center (an a priori defined reference point). The question is how these 
patterns change if one household has access to several towns. Furthermore, in the majority of studies, households are exclusively employed in agricultural production, i.e. all household labor is assigned to agriculture and income diversification through off-farm employment is neglected (Minten et al., 2013; Ebata et al., 2017; Vandercasteelen et al., 2017; Damania et al., 2017). This can be an unrealistic assumption as shown by other strands of literature implying that smallholder households will diversify their income sources if they have the chance (Fafchamps \& Shilpi, 2003; Deichmann et al., 2009).

Therefore, the first study of this dissertation contributes to the existing literature mainly by addressing two research questions:

\section{1) How do urbanization effects on agricultural management decisions change when households have access to more than one urban center?}

\section{2) How do agricultural management systems change when allowing for income diversification, i.e. off-farm employment?}

The theoretical approach of this study integrates these questions in two ways. First, transportation costs are no longer represented by distance to one town but by a household's explicit location in two-dimensional space. Thus, household location contains the aggregate effect of more than one urban center on household decision-making. ${ }^{2}$ Second, by extending the Barnum \& Squire model (Barnum \& Squire, 1979), household decision-making is modeled as utility maximization based on two equilibria: a) a production equilibrium and b) a consumption equilibrium. Previous studies model decision-making exclusively based on the production equilibrium assuming pure agricultural households (Vandercasteelen et al., 2017). Adding the consumption equilibrium allows for off-farm income (wages) to influence farming decisions. Thus, farmers' choices are described by trade-offs between output prices and wage rates, both defined as functions of transportation costs and consequently household location.

In the empirical analysis, we measure agricultural intensification by the adoption of modern inputs such as chemical fertilizers, pesticides, and new seeds varieties. To model potential nonconcentric and nonlinear urbanization effects, we apply the concept of so-called geosplines. These are two-dimensional effect functions - also referred to as surfaces - that are estimated as P-Splines (Fahrmeir et al., 2013). In a separate section of Chapter 2, we discuss

\footnotetext{
${ }^{2}$ We assume that spatial heterogeneity and the effects measured by household location exclusively result from urbanization patterns. Conditions under which this assumption holds, particularly for the empirical analysis, are discussed in detail in the first study (Chapter 2).
} 
the conditions under which the estimated effect surfaces equal the urbanization effect derived in the theoretical model. To assess the additional value of a two-dimensional approach, we contrast the results based on geosplines with model specifications that employ the onedimensional variable distance to Bangalore city center.

The second study (Chapter 3) "Digging deep and running dry - the adoption of borewell technology in the face of climate change and urbanization" is a result of a collaboration with Johannes Wegmann and Prof. Dr. Oliver Mußhoff. The study is currently under review at the journal Agricultural Economics after the first round of revisions. The focus lies on identifying drivers of borewell technology adoption. Similar with the first study, the assumption is that proximity to an urban center reduces transaction costs and increases the likelihood of technology adoption due to reduced net installation costs. Groundwater lifting technologies such as borewells have become crucial in many developing countries to intensify agricultural management systems or to prevent crop failure due to increasing weather and climate variability (Alcon et al., 2011; Genius et al., 2014). Like in many other regions of the world weather patterns are shifting in South India (Shah, 2007). Monsoon rains are becoming increasingly unpredictable which threatens the food security and livelihood of many smallholders. Groundwater access, therefore, presents an appealing opportunity for agricultural growth and poverty alleviation, and the Indian government heavily subsidizes it (Kajisa et al., 2007). Nevertheless, improved access to the technology and risk pressure due to weather changes can lead to overexploitation and a drop of groundwater tables (Srinivasan et al., 2017). Since such developments leave smallholders in even worse circumstances than before, a better understanding of the factors driving the adoption of groundwater lifting technology is essential to promote sustainable agricultural growth. Therefore, the second study addresses the following research question:

\section{How do urbanization and weather changes affect the adoption of groundwater lifting technology?}

Unlike the decision to adopt variable inputs such as fertilizers or pesticides (Chapter 2), the adoption of a borewell is generally a one-time and long-term management decisions. Several authors argued that for such technologies the timing of the adoption decision is more informative than the adoption as such (Dadi et al., 2004; Abdulai \& Huffman, 2005). 
Accordingly, the conceptual framework, as well as the empirical analysis rely on dynamic models. In the theoretical model of the study, farmers have the choice between building a borewell in the present or next year (Irwin \& Bockstael, 2004). To make this decision, they build expectations about potential profits with and without a borewell in both years. The farmer faces this decision every year until the borewell is adopted. We depict net input and output prices as functions of household location to account for varying transportation costs, i.e. urbanization effects (see first study). We integrate the weather component of the research question into farmers' decision-making by allowing their expectation about agricultural output to vary between systems with and without a borewell. The intuition is that farmers who expect unreliable rainfalls will calculate with a significantly lower agricultural output in a management system without borewell than in a system with borewell.

Empirically, we model the farmer's decision problem in a semiparametric hazard rate model, an extension of the so-called Cox model (Cox, 1972; Kneib, 2006). The dependent variable of this model type consists of adoption time spells, i.e. the number of years between the first time the technology became available and the actual time of adoption (Therneau \& Grambsch, 2000). We assume that the technology became widely available with the start of the Green Revolution around 1970. As in the first study urbanization effects are modeled as geosplines. To quantify the effect of weather changes, three rainfall variables-total, pre-monsoon, and monsoon rainfalls - are included in the model.

The third study (Chapter 4) "Farmers' decision-making and pollination services: A spatial autoregressive analysis" was written together with Arne Wenzel, Prashant Hulamani, Prof. Dr. Stephan von Cramon-Taubadel, and Associate Professor Nicole M. Mason. It is currently under review in the journal Agriculture, Ecosystems \& Environment. The study investigates the effect of agricultural intensification on pollinator populations. Many farmers, especially in developing countries, still rely on wild pollination of their crops (Kennedy et al., 2013). However, agricultural intensification, often promoted by better access to markets and information (see studies 1 and 2), has been shown to threaten pollinator communities (Ricketts, 2004; Motzke et al., 2016). If such pollinator services disappear, this does not only mean a general loss in biodiversity but also income losses for smallholders since many crops will fail without the pollination service (Klein et al., 2007). Therefore, understanding how 
farmers' management choices and pollinator communities interact is essential to promote sustainable management practices that ensure intact ecosystems and farmers' livelihoods.

Since this topic touches economic, as well as ecological questions, an interdisciplinary approach is necessary to obtain the full picture of linkages between agricultural management and pollinator communities. This claim has also become louder in the scientific literature (Bennett et al., 2015; Collins et al., 2011; Vanbergen \& Initiative, 2013; Zhang et al., 2007). Nevertheless, most studies are still either primarily ecological or economic. Considerable empirical evidence has been produced. Studies by Kremen et al. (2007) and Tscharntke et al. (2005) show that pollinator richness and abundance is best explained by landscape scale factors. This is intuitive since studies show that pollinators can have dispersal ranges as large as six kilometers (Beekman \& Ratnieks, 2000). This is the reason why they are also referred to as mobile agents. Therefore, conclusions and policy implications deduced in such studies often refer to the landscape scale. Even though this is valid from the perspective of pollinator communities, it contradicts the understanding of land use in the economic sense. Here, models generally assume that land use decisions are made at the local (i.e. plot) scale, i.e. it is not possible to manage the "landscape" as such (Bockstael, 1996). Therefore, the third study of this dissertation aims to bridge the different perspectives of economic and ecological models by addressing the following research question:

\section{How do farmers' management decisions on the plot scale affect pollinator abundance and richness on the landscape scale?}

The empirical analysis of this research question is based on a combined data set covering 131 plots in the rural-urban interface of Bangalore. The data set comprises of socio-economic and farm management data collected during a survey in February and March 2018 and the abundance and species richness of wild bees, a key pollinator in the region, caught in pan traps over the same period on all 131 plots (Fig. 1). These data enable us to directly link agricultural practices and bee abundance and richness at the plot level. Because bees are mobile agents, their dispersal ranges exceed the plot boundaries of farms in the Bangalore area (average farm size of 2 acres). Thus, bee abundance and richness observed at one plot is likely to be influenced by management choices on other plots. Accounting for such spillovers and endogeneity in the dependent variable, we apply spatial econometric models, in particular the Durbin model (Kelejian \& Prucha, 1999; LeSage \& Pace, 2009; Elhorst, 2010). In addition to standard effects of regression analysis, this model allows for influences of 
neighboring observations in the dependent and independent variables. These spillover effects are implemented by constructing so-called weight matrices based on the inverse distance between sampled plots.

Results presented in this dissertation underline the necessity of more flexible modeling approaches of urbanization effects on agricultural systems. The application of twodimensional P-Splines in the first two studies proves to be a useful instrument in this context. We show that in comparison with one-dimensional variables of urbanization, geosplines give a more nuanced insight. We are able to show the importance of satellite towns for agricultural intensification and significant differences in effect patterns between the two research transects, for example. Applying spatial econometric methods in the third study, we find that the use of pesticide has significant negative spillovers on the pollinator services on neighboring plots.

The three studies of this dissertation are presented in the following Chapters 2 to 4 investigating the interaction between urbanization, agricultural change, and environmental services. Chapter 5 summarizes the main findings and implications of the three studies. In addition, I discuss limitations and ideas for future research. 


\section{References}

Abdulai, A., \& Huffman, W. E. (2005). The Diffusion of New Agricultural Technologies: The Case of Crossbred-Cow Technology in Tanzania. American Journal of Agricultural Economics, 87, 645-659.

Alcon, F., Miguel, M. D. de, \& Burton, M. (2011). Duration analysis of adoption of drip irrigation technology in southeastern Spain. Technol. Forecast. Soc., 78, 991-1001.

Barnum, H. N., \& Squire, L. (1979). A model of an agricultural household: Theory and evidence. World Bank staff occasional papers, 27. Baltimore: Johns Hopkins Univ. Press.

Beekman, M., \& Ratnieks, F. L. W. (2000). Long-range foraging by the honey-bee, Apis mellifera L. Functional Ecology, 14, 490-496.

Bennett, E. M., Cramer, W., Begossi, A., Cundill, G., Díaz, S., Egoh, B. N., Geijzendorffer, I. R., Krug, C. B., Lavorel, S., Lazos, E., Lebel, L., Martín-López, B., Meyfroidt, P., Mooney, H. A., Nel, J. L., Pascual, U., Payet, K., Harguindeguy, N. P., Peterson, G. D., Prieur-Richard, A.-H., Reyers, B., Roebeling, P., Seppelt, R., Solan, M., Tschakert, P., Tscharntke, T., Turner, B. L., Verburg, P. H., Viglizzo, E. F., White, P. C. L., \& Woodward, G. (2015). Linking biodiversity, ecosystem services, and human well-being: three challenges for designing research for sustainability. Current Opinion in Environmental Sustainability, 14, 76-85.

Bockstael, N. E. (1996). Modeling Economics and Ecology: The Importance of a Spatial Perspective. American Journal of Agricultural Economics, 78, 1168.

Boserup, E. (1965). The conditions of agricultural progress: The Economics of Agrarian Change under Population Pressure: George Allen \& Unwin LTD, London.

Chamberlin, J., \& Jayne, T. S. (2013). Unpacking the Meaning of 'Market Access': Evidence from Rural Kenya. World Dev., 41, 245-264.

Christiaensen, L., Weerdt, J. de, \& Todo, Y. (2013). Urbanization and poverty reduction: the role of rural diversification and secondary towns 1. Agricultural Economics, 44, 435-447.

Collins, S. L., Carpenter, S. R., Swinton, S. M., Orenstein, D. E., Childers, D. L., Gragson, T. L., Grimm, N. B., Grove, J. M., Harlan, S. L., Kaye, J. P., Knapp, A. K., Kofinas, G. P., Magnuson, J. J., McDowell, W. H., Melack, J. M., Ogden, L. A., Robertson, G. P., Smith, M. D., \& Whitmer, A. C. (2011). An integrated conceptual framework for long-term social-ecological research. Frontiers in Ecology and the Environment, 9, 351-357.

Cox, D. R. (1972). Regression Models and Life-Tables. J. Roy. Stat. Soc. B. Met., 34, 187220. 
Dadi, L., Burton, M., \& Ozanne, A. (2004). Duration Analysis of Technological Adoption in Ethiopian Agriculture. J. Agric. Econ., 55, 613-631.

Damania, R., Berg, C., Russ, J., Federico Barra, A., Nash, J., \& Ali, R. (2017). Agricultural Technology Choice and Transport. American Journal of Agricultural Economics, 99, 265284.

Deichmann, U., Shilpi, F., \& Vakis, R. (2009). Urban Proximity, Agricultural Potential and Rural Non-farm Employment: Evidence from Bangladesh. World Dev., 37, 645-660.

Directorate of Census Operations Karnataka (2011). Census of India 2011: Karnataka, District Census Handbook, Bangalore. Series-30.

Ebata, A., Velasco Pacheco, P. A., \& Cramon-Taubadel, S. von (2017). The influence of proximity to market on bean producer prices in Nicaragua. Agricultural Economics, 48, $459-467$.

Elhorst, J. P. (2010). Applied Spatial Econometrics: Raising the Bar. Spatial Economic Analysis, 5, 9-28.

Ellis, F. (2000). The Determinants of Rural Livelihood Diversification in Developing Countries. Journal of Agricultural Economics, 51, 289-302.

Elmqvist, T., Fragkias, M., Goodness, J., Güneralp, B., Marcotullio, P. J., McDonald, R. I., Parnell, S., Schewenius, M., Sendstad, M., \& Seto, K. C. (2013). Urbanization, biodiversity and ecosystem services: challenges and opportunities: a global assessment: Springer.

Euler, M., Krishna, V., Schwarze, S., Siregar, H., \& Qaim, M. (2017). Oil Palm Adoption, Household Welfare, and Nutrition Among Smallholder Farmers in Indonesia. World Dev., 93, 219-235.

Fafchamps, M., \& Shilpi, F. (2003). The spatial division of labour in Nepal. J. Dev. Stud., 39, 23-66.

Fahrmeir, L., Kneib, T., Lang, S., \& Marx, B. (2013). Regression: Models, Methods and Applications. Dordrecht: Springer.

Food and Agriculture Organisation of the United Nations (2013). FAO Statistical Yearbook 2013. World Food and Agriculture.

Genius, M., Koundouri, P., Nauges, C., \& Tzouvelekas, V. (2014). Information Transmission in Irrigation Technology Adoption and Diffusion: Social Learning, Extension Services, and Spatial Effects. American Journal of Agricultural Economics, 96, 328-344. 
Haggblade, S., Hazell, P., \& Reardon, T. (2010). The Rural Non-farm Economy: Prospects for Growth and Poverty Reduction. World Development, 38, 1429-1441.

Hall, P., \& Pain, K. (Eds.) (2009). The polycentric metropolis: Learning from mega-city regions in Europe. (Paperback ed.). London: Earthscan.

Hoef, J. M. ver, Peterson, E. E., Hooten, M. B., Hanks, E. M., \& Fortin, M.-J. (2018). Spatial autoregressive models for statistical inference from ecological data. Ecological Monographs, 88, 36-59.

Hoffmann, E., Jose, M., Nölke, N., \& Möckel, T. (2017). Construction and Use of a Simple Index of Urbanisation in the Rural-Urban Interface of Bangalore, India. SustainabilityBasel, 9, 2146.

Humphrey, J. (2007). The supermarket revolution in developing countries: tidal wave or tough competitive struggle? Journal of Economic Geography, 7, 433-450.

Imai, K. S., Gaiha, R., \& Thapa, G. (2015). Does non-farm sector employment reduce rural poverty and vulnerability? Evidence from Vietnam and India. J. Asian Econ., 36, 47-61.

Irwin, E., \& Bockstael, N. (2004). Endogenous Spatial Externalities: Empirical Evidence and Implications for the Evolution of Exurban Residential Land Use Patterns. In L. Anselin, R. J. G. M. Florax, \& S. J. Rey (Eds.), Advances in Spatial Econometrics: Methodology, Tools and Applications (pp. 359-380). Berlin, Heidelberg: Springer Berlin Heidelberg.

Kajisa, K., Palanisami, K., \& Sakurai, T. (2007). Effects on poverty and equity of the decline in collective tank irrigation management in Tamil Nadu, India. Agr. Econ., 36, 347-362.

Kelejian, H. H., \& Prucha, I. R. (1999). A Generalized Moments Estimator for the Autoregressive Parameter in a Spatial Model. International Economic Review, 40, 509533.

Kennedy, C. M., Lonsdorf, E., Neel, M. C., Williams, N. M., Ricketts, T. H., Winfree, R., Bommarco, R., Brittain, C., Burley, A. L., Cariveau, D., Carvalheiro, L. G., Chacoff, N. P., Cunningham, S. A., Danforth, B. N., Dudenhöffer, J.-H., Elle, E., Gaines, H. R., Garibaldi, L. A., Gratton, C., Holzschuh, A., Isaacs, R., Javorek, S. K., Jha, S., Klein, A. M., Krewenka, K., Mandelik, Y., Mayfield, M. M., Morandin, L., Neame, L. A., Otieno, M., Park, M., Potts, S. G., Rundlöf, M., Saez, A., Steffan-Dewenter, I., Taki, H., Viana, B. F., Westphal, C., Wilson, J. K., Greenleaf, S. S., \& Kremen, C. (2013). A global quantitative synthesis of local and landscape effects on wild bee pollinators in agroecosystems. Ecology letters, 16, 584-599. 
Klein, A.-M., Vaissière, B. E., Cane, J. H., Steffan-Dewenter, I., Cunningham, S. A., Kremen, C., \& Tscharntke, T. (2007). Importance of pollinators in changing landscapes for world crops. Proceedings. Biological sciences, 274, 303-313.

Kneib, T. (2006). Mixed model-based inference in geoadditive hazard regression for intervalcensored survival times. Computation. Stat. Data An., 51, 777-792.

Kremen, C., Williams, N. M., Aizen, M. A., Gemmill-Herren, B., LeBuhn, G., Minckley, R., Packer, L., Potts, S. G., Roulston, T.'a., Steffan-Dewenter, I., Vázquez, D. P., Winfree, R., Adams, L., Crone, E. E., Greenleaf, S. S., Keitt, T. H., Klein, A.-M., Regetz, J., \& Ricketts, T. H. (2007). Pollination and other ecosystem services produced by mobile organisms: a conceptual framework for the effects of land-use change. Ecology letters, 10, 299-314.

LeSage, J. P., \& Pace, R. K. (2009). Introduction to spatial econometrics. Statistics, textbooks and monographs, 196. Boca Raton: CRC Press.

Lichstein, J. W., Simons, T. R., Shriner, S. A., \& Franzreb, K. E. (2002). SPATIAL AUTOCORRELATION AND AUTOREGRESSIVE MODELS IN ECOLOGY. Ecological Monographs, 72, 445-463.

Marull, J., Font, C., \& Boix, R. (2015). Modelling urban networks at mega-regional scale: Are increasingly complex urban systems sustainable? Land Use Policy, 43, 15-27.

Minten, B., Koru, B., \& Stifel, D. (2013). The last mile(s) in modern input distribution: Pricing, profitability, and adoption. Agr. Econ., 44, 629-646.

Motzke, I., Klein, A.-M., Saleh, S., Wanger, T. C., \& Tscharntke, T. (2016). Habitat management on multiple spatial scales can enhance bee pollination and crop yield in tropical homegardens. Agriculture, Ecosystems \& Environment, 223, 144-151.

Pribadi, D. O., \& Pauleit, S. (2015). The dynamics of peri-urban agriculture during rapid urbanization of Jabodetabek Metropolitan Area. Land Use Policy, 48, 13-24.

Reardon, T., Berdegué, J., Barrett, C. B., \& Stamoulis, K. (2007). Household income diversification into rural nonfarm activities. Transforming the rural nonfarm economy: opportunities and threats in the developing world, 115-140.

Ricketts, T. H. (2004). Tropical Forest Fragments Enhance Pollinator Activity in Nearby Coffee Crops. Conservation Biology, 18, 1262-1271.

Schipmann, C., \& Qaim, M. (2011). Supply chain differentiation, contract agriculture, and farmers' marketing preferences: The case of sweet pepper in Thailand. Food Policy, 36, $667-677$. 
Shah, T. (2007). The groundwater economy of South Asia: An assessment of size, significance and socio-ecological impacts. In M. Giordano, \& K. G. Villholth (Eds.), The agricultural groundwater revolution: Opportunities and threats to development (pp. 736). Wallingford: CABI.

Sharma, M. (2018). EC data reveals city's exponential growth: There are now over 1.25 crore of us Bengalureans. Bangalore Mirror, 12.05.2018. Accessed 12.10.2018.

Sridhar, K. S., Reddy, A. V., \& Srinath, P. (2012). Is it Push or Pull? Recent Evidence from Migration into Bangalore, India. Journal of International Migration and Integration, 15, 239.

Srinivasa Rao, C., Lal, R., Prasad, J. V.N.S., Gopinath, K. A., Singh, R., Jakkula, V. S., Sahrawat, K. L., Venkateswarlu, B., Sikka, A. K., \& Virmani, S. M. (2015). Potential and Challenges of Rainfed Farming in India. In D. L. Sparks (Ed.), Advances in Agronomy (pp. 113-181). Burlington: Elsevier Science.

Srinivasan, V., Penny, G., Lele, S., Thomas, B. K., \& Thompson, S. (2017). Proximate and underlying drivers of socio-hydrologic change in the upper Arkavathy watershed, India. Hydrology and Earth System Sciences Discussions, 1-28.

Sudhira, H. S., Ramachandra, T. V., \& Subrahmanya, M. B. (2007). Bangalore. Cities, 24, 379-390.

Taylor, P. J., Evans, D. M., \& Pain, K. (2008). Application of the Interlocking Network Model to Mega-City-Regions: Measuring Polycentricity Within and Beyond CityRegions. Regional Studies, 42, 1079-1093.

Therneau, T. M., \& Grambsch, P. M. (2000). Modeling Survival Data: Extending the Cox Model. Statistics for biology and health. New York, NY: Springer New York.

Thünen, J. H. von (1826). Der isolierte Staat: Beziehung auf Landwirtschaft und Nationalökonomie.

Tscharntke, T., Klein, A. M., Kruess, A., Steffan-Dewenter, I., \& Thies, C. (2005). Landscape perspectives on agricultural intensification and biodiversity - ecosystem service management. Ecology letters, 8, 857-874.

United Nations, Department of Economic and Social Affairs, Population Division (2019). World Urbanization Prospects 2018: Highlights.

Vanbergen, A. J., \& Initiative, t. I. P. (2013). Threats to an ecosystem service: pressures on pollinators. Frontiers in Ecology and the Environment, 11, 251-259. 
Vandercasteelen, J., Beyene, S. T., Minten, B., \& Swinnen, J. (2017). Cities and agricultural transformation in Africa: Evidence from Ethiopia. World Development, 105, 383-399.

Vandercasteelen, J., Beyene, S. T., Minten, B., \& Swinnen, J. (2018). Big cities, small towns, and poor farmers: Evidence from Ethiopia. World Development, 106, 393-406.

Vanderhaegen, S., Munter, K. de, \& Canters, F. (2015). High resolution modelling and forecasting of soil sealing density at the regional scale. Landscape and Urban Planning, $133,133-142$.

Zhang, W., Ricketts, T. H., Kremen, C., Carney, K., \& Swinton, S. M. (2007). Ecosystem services and dis-services to agriculture. Ecological Economics, 64, 253-260. 


\title{
2. Somewhere in between towns, markets, and jobs - Opportunity costs of agricultural intensification in the rural-urban interface
}

Linda Steinhübel, Stephan von Cramon-Taubadel

Under review in The Journal of Development Studies

\begin{abstract}
We propose a flexible conceptual and methodological framework to model the dynamics of agricultural intensification in the complex rural-urban interfaces of large cities. We focus particularly on the effects of polycentric urbanisation patterns and trade-offs between agricultural intensification and off-farm employment. In our conceptual frameworkmodelling household decision-making based on utility maximization-we show that agricultural intensification in the rural-urban interface is likely to exhibit non-linear and complex spatial patterns due to relative changes in location-dependent effective output prices and wage rates. This is confirmed by our empirical analysis based on a primary data set of 638 smallholder farms in the rural-urban interface of Bangalore. Applying Structured Additive Regression (STAR) techniques, we model two-dimensional urbanisation effects using household and village coordinates. Results imply that proximity to secondary towns and road infrastructure are the primary channels of urbanisation effects on the uptake of modern agricultural inputs. Furthermore, proximity to the large urban centre of Bangalore appears to increase the opportunity costs of agricultural intensification through improved access to offfarm labour opportunities. Overall, we show that agricultural intensification around urban centres does not necessarily occur in concentric and monotonic patterns.
\end{abstract}

Keywords: Agricultural intensification, household model, India, Structured Additive Regression, urbanisation 


\subsection{Introduction}

Today more than one-half of the world population lives in cities. This share is expected to increase to two-thirds by 2050 (United Nations Population Division, 2015). Cities in Asia and Africa are growing especially rapidly and the implications of urbanisation are attracting increasing attention in the fields of development and agricultural economics. Heinrich von Thünen's (1826) pioneering model of agricultural activity surrounding a city predicts the formation of concentric rings of land use as a function of yields, prices, production costs and transport costs to the city for different agricultural products. While his model's assumption of an isolated city located on a uniform plain is unrealistic, von Thünen's approach to analysing the effects of proximity to urban centres on land use remains relevant today. Many recent studies include proxies for urbanisation to analyse the effects of cities on the livelihoods or productivity of smallholders (Asfaw et al., 2016; Vandercasteelen et al., 2017; Vandercasteelen et al., 2018). Proximity to an urban centre is expected to improve access to markets, information and technology, and thus increase the likelihood that smallholders modernise their production systems and improve their standards of living (Chamberlin \& Jayne, 2013). Common urbanisation proxies used in empirical analyses include distance to the next city centre or market, transportation costs, or travel times (Minten et al., 2013; Damania et al., 2017; Ebata et al., 2017). The list is long and often variables are chosen based on the characteristics of a region such as topography or traffic conditions, or simply availability (Chamberlin \& Jayne, 2013). Regardless of which proxies are used, most studies show that proximity to urban centres and market access can significantly improve smallholders' productivity, as farmers who are closer to urban centres tend to receive higher net output prices and are more likely to adopt modern inputs (Vandercasteelen et al., 2017) .

While these insights are important, to date the literature on the effects of proximity to urban centres on smallholders has not considered two important characteristics of urban expansion into surrounding agricultural areas. The first of these is the complex, polycentric nature of most urban expansion (Taylor et al., 2008; Marull et al., 2015). Cities do not expand into the empty, uniform rural plains posited in von Thünen's seminal work. Indeed, in von Thünen's model the city does not expand at all, it is simply there. In reality, cities emerge from networks of settlements in heterogeneous space. Which settlements eventually come to dominate and grow most rapidly in a region is determined by a complex, path-dependent interaction of geography, chance and agglomeration effects (Krugman, 1996; Fujita \& Thisse, 2014). As it expands, a city will encounter and affect the growth of the other, surrounding 
settlements. The resulting expansion and coalescence processes generate polycentric urban hierarchies (Schneider \& Woodcock, 2008). Smallholders in the rural-urban interface, therefore, often find themselves in between an expanding urban centre and surrounding secondary towns, and subject to a web of interacting economic forces that pull in different directions. Hence, their production systems, choices and welfare are influenced by not only yields, prices and proximity to a single urban centre. In a polycentric rural-urban interface, for example, a smallholder might face a choice between delivering to the urban centre or delivering to a closer, perhaps specialised alternative market that is located in the opposite direction. In such settings, it is unrealistic to assume linear or monotonic gradients of agricultural intensification and productivity radiating out from the urban centre, and standard urbanisation proxies based on proximity to the centre may not perform well.

The other salient characteristic of urban expansion is that it provides alternative employment opportunities to the members of smallholder households in the rural-urban interface. Economists have generated a rich literature on the push and pull factors that drive rural-urban migration and urban population growth (Harris \& Todaro, 1970; Jedwab et al., 2017). However, smallholder households in the rural-urban interface do not necessarily have to migrate to switch from rural to urban. Indeed, such households will often be rural-urban composites, with some members engaged in farm and others in off-farm pursuits and this mixture shifting over time as household demographics evolve and urbanisation draws closer. Especially where urbanisation is driven by strong economic growth that generates pull forces, as is the case in the setting that we explore below (Bangalore), households in the rural-urban interface will face a choice between allocating labour to increasingly human capital-intensive modern agricultural production, or allocating it to off-farm employment opportunities. These effects might also lead to complex, non-linear patterns of agricultural intensification surrounding large, growing cities. While recent studies (for example Christiaensen et al., 2013; Vandercasteelen et al., 2018) do account for the varying effects of city size on surrounding smallholders, they maintain the assumption that farmers are production maximisers who are only affected by access to input (including on-farm labour) and output markets. In addition, these studies generally assign one town of reference to each farm household to measure its urban proximity. Thus, these studies do not account for complex, polycentric patterns of urbanisation, and for the potential role of off-farm earning opportunities in the rural-urban interface. 
This is the point of departure for our study. We derive theoretical and empirical models that are sufficiently flexible to capture the effects of polycentric urbanisation on the agricultural management decisions made by smallholder households. We develop a household model following Barnum \& Squire (1979) in which both output prices and off-farm wage rates vary in space. The result is an economic model that can explain and predict non-linear pattern of agricultural intensification that are driven by antagonistic dynamics in access to output and off-farm labour markets.

We illustrate the application of this model by analysing the use of modern agricultural inputs in the rural-urban interface of Bangalore, a rapidly growing megacity of roughly 12 million inhabitants (as of 2018) in southern India (Sharma, 2018). As India's 'Silicon Valley', Bangalore exerts not only a strong demand for food and other agricultural products on the surrounding rural areas; it also provides households in these areas with diverse off-farm employment opportunities (Sudhira et al., 2007; Directorate of Census Operations Karnataka, 2011). Furthermore, its rural-urban interface includes multiple secondary towns of different sizes that provide smallholders with opportunities for marketing agricultural produce as well as for off-farm employment. Thus, it exhibits the polycentric characteristics that we wish to study. Our analysis is based on primary data collected in a survey of 638 farm households in 2016.

Empirically, we test the implications of our theoretical model by estimating the effect of a household's location on its use of modern agricultural inputs. Standard models predict that the use of such inputs will increase monotonically with increasing proximity to the urban centre. The model that we propose considers the effects of location in two-dimensional space rather than proximity to a unique urban centre. The result is a framework that builds on but is more flexible than and subsumes previous models such as that of Vandercasteelen et al. (2018). To operationalise the model we employ Structured Additive Regression (STAR) techniques that allow us to directly model two-dimensional location effects based on household and village coordinates. We compare the results of this model with results generated using standard onedimensional urbanisation proxies based on distance to Bangalore city centre. Thus, we determine whether and under which circumstances a model that explicitly considers twodimensional effects will generate richer insights into the effects of urbanisation on smallholder decision-making in the rural-urban interface.

The rest of this paper is structured as follows. In chapter two, we introduce our conceptual framework and in chapter three, we present our study design and data set. We describe our 
empirical strategy in chapter four and discuss the results in chapter five. Chapter six summarizes our findings.

\subsection{Conceptual Framework}

Most studies of urbanisation effects on agricultural management focus on the effects of proximity to urban centres on access to input and output markets. Damania et al. (2017) and Vandercasteelen et al. $(2017,2018)$ develop models that predict a monotonic relationship between decreasing transportation costs and agricultural intensification-measured by the uptake of new and modern agricultural technologies - with increasing proximity to a city. However, a number of empirical studies on labour allocation demonstrate that smallholder households are likely to diversify their income if off-farm employment is available (Fafchamps \& Shilpi, 2003; Deichmann et al., 2009; Imai et al., 2015). Just as access to input and output markets varies in space, so do off-farm employment opportunities and effective wage rates. There is theoretical (Krugman, 1991) as well as empirical (Fafchamps \& Shilpi, 2003) evidence that as the costs of commuting fall with increasing proximity to cities, wage rates and off-farm employment increase. Thus, in this study we expand on existing models to consider the interacting effects of improved access to agricultural markets and off-farm employment opportunities on household agricultural production decisions. We extend the conceptual frameworks introduced by Vandercasteelen et al. $(2017,2018)$ and Damania et al. (2017), which assume that household maximize farm profits, and consider instead comprehensive household utility maximization that also accounts for the opportunity costs of agricultural intensification in terms of off-farm income. Following the Barnum-Squire 'Model of an Agricultural Household' (Barnum \& Squire, 1979) and the notation proposed by Ellis (1993), we assume that a farm household maximizes its utility given in equation (1).

$U=f\left(C, M, T_{Z}\right)$

$C$ is the amount of the total farm output $Q$ consumed by the household, and $M$ are purchased goods for consumption. In addition to $C$ and $M$ the household also consumes goods $Z$. These are goods that do not have market values but are produced and consumed by the household (for example tailoring, cleaning). Therefore, a household's utility also depends on the time allocated to the production of $Z$ denoted by $T_{Z}$.

This utility function (1) is maximized subject to a production function (equation 2), a time constraint (equation 3) and an income constraint (equation 4). 


$$
\begin{aligned}
& Q=f(A, L, V) \\
& T=T_{Z}+T_{F}+T_{W} \\
& p(Q-C)+w T_{W}-v V=m M
\end{aligned}
$$

Total farm output (equation 2) depends on land $(A)$, labour $(L)$ and other inputs $(V)$. The total time available to the household $(T)$ is split among time to produce goods $Z\left(T_{Z}\right)$, time to produce $Q\left(T_{F}\right)$ and time spent in off-farm wage labour $\left(T_{W}\right)$ (equation 3). A negative sign for wage labour $\left(T_{W}<0\right)$ indicates that labour is hired in for farm production; a positive sign $\left(T_{W}>0\right)$ implies off-farm employment. The income constraint (equation 4) states that total household expenditures equal the net household earnings, where $p$ is the market price for the farm output $Q, w$ is the wage rate, $v$ is the price of the inputs $V$ and $m$ is the price of the purchased goods $M$.

Household utility is maximized when two equilibrium conditions are met: a production equilibrium and a consumption equilibrium. The production equilibrium is established when the marginal products of labour and inputs $\left(M P P_{L}, M P P_{V}\right)$ equal the ratio of the wage to the output price $(w / p)$ and the ratio of the input to the output-prices $(v / p)$, respectively. The consumption equilibrium is met when the marginal rates of substitution (MRS) of all possible pairs of arguments in $U$ equal the price ratios between the respective pairs. A partial graphical depiction of these equilibrium conditions is given in Fig. 2.1 and $2.2\left(M P P_{L}=w / p\right.$, $\left.M R S_{C, T_{Z}}=w / p\right)^{3}$.

To model the effects of location on agricultural intensification, we propose two extensions to the Barnum-Squire Model. First, in equations (5) and (6) we assume that there are two different production systems that reflect different stages of agricultural intensification, each represented by a distinct production function:

$$
\begin{aligned}
Q_{M} & =f\left(\bar{A}, L, \overline{V_{\text {mod }}}\right) \\
Q_{T} & =f\left(\bar{A}, L, \overline{V_{\text {trad }}}\right)
\end{aligned}
$$

For simplicity, we limit the number of production systems to two: $Y_{\bmod }$ representing a modern production system and $Y_{\text {trad }}$ a traditional one. The household maximizes its utility

\footnotetext{
${ }^{3}$ We assume standard second-order conditions for both equilibria. Thus, the indifference curve, $M R S_{C, T_{Z}}$, is convex to the origin of $C$ and $T_{Z}$ (right origin in Fig. 2.1 and 2.2). Furthermore, the second derivative of $M P P_{L}$ is nonpositive.
} 
subject to either of the two production systems (equations (5) and (6)), choosing the system that yields the highest utility in equilibrium. Household land use is assumed to be constant $(\bar{A})$ and therefore neglected in the following. The package of inputs used $\left(\overline{V_{\text {mod }}}\right.$ or $\left.\overline{V_{\text {trad }}}\right)$ is assumed to be fixed given the choice of a specific production system (modern or traditional, respectively). The interesting factor is labour $(L)$. Labor productivity in a modern production system can be assumed to be substantially higher than in a traditional one (Haggblade et al., 2010). Hence, all other things equal, the shape of the total physical product (TTP) of labour and consequently the location of the production equilibrium differs between the two systems. Contrasting Fig. 2.1 and 2.2, we see that in the modern production system more labour (own and hired-in) is allocated to farm production, while in the traditional system, due to its lower marginal farm labour productivity, more labour is allocated to the off-farm employment and producing $Z$.

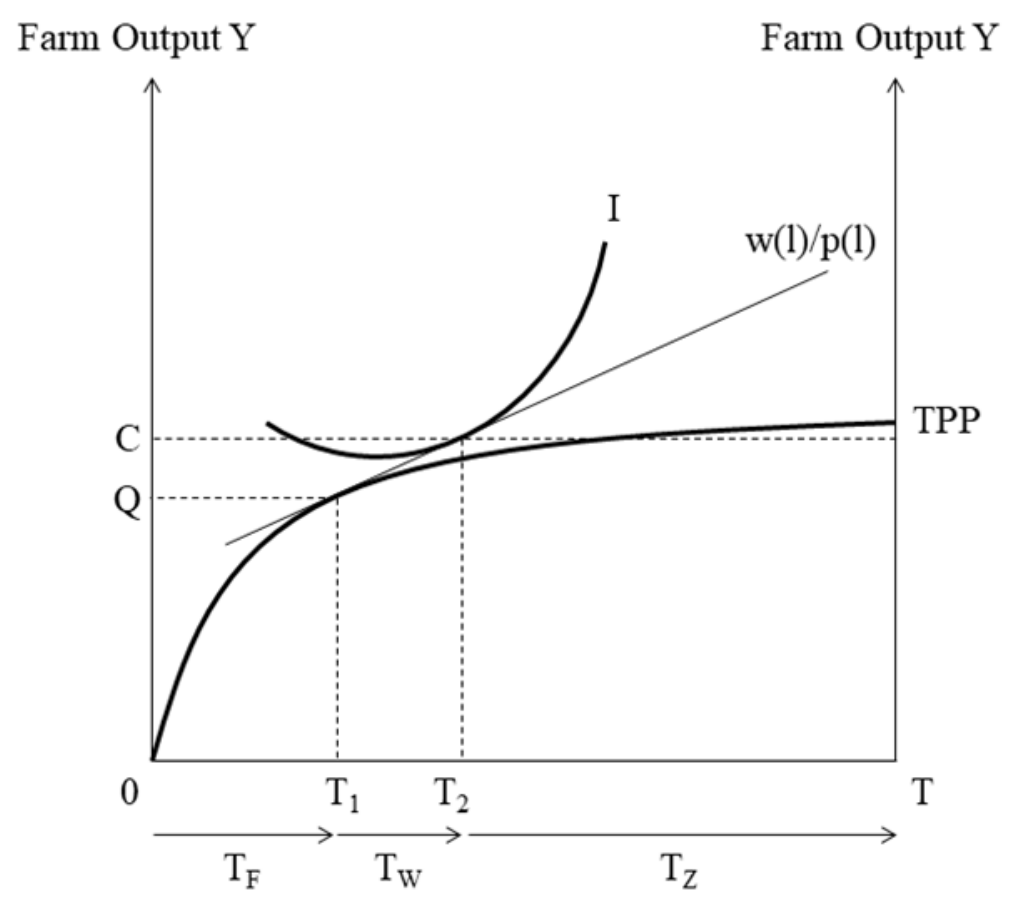

Fig. 2.1 Equilibrium in a traditional management system at location $l^{*}$. 


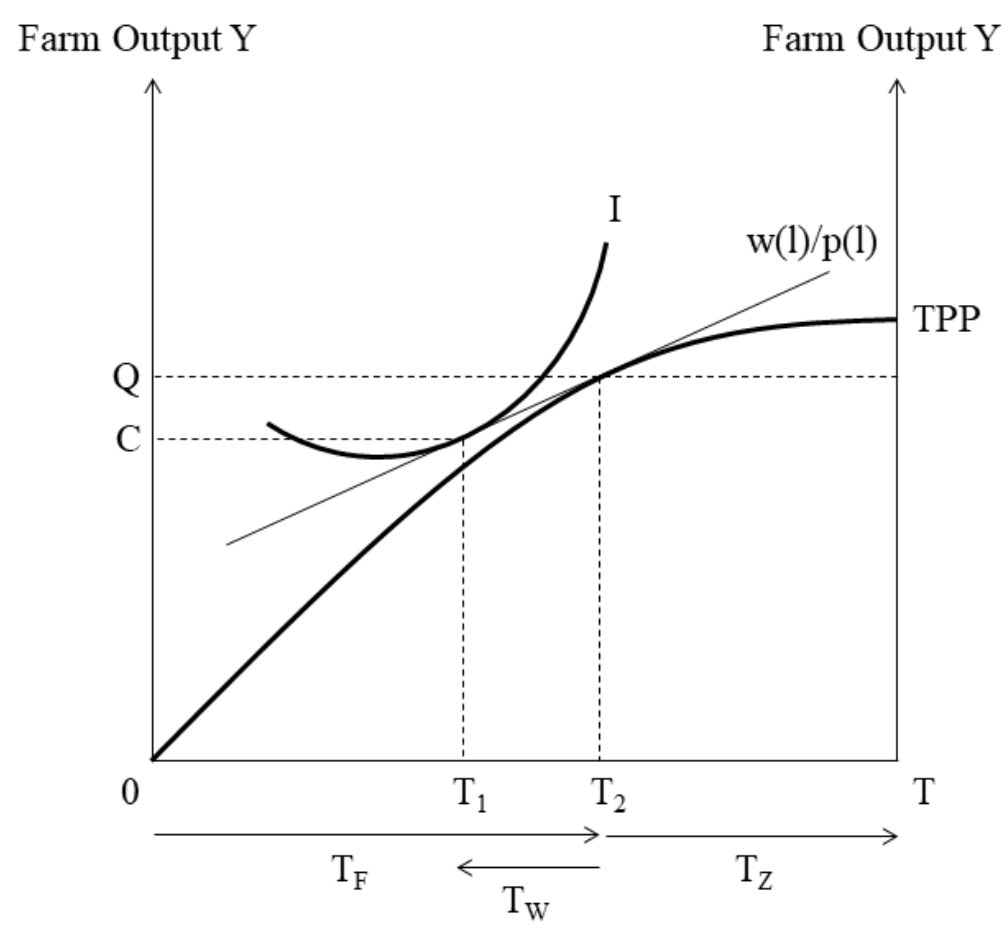

Fig. 2.2 Equilibrium in a modern management system at location $l^{*}$.

In the second extension to the basic Barnum-Squire Model, we define the effective output price and wage to be functions of household location (equations (7) and (8)).

$$
\begin{gathered}
p(l)=p^{\text {city }}-g(l) \text { with } g(l)>0 \\
w(l)=w^{\text {city }}-h(l) \text { with } h(l)>0
\end{gathered}
$$

$p^{\text {city }}$ and $w^{\text {city }}$ are the price of agricultural outputs and the wage rate at the urban centre. The per unit transport or access cost to the city as a function of distances from any urban centre defined by household location $l$ is denoted by $g(l)$ and and $h(l)$ with $\frac{\partial g(l)}{\partial l}>0$ and $\frac{\partial h(l)}{\partial l}>0$ respectively. This notation also allows effects of more than one urban centre accessible to a household because location $l$-in contrast to a usual distance measure-does not rely on a town of reference. More generally, the prices of purchased goods $(m)$ and inputs $(v)$, could also be considered location-dependent. However, allowing only $p$ and $w$ to vary with location is sufficient to produce complex non-linear spatial patterns of agricultural intensification, and further generalization would increase the complexity of the model without generating additional insights. 
Based on these extensions, we turn to Fig. 2.1 and 2.2 to analyse the effect of location on a household's choice between traditional and modern production. In both figures, the same slope of the wage/output price ratio $w(l) / p(l)$ applies and the household attains the same level of utility, denoted by the indifference curve $I$. However, in Fig. 2.1 the household uses traditional production technology while in Fig. 2.2 it uses modern production technology. Hence, at location $l^{*}$ traditional and modern production lead to the same utility and the household will be indifferent to which production system it chooses.

However, when we consider an otherwise identical household at another location $l^{* *}$ the price ratio $w(l) / p(l)$ will change depending on the relative slopes of $g(l)$ and $h(l)$. Hence, new equilibrium solutions will be obtained for the traditional and modern production systems, and the household will choose the production system that generates the highest utility. If, for example, the effective wage rate increases more rapidly than the farm output price with increasing proximity to the urban centre, then the ratio $w(l) / p(l)$ will become steeper in both figures, increasing the utility level that is attained in the traditional management system (as the household reduces agricultural production and allocates more labour to off-farm employment), but reducing the utility that is attained in the modern management system (as hired-in labour becomes more expensive). Under these conditions, therefore, we would expect to see more traditional and less modern agricultural production as we move towards the urban centre from location $l^{*}$. This is the opposite of the outcome that is generally predicted by models that only consider the effects of proximity on output and input prices.

Several authors mention that the size of a city, that is the magnitude of demand by its population, determines the degree of agricultural intensification in its hinterlands (Vandercasteleen et al., 2017, 2018; Fafchamps and Shilpi, 2003). This is true to the extent that increasing city size will affect the spatial pattern of output prices. Yet, the introduction of location-dependent wages implies that not only the size of a city but its structure will determine the surrounding spatial pattern of agricultural intensification. A city with a large industrial sector that demands unskilled labour will have a different effect on farm households' management decisions than a city with a large service sector that demands more skilled labour. In addition, not every household is characterised by the specific indifference curves and production functions presented in Fig. 2.1 and 2.2. The ratio $w(l) / p(l)$ will vary over space in a unique manner for each individual household, depending on its specific preferences and endowments (age structure, labour skills, land holdings, etc.). Hence, depending on the distribution of household types in space and the characteristics of the urban 
economy, agricultural intensification will not necessarily increase towards the urban centre; it might decrease or, more likely, vary in a more complex, non-monotonic manner.

Thus, two factors increase the likelihood of observing complex patterns of agricultural intensification surrounding a large city. First, we can extend the model above to distinguish between labour with higher and lower levels of human capital and different degrees of complementarity between human capital and other inputs in modern compared with traditional production systems. For example, the ratio $w(l) / p(l)$ might increase with proximity to the urban center for labor with high levels of human capital, but increase at a lower rate or even decrease for unskilled labour. This will have implications for spatial patterns of agricultural intensification if the successful implementation of modern production systems requires higher levels of human capital. Second, the spatial pattern of agricultural intensification will be further complicated by polycentric urbanisation that can lead to nonlinear variations in the ratio $w(l) / p(l)$ over space depending on the location of satellite towns and the quality of transportation infrastructure.

In summary, agricultural intensification will not necessarily increased monotonically with proximity to urban centres. Instead, agricultural intensification can follow non-linear and complex spatial patterns. We have identified several factors, such as off-farm employment opportunities and polycentric urban expansion, that might be expected to generate complex spatial patterns of agricultural intensification, but other factors might also contribute. Whatever their underlying causes, to identify these complex spatial patterns in empirical analysis, we require alternative modelling strategies and proxies for urbanisation effects.

\subsection{The Study Area, Survey Design and Data Set}

Bangalore, one of the largest and fastest growing cities in India, and sometimes referred to as India's 'Silicon Valley', is located in the South Indian state of Karnataka (Sudhira et al., 2007). The last official census published in 2011 counted 9.6 million people living in the Bengaluru urban district (Directorate of Census Operations Karnataka, 2011), an increase of more than 30 per cent compared with the previous census in 2001. Estimates of the population in 2018 range around 12 million (Sharma, 2018). Bangalore thus represents the type of megacity urbanisation that is predicted for many cities in developing countries in future decades (United Nations Population Division, 2015), especially in Asia.

There are several secondary towns within a 70 kilometre radius around Bangalore that have also experienced substantial growth during the last decades, developing their own industries, services and market infrastructure in the process (Fig. 2.3). In addition, the infrastructure 
linking these smaller towns to Bangalore has been continuously upgraded, although congestion and daily traffic jams have, if anything, become more severe. Hence, our study area is best characterized as a polycentric urban hierarchy with Bangalore in the centre.

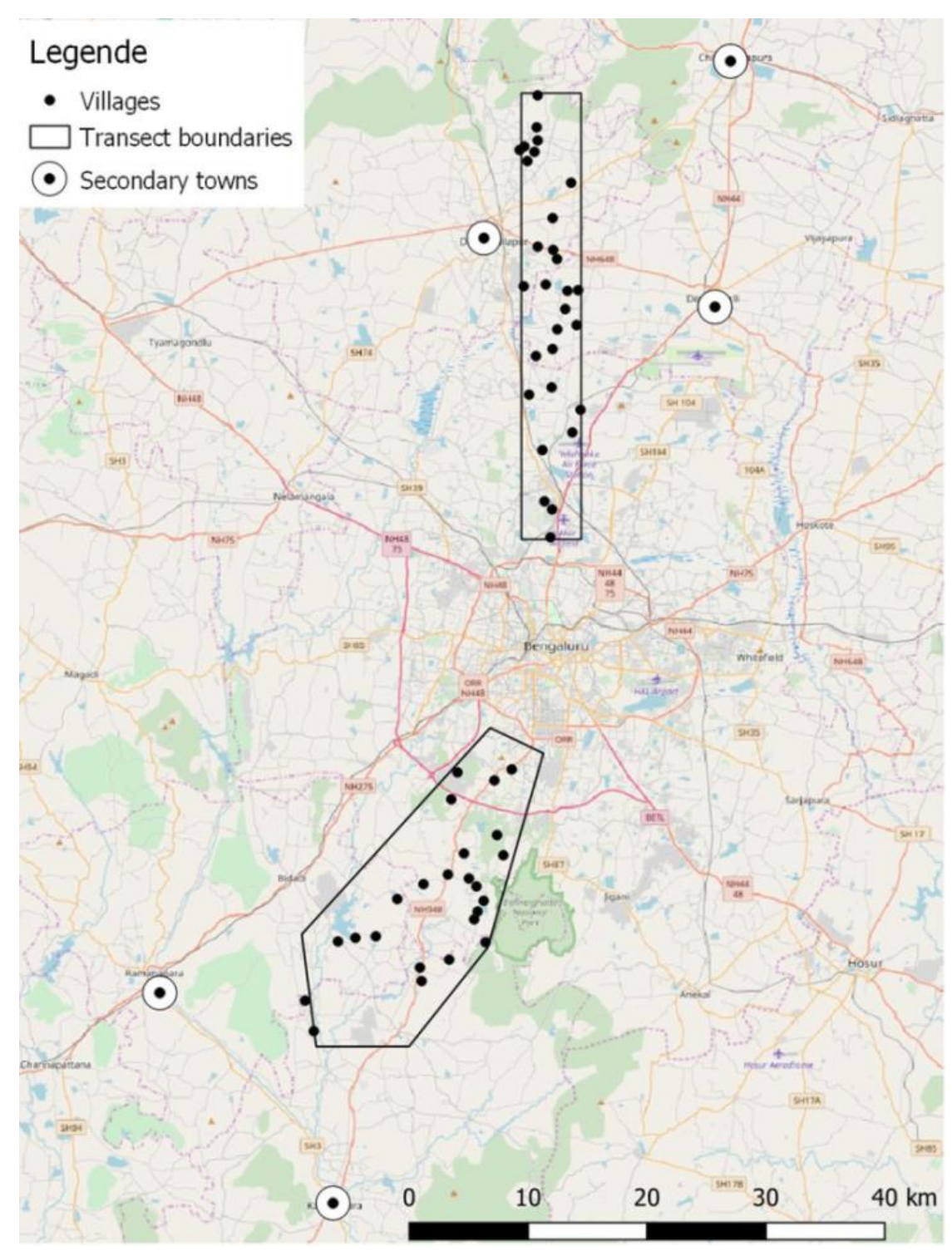

Fig. 2.3 Rural-urban interface of Bangalore, research transects, village location and secondary towns.

Rapid urbanisation notwithstanding, agricultural production still dominates the rural-urban interface surrounding Bangalore and the secondary towns (Directorate of Census Operations Karnataka, 2011). Individual household land holdings are small—about two acres—but the variety of crops produced is large and ranges from traditional staples to fruits and vegetables, tree crops, mulberry for silk production and even turf production for urban lawns. In addition, dairy cattle and other livestock are common. State regulated wholesale markets (referred to as 
APMC) and other retail formats (for example contracts, supermarkets, cooperatives, farmers' markets) in Bangalore and the secondary towns offer farmers a variety of marketing channels for their produce driven by increasing demand for agricultural products caused by economic and population growth in Bangalore, and by national and international trade.

Our empirical analysis is based on socioeconomic survey data that was collected from 1,275 households between December 2016 and May 2017. All households were selected in two predefined research transects that cut across the rural-urban interface of Bangalore (see Fig. 2.3). One transect is located to the north of Bangalore (hereafter referred to as the northern transect) and the other transect to the southwest (the southern transect). To ensure an even distribution of households in the transects and, thus, a valid representation of the spatial heterogeneity in the rural-urban interface, household selection followed a two-step sampling procedure based on the Survey Stratification Index (SSI) introduced by Hoffmann et al. (2017). First, each transect was separated into three strata, namely urban, peri-urban and rural. In each of the resulting six strata (three per transect) 10 villages were randomly selected. The 60 villages thus selected account for roughly 30 per cent of the total number of villages in the transects. In a second step, an average of just over 21 households per village was randomly drawn from household lists provided by the preschool teachers in each village. The exact number of household selected per village was proportional to total village population.

The survey was designed to produce a representative sample of households in the rural-urban interface, both agricultural and non-agricultural. As we are interested in agricultural intensification, in the following we only consider households that managed at least one agricultural plot in 2016. Therefore, our final sample includes 638 farm households; 354 households in the northern and 284 households in the southern transect. Fig. 2.3 shows the villages in which these agricultural households are located. All data are geo-referenced as we collected village and household coordinates. This allows us to calculate the distance to the Bangalore city centre for every household, but also to model location effects using the exact coordinates of each village and household in two dimensions.

Each household was asked to provide detailed information on its socio-economic characteristics and the agricultural management and marketing practices that it applied in 2016. The result is a complex data set with information on different scales. The smallest scale of observation is the crop level with 1,926 crop observations. At this scale, 72 different crop and 90 different inputs were recorded. Additional scales of observation are the plot, household, village and transect level. At the crop level, for example, we recorded information 
on the growing season, the use of inputs including irrigation, growing season and the use (own consumption, marketing) of the output. At the plot level, we recorded size, soil quality and slope. Household level information includes the number of plots cultivated, as well as socio-economic characteristics such as caste, education, wealth indicators such as durable assets and off-farm employment. An overview of the collected data is provided in Table 2.1.

Following Sharma et al. (2011), Lohr \& Park (2002), Wollni et al. (2010) and Teklewold et al. (2013), we use a count of modern inputs applied per crop as a measure of agricultural intensification. We classified all inputs observed in our data set into six categories: (a) organic fertilizer, (b) traditional seed varieties, (c) new seed varieties, (d) pesticides, (e) inorganic fertilizer and (f) hormones. We use a count of all inputs in categories (c) to (f) per crop observation-hereafter referred to as modern inputs - to locate each household on a scale from traditional to modern production. In the conceptual framework presented in chapter 2 , we assumed a strict dichotomy between traditional and modern production, but the ruralurban interface is characterized by transition between systems. Any attempt to classify each household into one of two categories would be arbitrary and would not take advantage of the richness of our survey data.

\section{Table 2.1}

\section{Descriptive statistics of all control variables}

\begin{tabular}{|c|c|c|c|c|}
\hline Variable & $\mathbf{N}$ & All & Northern transect & Southern transect \\
\hline Modern inputs (count) & 1926 & $1.7747(1.3592)$ & $1.8808(1.5565)$ & $1.6837(1.1568)$ \\
\hline \multicolumn{5}{|l|}{ Crop scale } \\
\hline Irrigation (dummy) & 1926 & 0.4766 & 0.3476 & 0.5873 \\
\hline Purpose production & 1926 & & & \\
\hline 1: Marketing & & 0.3240 & 0.2857 & 0.3568 \\
\hline 2: Exclusively fodder & & 0.1267 & 0.1159 & 0.1360 \\
\hline $\begin{array}{r}\text { 3: Fodder and home } \\
\text { consumption }\end{array}$ & & 0.1869 & 0.1834 & 0.1900 \\
\hline o: Others & & 0.3624 & 0.4151 & 0.3173 \\
\hline Sowing season ${ }^{\text {a) }}$ & 1926 & & & \\
\hline o: Perennial & & 0.2347 & 0.2385 & 0.2314 \\
\hline 1: Kharif 2015 & & 0.0223 & 0.0112 & 0.0318 \\
\hline 2: Rabi 2015 & & 0.1054 & 0.0765 & 0.1302 \\
\hline 3: Summer 2016 & & 0.0737 & 0.0720 & 0.0752 \\
\hline 4: Kharif 2016 & & 0.4927 & 0.5422 & 0.4503 \\
\hline 5: Rabi 2016 & & 0.0711 & 0.0596 & 0.0810 \\
\hline
\end{tabular}


Table 2.1 continued

\begin{tabular}{|c|c|c|c|c|}
\hline Variable & $\mathbf{N}$ & All & Northern transect & Southern transect \\
\hline \multicolumn{5}{|l|}{ Plot scale } \\
\hline Plot property & 1108 & & & \\
\hline 1:Owned & & 0.9179 & 0.9425 & 0.8839 \\
\hline 2:Rented & & 0.0659 & 0.0420 & 0.0989 \\
\hline 3:Common area & & 0.0009 & 0.0016 & 0 \\
\hline 4:Government (permission) & & 0.0072 & 0.0062 & 0.0086 \\
\hline 5:Government (no permission) & & 0.0081 & 0.0078 & 0.0086 \\
\hline Size (acres) & 1105 & $1.8229(3.9854)$ & $1.6991(3.6441)$ & $1.9926(4.4092)$ \\
\hline Slope & 1104 & & & \\
\hline 1:None & & 0.4092 & 0.4593 & 0.3412 \\
\hline 2:Moderate & & 0.4420 & 0.4158 & 0.4378 \\
\hline 3:Steep & & 0.1486 & 0.0956 & 0.2210 \\
\hline Soil quality & 1104 & & & \\
\hline 1:Poor & & 0.0362 & 0.0392 & 0.0322 \\
\hline 2:Middle & & 0.4710 & 0.4765 & 0.4635 \\
\hline 3:Very good & & 0.4928 & 0.4843 & 0.5043 \\
\hline Time to plot (minutes) & 972 & $14.1472(13.4997)$ & $13.7256(12.459)$ & $14.7789(14.9188)$ \\
\hline \multicolumn{5}{|l|}{ Household scale } \\
\hline Age household head (years) & 629 & $45.0254(13.5583)$ & $44.8357(13.6167)$ & $45.2589(13.5066)$ \\
\hline $\begin{array}{l}\text { Automobile owned in } 2016 \\
\text { (dummy) }\end{array}$ & 638 & 0.0345 & 0.0 & 0.0211 \\
\hline Dairy (dummy) & 638 & 0.7743 & 0.7684 & 0.7817 \\
\hline Durable assets (count) & 638 & $2.8151(1.2779)$ & $2.8107(1.2778)$ & $2.8204(1.2802)$ \\
\hline $\begin{array}{l}\text { Education household head } \\
\text { (years) }\end{array}$ & 600 & $6.275(5.1595)$ & $6.7868(5.2273)$ & $5.6367(5.0104)$ \\
\hline $\begin{array}{l}\text { Experience household head } \\
\text { (years) }\end{array}$ & 632 & $28.5997(14.299)$ & $28.1543(14.0771)$ & $29.1525(14.5759)$ \\
\hline Extension (dummy) & 619 & 0.0969 & 0.0977 & 0.0959 \\
\hline $\begin{array}{l}\text { Gender household head } \\
\text { (dummy) }\end{array}$ & 629 & 0.1653 & 0.1672 & 0.1631 \\
\hline Household size (count) & 629 & $4.6391(2.0785)$ & $4.732(2.1745)$ & $4.5248(1.9517)$ \\
\hline \multicolumn{5}{|l|}{ Caste } \\
\hline 1:General & & 0.5192 & & 0.4646 \\
\hline 2:Scheduled Castes & & 0.1314 & & 0.1159 \\
\hline 3:Scheduled Tribes & & 0.0483 & & 0.0697 \\
\hline 4:Other Backward Class & & 0.2648 & & 0.3116 \\
\hline 5:Other ${ }^{\mathrm{b})}$ & & 0.0363 & & 0.0382 \\
\hline $\begin{array}{l}\text { Adult household members in } \\
\text { off-farm employment (share) }\end{array}$ & 638 & $0.2143(0.2431)$ & $0.2119(0.2462)$ & $0.2163(0.2405)$ \\
\hline $\begin{array}{l}\text { Off-farm employment } \\
\text { (dummy) }\end{array}$ & 638 & 0.6191 & 0.6271 & 0.6092 \\
\hline
\end{tabular}

Note: Standard deviation in brackets. For dummy and factor variables shares are given. The number of

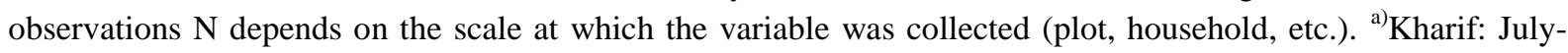
October (monsoon season); Rabi: October-March; Summer: March-June. ${ }^{\text {b) }}$ This category includes households that did not associate themselves with any caste. 


\subsection{Methods}

In our empirical analysis, we use a Structured Additive Regression (STAR) framework. STAR models allow for different types of covariates in addition to classical linear effects (Fahrmeir et al., 2013). This flexibility allows us to account for the multiple scales at which our data was collected (plot, household, village and so forth), and to incorporate non-linear one- and two-dimensional spatial effects. Following Sharma et al. (2011), we assume that the dependent variable (number of adopted modern inputs) is Poisson distributed. We logtransform the rate $\lambda$ of the Poisson distribution to ease interpretation and define the additive and semiparametric predictor $\eta^{\text {struc }}$ as follows:

$y \sim P o(\lambda)$, with $\log (\lambda)=\eta^{\text {struc }}=X \beta+Z \gamma+f_{\text {Dist }}+f_{\text {Loc }}$

The predictor consists of four elements, namely linear effects of standard control variables $X \beta$, random intercepts for the different scales of the data set $Z \gamma$, where $Z$ is an $n \times n$ identity matrix, a non-linear effect (one-dimensional spline) of distance to the Bangalore city centre $f_{\text {Dist }}$, and a vector of two-dimensional splines $f_{\text {Loc }}$ to capture the effects of explicit household or village location.

Descriptive statistics for the variables in $X$ are presented in Table 2.1. As control variables, we include information on crop, plot and household characteristics.

The main purpose of the random intercepts is to handle effects at different scales. Because the northern and the southern transects differ considerably in agricultural and economic structure, we estimate separate models for each transect and there is no need for random effects at the transect level. However, we do include random effects at the crop, plot, household and village levels: $\gamma=\left(\gamma_{\text {crop }}, \gamma_{\text {plot }}, \gamma_{\text {household }}, \gamma_{\text {village }}\right)^{\prime}$. The crop level is especially important due to the high crop diversity observed in our sample. By introducing random effects for different crops, we capture each crop's individual input requirements as a deviation from the overall sample intercept. The interpretation of the other random effects is similar.

Many models in the literature include distance to the next city or market as a standard linear effect. Our conceptual framework shows that urbanisation effects can be non-linear. We therefore estimate the effect function of distance to Bangalore city centre as a onedimensional P-spline, $f_{\text {Dist }}$. P-splines are polynomial splines of degree $l \geq 0$ with an additional penalty term ensuring the smoothness of the function (Fahrmeir et al., 2013). Polynomial splines consist of a series of polynomials of degree $l$ over intervals $\left[\kappa_{j}, \kappa_{j+1}\right)$ with 
$a=\kappa_{1}, \ldots, \kappa_{m}$ being a defined number of knots. Furthermore, $f_{\text {Dist }}$ has to be $(l-1)$-times continuously differentiable to be a smooth function. The penalty is simultaneously estimated with the polynomial splines and is based on the difference to neighbouring coefficients. We specify P-spline $f_{\text {Dist }}$ with 20 knots and a second order random walk penalty. For a detailed introduction to P-splines see Kneib \& Fahrmeir (2006) or Fahrmeir et al. (2013). The explicit spatial effects $f_{\text {Loc }}$ are estimated as a two-dimensional P-spline surface smoother. The construction of the two-dimensional P-spline is equivalent to the one-dimensional P-spline. However, since the calculation is more complex, the two-dimensional spline is specified by only 10 knots and a first order random walk penalty. The function $f_{L o c}$ represents the direct effect of household or village coordinates (bivariate variable), $f_{\text {Loc }}=\left(f\left(s_{\text {household }}\right), f\left(s_{\text {village }}\right)\right)^{\prime}$, on the number of adopted modern inputs. It can be interpreted as a bivariate non-linear effect that reflects position in the plain and is thus able to capture complex location effects in a polycentric setting.

Inference in model (9) is based on a mixed model representation and estimation follows an empirical Bayesian approach; from a frequentist perspective, this is comparable to penalized likelihood estimation. The main difference between the Bayesian and frequentist perspectives is the definition of the penalty in the non-linear smoothers $f_{\text {Dist }}$ and $f_{\text {Loc }}$; this penalty takes the form of a smoothing parameter in the Bayesian approach, and a variance component in the frequentist approach (Kneib \& Fahrmeir, 2006). ${ }^{4}$

\subsubsection{Model Specifications}

We estimate two models. Model one includes the one-dimensional urbanisation proxy distance to the Bangalore city centre, $f_{\text {Dist }}$ :

$$
\log (\lambda)=\eta^{\text {struc }}=X \beta+Z \gamma+f_{\text {Dist }}
$$

The second model contains the two-dimensional location effects $f_{\text {Loc }}$. We compared estimates of $f_{L o c}$ based on household and village coordinates and find that two-dimensional splines based on village coordinates yield a lower Akaike information criterion (AIC). Therefore, we only considered village coordinates, $f\left(s_{\text {village }}\right)$ in the ensuing analysis:

\footnotetext{
${ }^{4}$ The estimation of the model was conducted in R using the package 'R2BayesX' (Umlauf et al., 2013), which provides an interface to the free Software 'BayesX' for Bayesian inference. For more information on the estimation techniques and inference see Kneib \& Fahrmeir (2006), Umlauf et al., (2015) and Fahrmeir et al. (2013).
} 
$\log (\lambda)=\eta^{\text {struc }}=X \beta+Z \gamma+f\left(s_{\text {village }}\right)$

Estimating and comparing models (10) and (11) allows us to determine how well the onedimensional and two-dimensional non-linear effects capture spatial heterogeneity, and whether there are substantial differences between the two effects.

With 20 control variables and four sets of random effects the models are already quite large and possibly subject to convergence and computational challenges, especially when we attempt to include the two-dimensional splines, $f_{\text {Loc }}$. To avoid these problems and overparameterization, we apply an adaptive algorithm based on the improved Akaike information criterion (iAIC) to eliminate covariates in $X$ and random effects $\gamma$ that do not contribute to the fit of the base model (for details see Brezger \& Lang, 2006; Belitz et al., 2012).

\subsubsection{Linking theoretical and empirical Concepts of Location}

Before we present results, we briefly consider the relationship between the location effects discussed in our conceptual framework above and the location effects estimated using $f_{\text {Dist }}$ and $f\left(s_{\text {village }}\right)$ in our empirical application. In the conceptual framework, proximity to urban centre affects the demand for agricultural outputs and off-farm earning opportunities. $f_{\text {Dist }}$ measures proximity to the urban center of Bangalore and will capture these effects if two assumptions hold: first that these urbanisation effects are common in all directions moving away from the centre of Bangalore, and second that there are no uniform concentric geological or biophysical patterns around Bangalore. If, for example, there were uniform a ring of especially good soil at a certain distance from the centre of Bangalore, its effects on household agricultural decisions would influence the estimated shape of the spline $f_{\text {Dist }}$, which would then no long only reflect urbanisation effects. Since we can safely assume that there are no such uniform and concentric geological or biophysical patters surrounding Bangalore, we can use the performance of $f_{\text {Dist }}$ in our second model to assess whether the effects of urbanisation on agricultural decision making do indeed follow a common pattern moving away from the urban centre independent of direction.

Interpreting $f\left(s_{\text {village }}\right)$ is less straightforward because it does not measure a distance from the urban centre but rather a set of location coordinates. Therefore, it might also capture local geological or biophysical effects such as soil quality or elevation that affect agriculture and are defined by the physical location of a village. To control for this and to ensure that the 
urbanisation effects that we estimate using $f\left(s_{\text {village }}\right)$ are not confounded by geological or biophysical effects such as spatial variations in soil quality, we employ two strategies. First, we include plot characteristics such as soil quality and slope in $X$, to control for small-scale biophysical factors. Second, we include village-level random intercepts to control for unobserved variation at a larger scale, for example, distinct biophysical or hydrological features that affect agricultural decision making in a particular village. Examples of such features are hills, lakes, or wastewater drainages that could be used as alternative irrigation sources. We are confident that because of these controls the location effects that we estimate using $f_{\text {Dist }}$ and $f\left(s_{\text {village }}\right)$ will primarily capture the urbanisation effects discussed in our conceptual framework.

\subsection{Results and Discussion}

We begin with the estimation results for the first model, which includes one-dimensional effects of distance to Bangalore on the use of modern inputs (equation (10)). For the northern transect the results suggest that the use of modern inputs increases significantly with increasing distance from Bangalore (Fig. 2.4, left panel). The y-axis in both panels of Fig. 2.4 displays estimated coefficients. Because the models were estimated in log-linear form, the exponential of the coefficients yields the multiplicative effects on the mean rate of adopted modern inputs. For the northern transect this means on averag 11 per cent $\left(e^{0.1} \approx 1.11\right)$ more adopted modern inputs on average at household locations beyond 40 kilometres. The effect for households located closer to Bangalore is of a similar magnitude but with a negative sign, that is 11 per cent fewer mean adopted modern inputs for households closest to Bangalore. For the southern transect the one-dimensional effect suggests that modern input use increases with proximity to Bangalore, however the confidence intervals indicate that this effect is weak and insignificant at conventional levels.

There are two interesting findings from these results. First, even though our estimation approach allows for non-linear effects, both P-splines in Fig. 2.4 are very close to linear. Second, the estimated urbanisation effect in the northern transect is the opposite of what is found in previous studies (Vandercasteelen et al., 2017; Damania et al., 2017) because it indicates that modern input use falls with increasing proximity to Bangalore. 


\section{Northern transect}

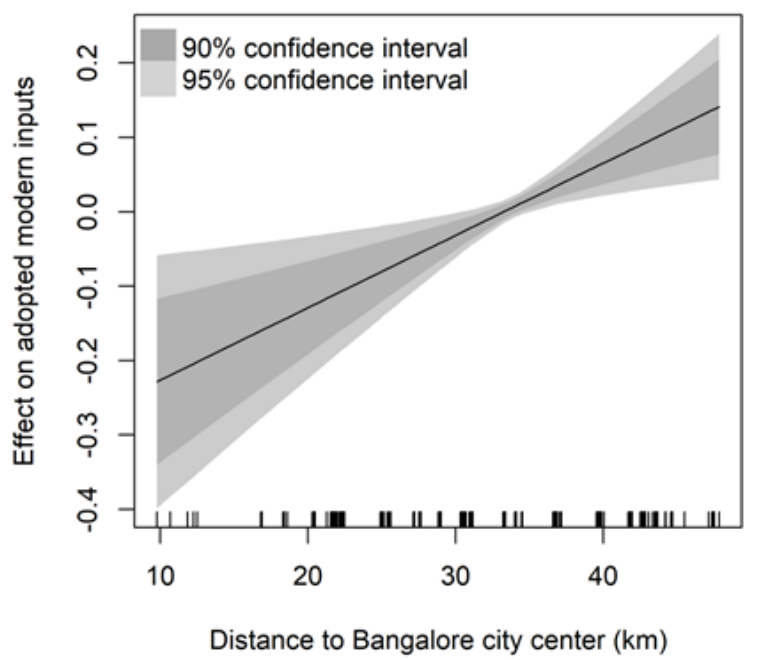

Southern transect

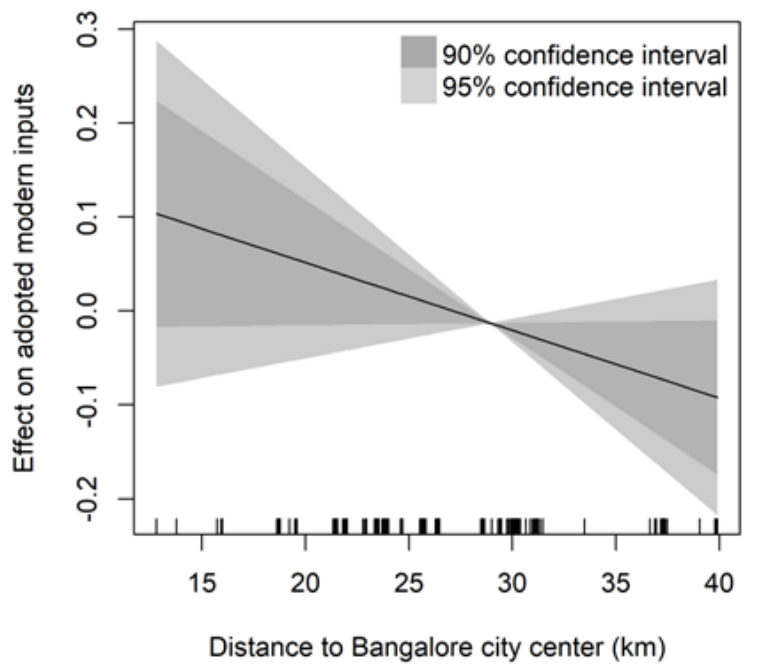

Fig. 2.4 Estimates of one-dimensional splines, $f_{\text {Dist }}$, model specification (10) $\left(\mathrm{N}_{\text {north }}=829\right.$, $\mathbf{N}_{\text {south }}=983$ ).

The results of our second model (equation (11)), which includes two-dimensional splines for village coordinates $\left(f\left(s_{\text {village }}\right)\right.$, are presented in Fig. 2.5 . These results are roughly similar to those of the one-dimensional model presented in Fig. 2.4 above, but provide several additional insights. In the northern transect the two-dimensional location effects confirm the result presented above that the use of modern inputs increases with increasing distance from Bangalore. The magnitude of this effect is comparable to the one-dimensional splines as well. The two-dimensional spline for the northern transect shows that modern input use is roughly 11 per cent above average in the dark red areas in the northern ranges of the transect and 11 per cent below average in the southern ranges closest to Bangalore centre. However, the twodimensional location effects also reveal nuances that are not apparent in Fig. 2.4. Specifically, Fig. 2.5 reveals a cluster of high modern input use towards the northwest of the northern transect. This cluster might be related to the secondary town Doddaballapura, which has roughly 300,000 inhabitants and good agricultural marketing infrastructure including a stateregulated APMC wholesale market and many local traders. The absence of such an effect cluster close to Bangalore might hint at higher opportunity costs of agricultural intensification closer to the large city. 


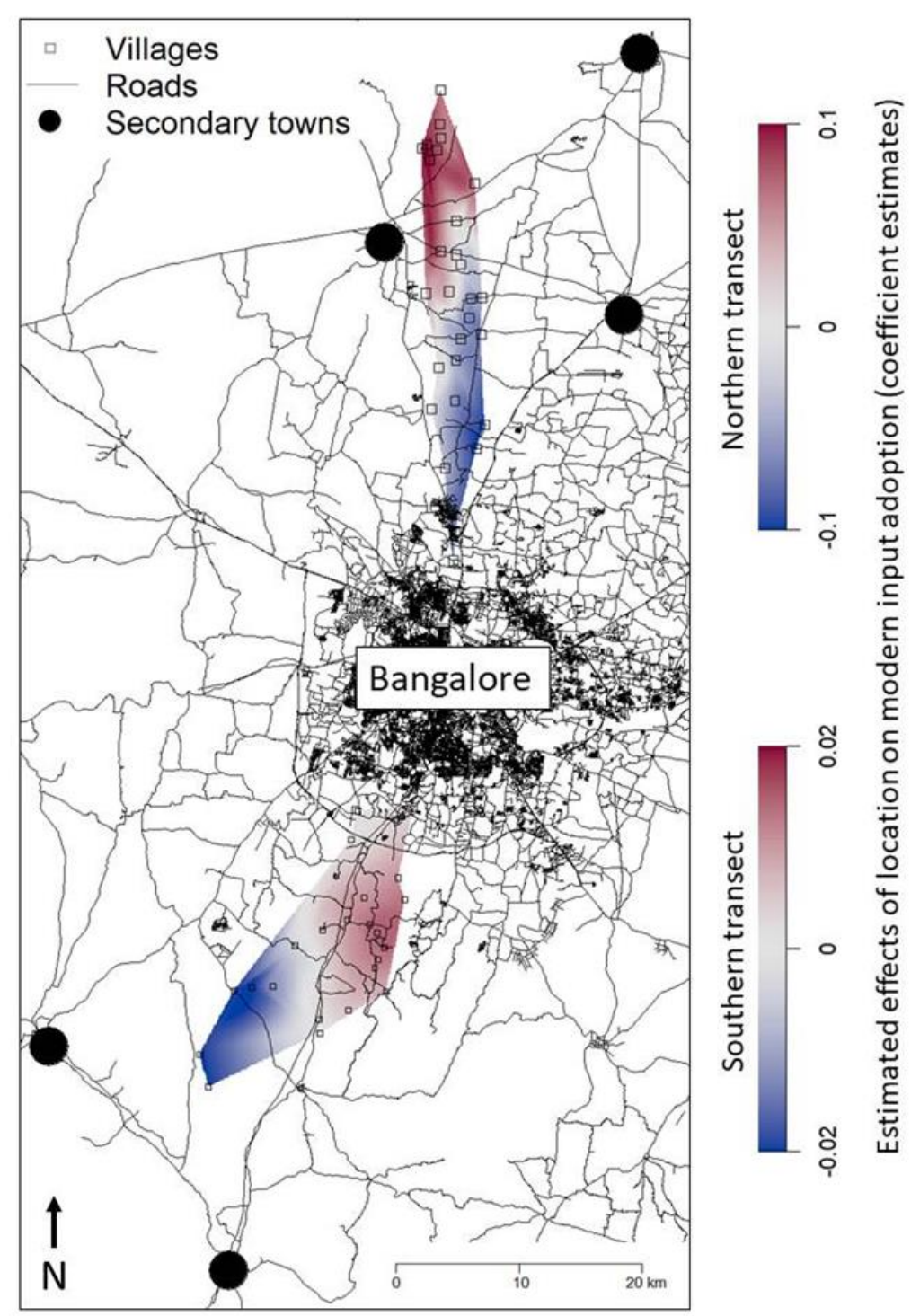

Fig. 2.5 Estimates of two-dimensional splines, $f\left(s_{\text {village }}\right)$, model specification (11) $\left(\mathbf{N}_{\text {north }}=829, \mathbf{N}_{\text {south }}=983\right)$.

In the southern transect the results of the model that includes two-dimensional effects (Fig 2.5) confirm that modern input use roughly declines with increasing distance from Bangalore. However, the magnitude of the estimated spatial effects is a factor of five lower in the southern than in the northern transect. As is the case in the northern transect, the twodimensional results for the southern transect reveal more spatial complexity. The results presented in Fig. 2.5 show that modern input use does not increase smoothly with increasing proximity to Bangalore but rather appears to peak in a cluster in the middle of the eastern range of the transect. The road map included in Fig. 2.5 suggests that this spatial cluster of higher modern input use might be related to the road that connects Bangalore to the secondary 
town of Kanakapura in the south. Thus, the effect might be rather driven by proximity to infrastructure than Bangalore itself.

In summary, the one-dimensional model captures the main feature of the two-dimensional pattern presented in Fig. 2.5. However it is less nuanced and does not, for example reveal the apparent cluster of higher modern input use near the secondary town Doddaballapura (Fig. 2.5), or the cluster of higher input use along the eastern boundary of the southern transect. Furthermore, the fact that we observe very different patterns of urbanisation effects in the northern compared with the southern transect implies that approaches that are more flexible are necessary.

Using a one-dimensional urbanisation proxy such as distance to the urban centre is based on the assumption that urbanisation effects are concentric and uniform. Our results prove that this can be an unreasonable assumption in settings characterized by rapid and polycentric urbanisation. Indeed, if we estimate the model in equation (10) with one-dimensional distance effects using pooled data from both transects, the results (Appendix 2.1) resemble those in the left panel of Fig. 2.4 estimated for the northern transect alone, but they are much less significant and essentially represent a hybrid of the separate results for the northern and the southern transects that blurs the differences between the two. Applying the two-dimensional model does not suffer from such a bias because it is based on the explicit location of households.

In Table 2.2, we present the effects of explanatory variables on modern input use. Several aspects of these results are worth noting. First, in the northern transect a 1 per cent higher share of adult household members in off-farm employment decreases the mean rate of modern inputs used by almost 20 per cent. This result is in line with the expectation generated by our conceptual model that proximity to urban centres affects agriculture not only via its effects on output prices, but also by increasing the opportunity costs of agricultural labour. This is especially interesting in the light of the negative location effects close to Bangalore in the Northern transect (Fig. 2.5).

In the southern transect the effect of off-farm employment is insignificant. However, the variable is important for the model fit according to the iAIC and also has a negative sign in the southern transect. Table 2.1 shows that in 62 per cent of all households at least one member is employed off-farm, and that on average about 21 per cent of all household members work in the off-farm sector. These results do not prove the dynamics implied by our conceptual framework. However, they do suggest that proximity to urban centres affects 
agriculture not only via its effects on input and output prices, but also via its effects on alternative earnings opportunities. ${ }^{5}$ This can lead to more complex patterns of agricultural intensification than considered in the literature to date.

Besides off-farm employment, several other control variables also have significant effects on the use of modern inputs (Table 2.2). In some cases, these effects are similar in the northern and the southern transects, in other cases they differ. First, irrigation has a highly significant positive effect on the number of adopted inputs in both transects. This is expected as access to irrigation is often a prerequisite of modern, intensive agricultural systems (Elliott et al., 2014). Second, more modern inputs are applied to market crops, and fewer are applied to fodder crops. The former effect is statistically significant in the northern transect, where on average a household uses 37.9 per cent more modern inputs on crops grown exclusively for marketing rather than own consumption; the latter effect is statistically significant in the southern transect, where almost 22 per cent fewer modern inputs are applied to fodder crops. In addition, the results show that seasonal crops such as corn, tomatoes and other vegetablesindependent of the season-receive more modern inputs than perennial crops such as eucalyptus or coconut, an effect that is most pronounced in the northern transect

If households own an automobile in the northern transect, the mean rate of adopted modern inputs increases by more than 60 per cent. This can be interpreted in two ways. An automobile indicates relatively high wealth (only roughly $3.5 \%$ of all households in our sample own automobiles), and wealthier farmers likely face less liquidity constraints that might otherwise restrict access to modern agricultural inputs. Second, an automobile implies better access to input and output markets. In the southern transect, if a household has received extension services, its average modern input use increases by approximately 22 per cent.

\footnotetext{
${ }^{5}$ If we consider the conceptual framework, the decision of off-farm employment and agricultural intensification happens simultaneously. However, in our empirical model, we treat off-farm employment as standard exogenous variable. We believe that this is a reasonable assumption based on the structure of our data set. We only consider agricultural management decisions in the agricultural year of 2016. These decisions concern primarily seasonal crops and thus are short-dated. If household members are employed in the off-farm sector these are general permanent or long-term employments (teachers, drivers, etc.) or even self-employment such as shop owners. Even though seasonal or casual labor exists in the area, it does not contribute a significant share of off-farm employments in our sample. Consequently, we can assume that the labor allocation within the household is somewhat fixed before the agricultural year of 2016 and off-farm employment can be treated as exogenous. Nevertheless, it would be interesting for future studies to model the possible simultaneity of labor allocation decision either with data sets from areas with a higher share of casual labor or panel data.
} 
Table 2.2

Estimation results for model with two-dimensional splines, northern and southern transect separate

\begin{tabular}{|c|c|c|}
\hline \multirow[t]{2}{*}{ Variables } & \multicolumn{2}{|c|}{$\begin{array}{l}\text { Effects of explanatory variables as percentage change of the } \\
\text { mean rate of adopted modern inputs } \\
\qquad\left(\left(e^{\widehat{\beta}}-1\right) \times 100\right)\end{array}$} \\
\hline & Northern transect & Southern transect \\
\hline Intercept & $-1.558 \quad(0.934)$ & $-8.552(0.588)$ \\
\hline \multicolumn{3}{|l|}{ Crop characteristics } \\
\hline Yes & $35.866(<0.001)$ & $53.373(<0.001)$ \\
\hline \multicolumn{3}{|c|}{ Purpose production (ref.: Other) } \\
\hline Exclusively fodder & $-5.776(0.632)$ & $-22.167(0.046)$ \\
\hline Fodder and home consumption & $11.460(0.178)$ & $12.829(0.142)$ \\
\hline Marketing & $37.892(<0.001)$ & $8.383 \quad(0.372)$ \\
\hline \multicolumn{3}{|c|}{ Sowing season (ref.: Perennial) } \\
\hline Kharif 2015 & $44.991(0.163)$ & $6.759 \quad(0.727)$ \\
\hline Rabi 2015 & $40.270(0.037)$ & $22.385(0.120)$ \\
\hline Summer 2016 & $44.513(0.026)$ & $25.722(0.114)$ \\
\hline Kharif 2016 & $45.150(0.013)$ & $23.121(0.103)$ \\
\hline Rabi 2016 & $78.515(<0.001)$ & $22.569(0.155)$ \\
\hline \multicolumn{3}{|c|}{ Plot characteristics } \\
\hline \multicolumn{3}{|l|}{ Slope (ref.: None) } \\
\hline Moderate & $-3.004(0.618)$ & \\
\hline Steep & $17.492(0.114)$ & \\
\hline \multicolumn{3}{|c|}{ Household characteristics } \\
\hline \multicolumn{3}{|l|}{ Automobile owned in 2016} \\
\hline Yes & $60.031(<0.001)$ & $-15.591(0.330)$ \\
\hline \multicolumn{3}{|l|}{ Caste (ref.: General) } \\
\hline Scheduled Castes & & $1.227 \quad(0.890)$ \\
\hline Scheduled Tribes & & $34.797(0.044)$ \\
\hline Other Backward Class & & $22.140(0.009)$ \\
\hline Other & & $-3.468(0.838)$ \\
\hline $\begin{array}{l}\text { Education household head } \\
\text { (years) }\end{array}$ & $-0.807(0.219)$ & \\
\hline $\begin{array}{l}\text { Experience household head } \\
\text { (years) }\end{array}$ & $-0.300(0.193)$ & $-0.240 \quad(0.267)$ \\
\hline \multicolumn{3}{|l|}{ Extension } \\
\hline Yes & & $20.973(0.031)$ \\
\hline $\begin{array}{l}\text { Adult household members in } \\
\text { off-farm employment } \\
\text { (share) }\end{array}$ & $-19.668(0.086)$ & $-11.944(0.295)$ \\
\hline \multicolumn{3}{|l|}{ Random effects } \\
\hline Crop & Included & Included \\
\hline Plot & & \\
\hline Household & Included & Included \\
\hline Village & Included & \\
\hline & $(\mathrm{N}=829)$ & $(\mathrm{N}=983)$ \\
\hline
\end{tabular}

Note: $p$-values in parentheses. The original number of observations for the northern transect was 850 and 1037 for the southern. Differences result from dropped observations because of missing values. 


\subsection{Conclusions}

The rapid growth and expansion of Bangalore is a good example of future urbanisation trends and their effects on agriculture in surrounding areas. The goal of this study is to contribute to our understanding of the effect of urbanisation processes on agricultural intensificationmeasured by the amount of adopted modern inputs - in the rural-urban interface of Bangalore. Past studies have focused on how urban centres affect agriculture via their effects on access to input and output markets, and have employed one-dimensional measures of proximity as proxies for these effects. We expand this framework by also considering the effects of polycentric urbanisation patterns and of potential opportunity costs of agricultural intensification due to off-farm opportunities.

In our conceptual framework we model household decision-making as a utility maximization problem following Barnum \& Squire (1979). In this model, the household allocates its labour between two types of agricultural production (traditional and modern), off-farm employment and the production of household goods subject to location-dependent agricultural output prices and off-farm wage rates. This model predicts that agricultural intensification in ruralurban interfaces will display non-linear and complex patterns that cannot be captured by onedimension proxies for urban proximity.

To test this model we analyse the use of modern agricultural inputs in a sample of 638 farm households in two study areas (transects) in the rural-interface of Bangalore. Based on household and village coordinates, we estimate two-dimensional splines measuring urbanisation effects in a STAR framework. The results confirm the existence of complex spatial patterns of agricultural intensification. In the northern transect the use of modern inputs generally increases with increasing distance from the centre of Bangalore and appears to be influenced by the secondary town of Doddaballapura. We observe a cluster of increased modern input use in the eastern-central range of the southern transect that may reflect the influence of road infrastructure that links Bangalore to the secondary town of Kanakapura. Hence, our empirical results indicate that the effects of urbanisation on agriculture are not uniform in all directions from the urban centre, and can display complex, non-linear patterns in any given direction from the urban centre. One-dimensional urbanisation proxies are not able to capture these complex patterns and can therefore lead to misleading results and interpretation in many real-world settings.

Even though our results are rather explorative, we believe that we demonstrate some interesting concepts and methods for future research. We see a possible extension of our work 
particularly in considering the simultaneity in decision-making concerning labour allocation between farm and off-farm labour within a household. Simultaneous equation models might be an adequate modelling approach. In addition, the differentiation between skilled and unskilled as well as between long- and short-term off-farm employments might lead to additional insights. 


\section{References}

Asfaw, S., Di Battista, F., \& Lipper, L. (2016). Agricultural Technology Adoption under Climate Change in the Sahel: Micro-evidence from Niger. Journal of African Economies, 25, 637-669.

Barnum, H. N., \& Squire, L. (1979). A model of an agricultural household: Theory and evidence. World Bank staff occasional papers, 27. Baltimore: Johns Hopkins Univ. Press.

Belitz, C., Brezger, A., Kneib, T., \& Lang, S. (2012). BayesX: Software for Bayesian Inference in Structured Additive Regression Models. Version 2.0. 1. Methodology manual 2012.

Brezger, A., \& Lang, S. (2006). Generalized structured additive regression based on Bayesian P-splines. Computational Statistics \& Data Analysis, 50, 967-991.

Chamberlin, J., \& Jayne, T. S. (2013). Unpacking the Meaning of 'Market Access': Evidence from Rural Kenya. World Development, 41, 245-264.

Christiaensen, L., Weerdt, J. de, \& Todo, Y. (2013). Urbanization and poverty reduction: the role of rural diversification and secondary towns 1. Agricultural Economics, 44, 435-447.

Damania, R., Berg, C., Russ, J., Federico Barra, A., Nash, J., \& Ali, R. (2017). Agricultural Technology Choice and Transport. American Journal of Agricultural Economics, 99, 265 284.

Deichmann, U., Shilpi, F., \& Vakis, R. (2009). Urban Proximity, Agricultural Potential and Rural Non-farm Employment: Evidence from Bangladesh. World Development, 37, 645660.

Directorate of Census Operations Karnataka (2011). Census of India 2011: Karnataka, District Census Handbook, Bangalore. Series-30.

Ebata, A., Velasco Pacheco, P. A., \& Cramon-Taubadel, S. von (2017). The influence of proximity to market on bean producer prices in Nicaragua. Agricultural Economics, 48 , 459-467.

Elliott, J., Deryng, D., Müller, C., Frieler, K., Konzmann, M., Gerten, D., Glotter, M., Flörke, M., Wada, Y., Best, N., Eisner, S., Fekete, B. M., Folberth, C., Foster, I., Gosling, S. N., Haddeland, I., Khabarov, N., Ludwig, F., Masaki, Y., Olin, S., Rosenzweig, C., Ruane, A. C., Satoh, Y., Schmid, E., Stacke, T., Tang, Q., \& Wisser, D. (2014). Constraints and potentials of future irrigation water availability on agricultural production under climate change. Proceedings of the National Academy of Sciences of the United States of America, $111,3239-3244$. 
Ellis, F. (1993). Peasant economics: Farm households and agrarian development. (2. ed.). Wye studies in agricultural and rural development.

Fafchamps, M., \& Shilpi, F. (2003). The spatial division of labour in Nepal. Journal of Development Studies, 39, 23-66.

Fahrmeir, L., Kneib, T., Lang, S., \& Marx, B. (2013). Regression: Models, Methods and Applications. Dordrecht: Springer.

Fujita, M., \& Thisse, J.-F. (2014). The New Economic Geography: A Selective Survey. In D. Cohen (Ed.), Contemporary Economic Issues: Trade, Payments and Debt (pp. 23-43). London: Palgrave Macmillan.

Haggblade, S., Hazell, P., \& Reardon, T. (2010). The Rural Non-farm Economy: Prospects for Growth and Poverty Reduction. World Development, 38, 1429-1441.

Harris, J. R., \& Todaro, M. P. (1970). Migration, Unemployment and Development: A TwoSector Analysis. The American Economic Review, 60, 126-142.

Hoffmann, E., Jose, M., Nölke, N., \& Möckel, T. (2017). Construction and Use of a Simple Index of Urbanisation in the Rural-Urban Interface of Bangalore, India. Sustainability, 9, 2146.

Imai, K. S., Gaiha, R., \& Thapa, G. (2015). Does non-farm sector employment reduce rural poverty and vulnerability? Evidence from Vietnam and India. Journal of Asian Economics, 36, 47-61.

Jedwab, R., Christiaensen, L., \& Gindelsky, M. (2017). Demography, urbanization and development: Rural push, urban pull and ... urban push? Journal of Urban Economics, 98, 6-16.

Kneib, T., \& Fahrmeir, L. (2006). Structured additive regression for categorical space-time data: a mixed model approach. Biometrics, 62, 109-118.

Krugman, P. (1991). Increasing Returns and Economic Geography. Journal of Political Economy, 99, 483-499.

Krugman, P. (1996). How the economy organizes itself in space: a survey of the new economic geography.

Lohr, L., \& Park, T. A. (2002). Choice of insect management portfolios by organic farmers: lessons and comparative analysis. Ecological Economics, 43, 87-99.

Marull, J., Font, C., \& Boix, R. (2015). Modelling urban networks at mega-regional scale: Are increasingly complex urban systems sustainable? Land Use Policy, 43, 15-27. 
Minten, B., Koru, B., \& Stifel, D. (2013). The last mile(s) in modern input distribution: Pricing, profitability, and adoption. Agricultural Economics, 44, 629-646.

Schneider, A., \& Woodcock, C. E. (2008). Compact, Dispersed, Fragmented, Extensive? A Comparison of Urban Growth in Twenty-five Global Cities using Remotely Sensed Data, Pattern Metrics and Census Information. Urban Studies, 45, 659-692.

Sharma, A., Bailey, A., \& Fraser, I. (2011). Technology Adoption and Pest Control Strategies Among UK Cereal Farmers: Evidence from Parametric and Nonparametric Count Data Models. Journal of Agricultural Economics, 62, 73-92.

Sharma, M. (2018). EC data reveals city's exponential growth: There are now over 1.25 crore of us Bengalureans. Bangalore Mirror, 12.05.2018. Accessed 12.10.2018.

Sudhira, H. S., Ramachandra, T. V., \& Subrahmanya, M. B. (2007). Bangalore. Cities, 24, 379-390.

Taylor, P. J., Evans, D. M., \& Pain, K. (2008). Application of the Interlocking Network Model to Mega-City-Regions: Measuring Polycentricity Within and Beyond CityRegions. Regional Studies, 42, 1079-1093.

Teklewold, H., Kassie, M., \& Shiferaw, B. (2013). Adoption of Multiple Sustainable Agricultural Practices in Rural Ethiopia. Journal of Agricultural Economics, 64, 597-623.

Thünen, J. H. von (1826). Der isolierte Staat: Beziehung auf Landwirtschaft und Nationalökonomie.

Umlauf, N., Adler, D., Kneib, T., Lang, S., \& Zeileis, A. (2013). R2BayesX: Estimate structured additive regression models with Bayes $X$.

Umlauf, N., Adler, D., Kneib, T., Lang, S., \& Zeileis, A. (2015). Structured Additive Regression Models: An R Interface to BayesX. Journal of Statistical Software, 63. United Nations Population Division (2015). World Urbanization Prospects: The 2014 Revision.

Vandercasteelen, J., Beyene, S. T., Minten, B., \& Swinnen, J. (2017). Cities and agricultural transformation in Africa: Evidence from Ethiopia. World Development, 105, 383-399.

Vandercasteelen, J., Beyene, S. T., Minten, B., \& Swinnen, J. (2018). Big cities, small towns, and poor farmers: Evidence from Ethiopia. World Development, 106, 393-406.

Wollni, M., Lee, D. R., \& Thies, J. E. (2010). Conservation agriculture, organic marketing, and collective action in the Honduran hillsides. Agricultural Economics, 41, 373-384. 


\section{Appendix}

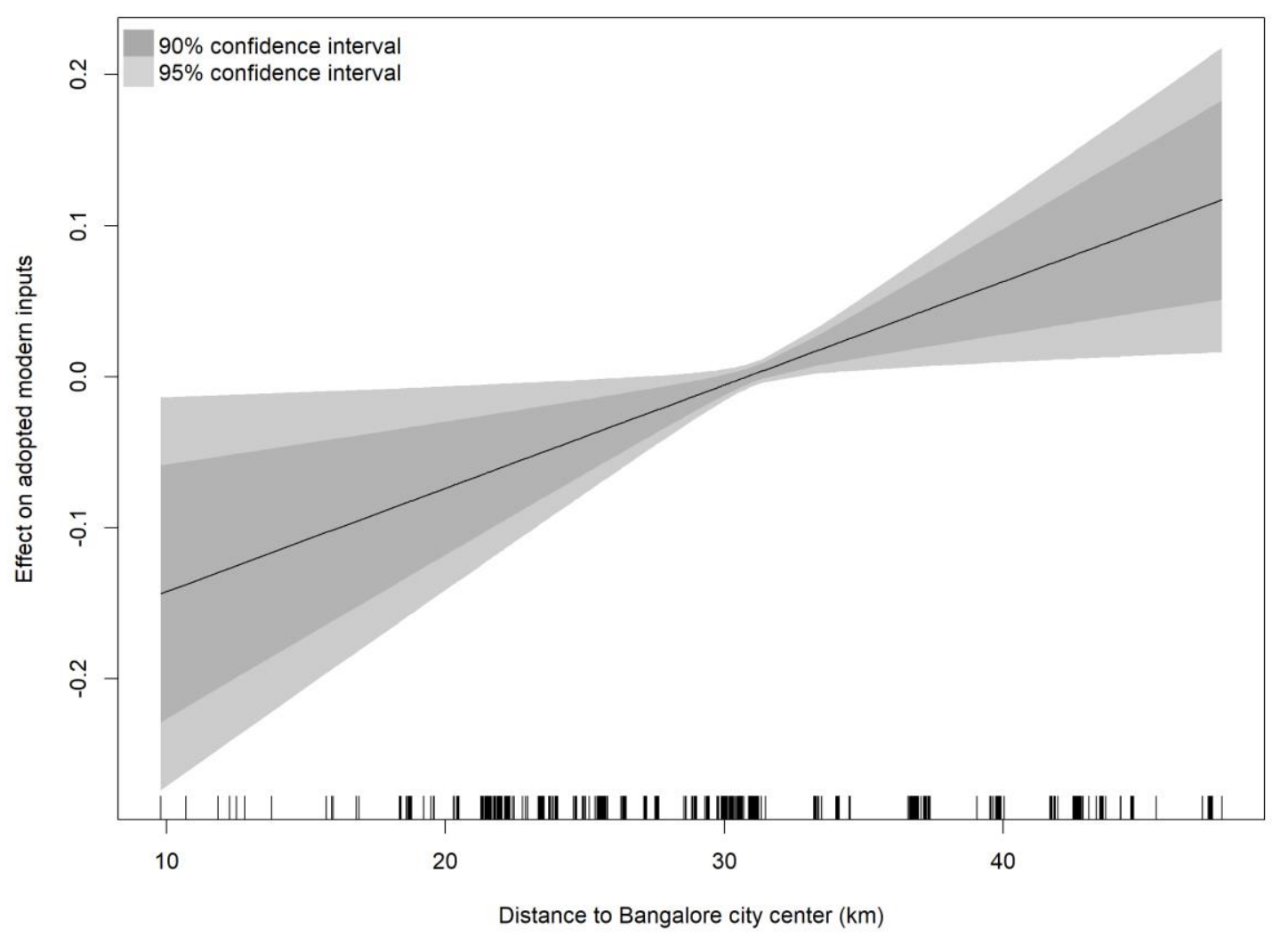

Appendix 2.1 Estimates of one-dimensional splines, $f_{\text {Dist }}$, pooled data set $\left(\mathrm{N}_{\text {pooled }}=1752\right)$ 


\title{
3. Digging deep and running dry - the adoption of borewell technology in the face of climate change and urbanization
}

\author{
Linda Steinhübel, Johannes Wegmann, Oliver Mußhoff \\ Under review after first round of revisions in Agricultural Economics
}

\begin{abstract}
In this article, we analyze the effects of household location and weather variability on the adoption of borewell technology along the rural-urban interface of Bangalore, India. Understanding these effects can help to design policies that ensure smallholders' livelihoods and the functioning of ecosystems in drought-prone areas. First a theoretical framework was developed that conceptualizes how household location and weather can influence the farmers' adoption decisions. Afterwards, an empirical analysis based on a primary data set collected in 2016 and 2017, covering 574 farm households was conducted. With a semiparametric hazard rate model, determinants of the borewell adoption rate were analyzed. Different rainfall variables to capture the effect of changing climate conditions and a two-dimensional penalized spline (P-spline) to capture the effects of household location were incorporated. Results show that proximity to Bangalore but also secondary towns accelerates adoption rates. In terms of weather variability, the study finds that a higher amount of total annual rainfall decelerates adoption rates whereas higher amounts of rainfall during the southwest monsoon (the most important cropping season) accelerate adoption rates.
\end{abstract}

Key words: borewell technology, climate change, India, semiparametric duration models, urbanization 


\subsection{Introduction}

Borewell technology has surged in India since the Green Revolution of the 1970s, making India the largest groundwater user in the world today (Shah, 2014). The Indian government supported the uptake of groundwater lifting technology from the start and the adoption of this technology has maintained momentum to the present day. Changing rain patterns have made traditional rainfed agriculture less predictable and more vulnerable, thereby making borewell technology an attractive option to compensate for unreliable or a lack of sufficient rainfall (Alcon et al., 2011; Genius et al., 2014). Furthermore, economic development, improved infrastructure, and urbanization has improved access to input and output markets and has made it more profitable to modernize and intensify agriculture (Vandercasteelen et al., 2017). Though agricultural intensification can considerably improve smallholders' livelihood, increased uptake of borewell technology comes at a cost. More wells and uncontrolled water extraction have already led to over-exploited aquifers in many regions of India (Srinivasan et al., 2017). As a consequence, borewells dry up, threatening the well-being of water users. Thus, it is essential to implement policies that strike a balance between the present well-being of smallholders and sustainable, long-term availability of water resources.

To do so, it needs to become clearer what determines farmers' decisions to adopt borewell technology, particularly when facing weather changes and urbanization. Recent literature primarily focuses on the adoption of irrigation technologies in the light of water use efficiency (Caswell \& Zilberman, 1985; Caswell \& Zilberman, 1986; Alcon et al., 2011). However, these studies - generally examining case studies in the global north-assume that farmers already have access to groundwater and the question is how they use it. The case is different in developing countries, where many farmers still rely on rain water as a primary irrigation water source (Srinivasa Rao et al., 2015). Thus, adoption decisions in this part of the world focus more on the access to groundwater itself than on technologies for efficient water use. To enhance agricultural productivity the Indian government subsidizes borewell implementation and electricity for pumping water; water extraction is hardly regulated and generally free of cost once a borewell is installed (Srinivasan et al., 2017). This is an obvious difference to the water management policies in the global north, where groundwater access is strictly regulated and studies show that water prices, for example, have a statistically significant effect in adoption decisions (Caswell \& Zilberman, 1985; Alcon et al., 2011). It follows that results from adoption studies based on data from the global north cannot be generalized and applied 
in a developing context without respective empirical analysis. However, to the best of our knowledge such evidence is scarce in the literature so far.

By analyzing farmers' decisions to adopt borewell technology in the rural-urban interface of Bangalore, this study aims at providing such empirical evidence. Bangalore is a rapidly growing city and the area has experienced drastic weather changes (reduced or absent monsoon rains) in recent years. Such developments are prevalent in many developing countries and have been repeatedly identified as drivers of smallholders' decisions to adopt new technologies (Dadi et al., 2004; Euler et al., 2016; Damania et al., 2017). Thus, the area presents an excellent showcase to analyze farmers' decision-making regarding groundwater extraction in a developing context.

For the analysis, a microeconomic model was developed to conceptualize the influence of weather and household location on farmers' borewell adoption behavior. Location is used as a proxy of market access, i.e. the location of a household in the rural-urban interface defines the transaction costs necessary to reach potential market centers. This approach was chosen instead of the traditional one-dimensional (1D) measures such as distance to markets (Key et al., 2000; Chamberlin \& Jayne, 2013) because Bangalore is surrounded by several satellite towns and farmers have access to more than one market. Therefore, our definition based on household location allows for an aggregate effect of several markets. In the empirical analysis, a duration model framework was applied. This model class has been shown to be particularly suitable for analyzing the adoption of durable technologies such as a borewell (Dadi et al., 2004; Abdulai \& Huffman, 2005). Several nonparametric elements were included in the model, among others a two-dimensional (2D) Penalized Spline (P-Spline) based on household GPS coordinates to directly estimate the effect of household location derived in the microeconomic model. The coordinates were treated as bivariate variable (latitude, longitude) and used to estimate nonlinear effect surfaces (2D spline). Because these surfaces are spatially explicit (coordinates), they can be mapped and areas with high or low effects on borewell adoption rates can be identified.

The remainder of this paper is structured as follows: First, a short overview of irrigation in South India and technology adoption is given. Then a conceptual framework (section 3) is developed and the empirical strategy (section 4) is described. Finally, results (section 5) are discussed and the findings (section 6) are summarized. 


\subsection{Background on irrigation in South India and technology adoption}

The adoption of borewells has become crucial for the food security in large parts of South Asia; however, nowadays it is threatened by increasing over-exploitation and degradation of aquifers (Shah, 2007). A borewell describes a deep and narrow well that is cased into the ground using a tube. This type of well is often equipped with an electric pump and is the most frequently used technology for groundwater extraction in the study area (Srinivasan et al., 2015). Water pumped from the ground can be combined with other irrigation techniques; most commonly in the region are flood, sprinkler, or drip irrigation.

The traditional irrigation system in South India was dominated by reservoirs and local water bodies, also called tanks. These tanks were used and managed at the communal level. Since the 1990s, however, many farmers have decided to exit the communal irrigation system by investing in private well equipment to extract groundwater (Srinivasan et al., 2017). The reasons are manifold. First, coordination problems within the command area of the tanks led to uncertainty in water availability. Particularly during the critical stages of cultivation, farmers favor independent and secure water sources (Kajisa et al., 2007). Second, the maintenance of local water bodies requires high labor inputs (Shah, 2003). Third, pumping technology and drilling have become cheaper in absolute and relative terms. Domestic production of pumps and improved drilling technologies have lowered the prices for establishing a borewell, and decreased input prices through subsidized flat rate electricity prices (Srinivasan et al., 2017). However, increased output prices for agricultural products have lowered the relative price of groundwater irrigation (Kajisa et al., 2007). Due to the aforementioned reasons, India is now the biggest user of groundwater globally (Siebert et al., 2010).

Nevertheless, this development is spatially concentrated and large areas remain under rainfed agriculture (Srinivasa Rao et al., 2015), indicating that there are local differences in adoption rates. To understand what drives the adoption process at individual farm level, several factors were analyzed.

One of the main reasons for adopting groundwater lifting technology is to hedge against production risks. One major production risk in agriculture is adverse climate and its consequences, such as drought and water scarcity as well as increased volatility in weather events (Alcon et al., 2011; Genius et al., 2014). At farm level, unfavorable slopes and soil characteristics (Koundouri et al., 2006; Genius et al., 2014) as well as farm size and the degree of commercialization additionally increase the probability to adopt (Feder et al., 1985). 
Another important factor which may explain the differences in adoption rates is the diffusion of technology. Diffusion is understood as the adoption process of a technology over time (Taylor \& Zilberman, 2017). A key role in the diffusion of technology in agriculture is the distance to regional centers. The less remote a producer is, the higher the probability is that they will adopt earlier than other producers. Since learning and implementation may require traveling, opportunity costs can be high and impede technology adoption (Sunding \& Zilberman, 2001). More recently, the interconnectedness of market access and technology adoption has been studied. Damania et al. (2017) or Vandercasteelen et al. (2017), for example, find that lower transportation costs due to the proximity to cities and/or markets increase the likelihood of technology adoption. Another factor related to technology diffusion is learning due to social interaction (Abdulai \& Huffman, 2005; Sampson \& Perry, 2019). Even though our research focuses on exogenous spatial heterogeneity induced by urbanization dynamics, potential spatial interdependence in the decision making of neighboring farmers has to be mentioned and will be controlled in the empirical analysis of this study.

\subsection{Conceptual framework}

To identify mechanisms of technology adoption in the context of weather variability and urbanization, some microeconomic intuition is provided in this section following models such as Irwin \& Bockstael (2004), Abdulai \& Huffman (2005), and Genius et al. (2014). Note that for the conceptual model, it is assumed that spatial heterogeneity exclusively results from urbanization dynamics.

It is assumed that smallholders are profit maximizing agricultural producers and they choose one out of two possible production systems $s$. The possible production systems are defined by the source of irrigation, i.e. $s=1$ if the household adopted the borewell technology, and $s=0$ if the technology has not been adopted. In that way, it can be noted that household $i$ 's expected operational cash flows $A_{s, i}$ are generated by either system, $s$, as function of time period $t$ and household $i$ 's location $l: 6$

$A_{s}(t, l)=p(t, l) q_{s}(t)-c(t, l) a_{s}$, with $s=0,1$

$A_{s}(t, l)$, is described by the difference between the product of expected output prices $p(t, l)$ and expected output $q_{s}(t)$ and the product of expected input prices $c(t, l)$ and expected used

\footnotetext{
${ }^{6}$ For better clarity we drop the subscript $i$ in equations (1) to (6).
} 
inputs $a_{s}$. Both prices $p(t, l)$ and $c(t, l)$ are represented as the difference between the price paid at the market in time, $t$, and transportation costs $\mu(l)$ with $\frac{\partial \mu(l)}{\partial l}>0$ defined by the household location, $l$, in the rural-urban interface (urbanization gradient): ${ }^{7}$

$$
\begin{aligned}
& p(t, l)=p_{\text {market }}(t)-\mu(l), \text { with } \mu(l)>0 \\
& c(t, l)=c_{\text {market }}(t)+\mu(l), \text { with } \mu(l)>0
\end{aligned}
$$

The amount of used inputs $a$ only depends on $s$. With reliable irrigation $(s=1)$, farmers might apply additional and more sophisticated inputs. Such a system is also likely to generate a higher output, $q_{s}$, as more consistent irrigation is possible. Additionally, in regions highly vulnerable to altering weather patterns in the course of climate change, farmers' expectations concerning their production and outputs (i.e. a production function) are likely to vary with changing weather patterns, i.e. time. For example, if a farmer expects decreasing rainfall, the expected outputs from a rainfed production system will decrease. Therefore, the weather component of the research objective is captured by allowing farmers' expectations regarding output quantities to vary over time, $q_{s}(t){ }^{8}$

In the decision to adopt a borewell, also one-time installation costs $C(t, l)$ have to be considered. These costs depend on when a household decides to adopt the borewell technology and, as in the case of other input costs, the household's location (inherent transportation costs).

Equation (1) and the one-time installation costs, $C(t, l)$, are the basic building blocks that are used to formalize the decision of a profit maximizing farmer. Furthermore, for durable technologies such as a borewell, the timing of adoption is often more important to understand the drivers of decision-making (optimal timing problem) (Dadi et al., 2004; Irwin \& Bockstael, 2004; Abdulai \& Huffman, 2005). Therefore, it can be assumed that the farmer optimizes the time of adoption based on the comparison of the present value of expected net returns, $V(T, l)$, of adopting a borewell in time period $T$ (equation $4 \mathrm{a}$ ), and the present value

\footnotetext{
${ }^{7}$ For simplicity we assume the same transportation costs, $\mu(l)$, to input and output markets. However, these markets do not necessarily coincide and differences can be possible.

${ }^{8}$ Thus, when talking about weather variability in this study, we generally refer to changing weather patterns over time. One could argue that $q_{s}$ also depends on location, i.e. rainfall might also show spatial patterns. However, the research area is rather small and farmers mainly refer to Bangalore weather forecasts. Furthermore, possible alternative water sources in the research area are limited to one larger water reservoir in the southern transect, which is also completely rainfed. That means farmers' expectations concerning the reliability also depend on their expectations about weather, rather than the location as such.
} 
of expected net returns, $V(T+1, l)$, of adopting a borewell in time period $T+1$ (equation $4 \mathrm{~b}$ ) as:

$$
\begin{gathered}
V(T, l)=\sum_{h=0}^{\infty} A_{1}(T+h, l) \delta(h)-C(T, l)-\sum_{h=0}^{\infty} A_{0}(T+h, l) \delta(h) \\
V(T+1, l)=A_{0}(T, l)+\sum_{h=1}^{\infty} A_{1}(T+h, l) \delta(h)-C(T+1, l) \delta(1) \\
-A_{1}(T, l)-\sum_{h=1}^{\infty} A_{0}(T+h, l) \delta(h)
\end{gathered}
$$

For simplicity, the time horizon of the decision is limited to $T+1$, i.e. until the technology is adopted, the farmer decides every year whether to adopt a borewell at that moment or wait another year ${ }^{9}$.

If the technology is adopted in $T$ (equation 4a), the present value of the expected net returns is given by the present value of the expected operational cash flows of a production system with borewell discounted to time $T$ with discount factor $\delta(h)$, minus the installation costs in $T$, and minus the expected operational cash flows of the production system without the technology discounted to time $T$. The net present value of a production system with a borewell $(s=1)$ represents the farmer's expectation of all potential profits, which they make after the installation of the well; the net present value of a production system without a borewell $(s=0)$ represents the forgone profit that is not earned because of the change to the system with the well. Analogously, in equation (4b) the first two elements depict the profits from one more year in the management system without the borewell plus all profits after the installation of the technology for all the following years. Since the adoption decision is delayed by one year $(T+1)$, also the installation costs of the year $T+1$ are considered. The last two elements represent the forgone profits from waiting until year $T+1$.

Assuming that equations (4a) and (4b) are the basis on which household $i$ makes its decision, two decision criteria were defined, which have to be fulfilled so that the adoption of the borewell technology takes place in year $T$. First, the net returns of adopting the borewell technology in $T$ have to be positive:

\footnotetext{
${ }^{9}$ We are aware that a full strand of literature on optimal stopping problems and stochastic dynamic optimization (Dixit \& Pindyck (1994) exists. However, we believe that our simplification represents the time horizon of decision-making in our research area appropriately. For example, many farmers make cropping decisions from season to season which underlines the farmers' short-term decision-making.
} 
$V(T, l) \geq 0$

Secondly, given the first criterion in equation (5), the technology is adopted in $T$, if the net returns in time $T$ exceed the net returns of waiting (value of waiting) for another year $T+1$ (see Appendix 3.1 for derivations):

$V(T, l) \geq V(T+1, l)$

$\Leftrightarrow q_{1}(T)-q_{0}(T) \geq \frac{C(T, l)-C(T+1, l) \delta(1)}{2 p(T, l)}+\frac{c(T, l)\left(a_{1}-a_{0}\right)}{p(T, l)}$

The left-hand side describes the expected output difference of both production systems in $T$. It therefore quantifies how relevant a farmer thinks water is for the success of their production system, and to what extent available rain-dependent water sources (e.g. reservoirs, rain) are as reliable as a borewell. Thus, a farmer who thinks that weather is becoming less predictable will expect a larger output difference than a farmer who assumes sufficient and timely rain or has alternative water sources.

The first term on the right-hand side of equation (6) shows the difference of expected installation cost in $T$ and $T+1$ normalized by two times the price of one output unit $q_{S}$. Similarly, the second term describes the difference between the variable inputs of both production systems normalized by the unit output price. Note that this representation places all variables that are influenced by farmers' expectations concerning weather and water availability in general to one side, and all variables that are affected by the household's location - market access - to the other side. Thus, the household will adopt the borewell technology if the output gain due to a management system with borewell is larger than or equal to the net installation costs and additional net variable input costs relative to the price can be achieved for the output gain. Therefore, the more pessimistic a farmer is about weather prospects, and the greater the access to borewell technology and input and output markets is, the higher the likelihood that they adopt the technology in $T$. 


\subsection{Empirical strategy}

The theoretical model of optimal timing of the adoption decision presented in the previous section can be empirically represented in the duration model framework. Thus, it can be assumed that the borewell technology became available to the sample population with the Green Revolution, $t_{0}=1970$, after which households subsequently-some sooner, some later-adopt the technology at time points $t+h, h=1, \ldots n$ until time $t_{n}$ when all households adopted the technology. Based on the observed adoption time spells it is possible to estimate the probability that a household will adopt a borewell in the next time interval $h$, if it has not adopted the borewell until $t$. This probability is referred to as hazard rate $\lambda_{i}(t)$ with $T$ being a non-negative random number and the non-adoption spell ending if $T=t$ :

$\lambda_{i}(t)=\frac{\lim _{h \rightarrow 0} \operatorname{Pr}\left(t \leq T^{*}<t+h \mid T^{*} \geq t\right)}{h}$

One of the most popular duration models to estimate covariate effects on the hazard rate is the so-called Cox model (Cox, 1972):

$\lambda_{i}(t)=\lambda\left(t, x_{i}\right)=\lambda_{0}(t) \exp \left(x_{i}^{\prime} \beta\right)$

In this model the hazard rate, $\lambda_{i}(t)$, consists of two parts: the baseline hazard $\lambda_{0}(t)$ and the effects of covariates $x_{i}$. The baseline hazard can be understood as the pure time effect on the hazard rate and, by construction, must be nonnegative as adoption rates cannot be negative (Therneau \& Grambsch, 2000). The overall framework of the Cox model in the empirical analysis was followed but extended by a semiparametric predictor to accommodate for more flexible effects. Since duration models require a certain type and preparation of data, the next sections describe the survey, data set, and variables included in the empirical analysis; afterwards the specifications of the semiparametric predictor are presented.

\subsubsection{Survey design and data set}

The empirical analysis is based on data collected in a survey from 1,275 households in two transects following the rural-urban gradient of Bangalore (Fig. 3.1). To capture the systematic spatial heterogeneity caused by urbanization dynamics, a two-stage stratified sampling approach was applied to identify the households to be interviewed. In the first stage, a Survey Stratification Index (SSI) was used to classify all villages in the transects into three strata 
(rural, peri-urban, urban) (Hoffmann et al., 2017). Then, ten villages in each stratum per transect were randomly selected. This equates to about one third of all villages located in the transects. Afterwards, an average of 20 households (adjusted by the village population) was randomly drawn from the household lists of the selected villages. All households were interviewed between December 2016 and May 2017. Thus, the maximum observed time spell in the duration model is 47 years (1970-2016). Household information prior to 2016 is based on recall data (e.g. year an asset was purchased) and calculation (e.g. age or years of experience).

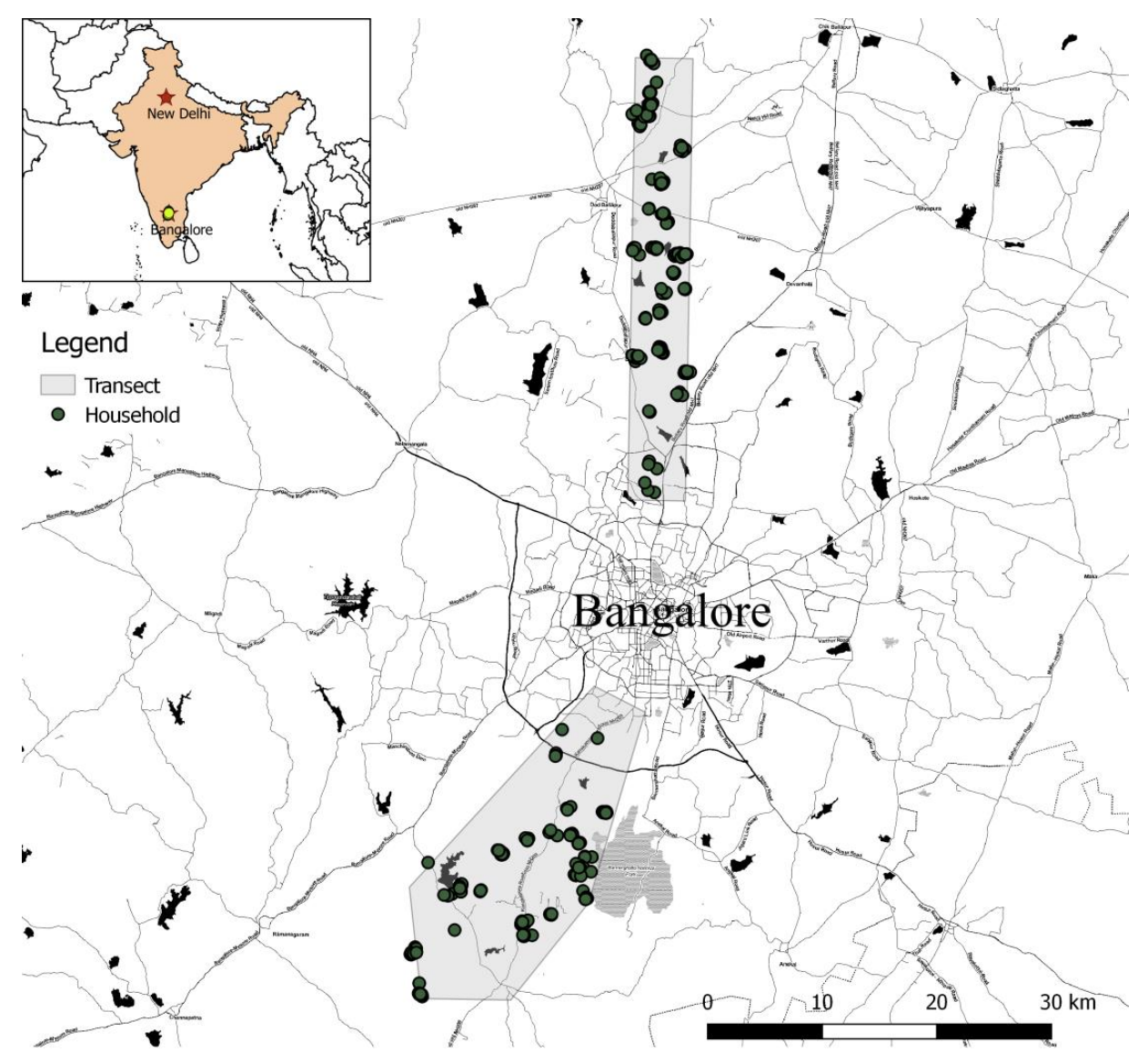

Source: Survey data.

Fig. 3.1 Research area, grey polygons indicate northern and southern transect, respectively 
Because the focus is on the adoption of borewells for agricultural purpose, in the following analysis only households that grew at least one crop in 2016 were considered (farm households). Therefore, the sample comprises of a total of 576 households of which 316 are located in the transect north of Bangalore (northern transect) and 260 in the transect south of Bangalore (southern transect). ${ }^{10}$

To accommodate time-variant covariates, the data set had to be augmented in a way that there is one observation per year and per household, i.e. a maximum number of 47 observations per household. An indicator variable (1/0) for each year observation signals whether or not the household adopted the borewell technology in the respective year. Once the household adopted the technology $(t=T)$ all subsequent year observations were dropped; the adoption spell of the respective household ended. Comparably, year observations were omitted, if households entered the adoption spell later due to migration or age (left-truncation). If the technology had not been adopted, the indicator variable remains zero in the last year observation (year 47). These observations are called right-censored and it is assumed that they will adopt the technology in the future (Moore, 2016). As a consequence, our final data set for estimation included 7,641 observations for the northern and 6,563 observations for the southern transect.

The consideration of time-variant covariates has some important methodological advantages (Dadi et al., 2004; Euler et al., 2016). First, one general assumption of the Cox model is that the hazard ratio of different subjects stays constant throughout the entire time spell (proportional hazard). Therefore, the baseline hazard can be left unspecified for estimating the covariate effects $\beta$ and no a priori assumptions about the functional form of the baseline hazard are necessary. However, it is unlikely that the hazard ratio is actually constant over longer periods such as the 47 years in our case. Time-variant covariates in $x_{i}^{\prime} \beta$ can counter the proportional hazard assumption (Therneau \& Grambsch, 2000). Second, some covariates might cause problems of reverse causality or endogeneity if they are included in a crosssectional fashion. If these covariates are included as time varying, temporal causality is established and, thus, these issues (see section 3.4.2. for respective variables) are avoided.

\footnotetext{
${ }^{10}$ This number of households excludes 66 observations which were excluded during the empirical analysis because of missing values in important covariates. The inference strategy does not allow for missing values unfortunately. The dropped observation is evenly distributed over both transects and includes two households, which already had adopted the borewell technology.
} 


\subsubsection{Variable description}

To estimate adoption probabilities and the hazard rate, all 574 farm households were asked whether they have a borewell and, if yes, when they installed it. To prevent recall bias and heaping effects ${ }^{11}$, i.e. a farmer is more likely to give responses such as five or ten years than seven years, farmers were asked to give the year of adoption instead of the number of years that they have a borewell. Table 3.1 shows that 148 (26\%) of the farm households in the sample had adopted the technology by 2016. Of these 148 households, 88 are located in the northern and 60 in the southern transect. Thus, the adoption level appears to be higher in the northern transect.

To model the effect of urbanization, i.e. market access, on borewell adoption rates, explicit household locations were used. The GPS coordinates of every household are a bivariate and continuous variable consisting of the latitude and longitude information of the repective location. Therefore, they can be used to estimate smooth surfaces of location effects (see section 3.4.3 for details). Previous studies quantify market access by proxies such as distance to the city based on the assumption that distance and transportation costs are proportional (Chamberlin \& Jayne, 2013). However, urbanization dynamics in the rural-urban interface of Bangalore are likely to be polycentric, with several satellite towns offering additional marketing options to farmers. As a consequence, it is impossible to determine only one market or town of reference to establish a $1 \mathrm{D}$ proxy such as distance.

\section{Table 3.1}

\section{Summary of Rainfall Variables, 1970-2016}

\begin{tabular}{lcccc}
\hline Variable & Mean & Std. Deviation & Min & Max \\
\hline Total Rainfall (mm/year) & 777.24 & 211.31 & 475 & 1,200 \\
$\begin{array}{l}\text { Pre-monsoon (mm/year) } \\
\text { Southwest monsoon }\end{array}$ & 157.89 & 59.38 & 60 & 313 \\
$(\mathrm{~mm} /$ year) & 444.7 & 129.46 & 129 & 730 \\
\hline
\end{tabular}

Source: Rainfall data (Department of Agrometerology, UASB).

\footnotetext{
${ }^{11}$ The problem is that estimates of adoption probability will approximate zero at time points with no observed positive adoption decisions (Kneib (2006). This would lead to highly fluctuating estimates of the baseline hazard in the duration analysis. This does not seem to be a problem either (see Appendix 3.4). In addition the histogram in Appendix 3.3 shows that there is no obvious heaping. Therefore, we are confident that recall bias in the dependent variable is no issue in the empirical analysis and hence strategies such as interval censoring to correct it were not applied.
} 
The amount of rainfall was used to measure weather variability over time. Rainfall has become more and more volatile in recent years in the Bangalore area (appendix 3.2), substantially increasing the drought pressure. Rain patterns define the agricultural seasons in Bangalore, of which the southwest monsoon determines the main cropping season. Therefore, to obtain a more nuanced understanding of the effect of the weather, not only the amount of total yearly rainfall, but also the amount of pre-monsoon rainfall and of rainfall during the southwest monsoon was included in the dataset. A summary of the rainfall variables are presented in Table 3.1. Furthermore, the current and previous years' rainfall is considered. Rainfall data was used for the Bangalore urban district published on the website of the Agrometerology Department of the University of Agricultural Sciences, Bangalore (UASB). The department provides disaggregated measures such as pre-monsoon or southwest monsoons on a yearly basis. The rainfall variables are time-variant but can be assumed to be consistent for the entire research area, i.e. they vary over time $t$ but not among the households. This assumption is reasonable as the research area is rather small and farmers in the transects generally build their expectations about weather based on the weather forecast for Bangalore.

Table 3.2 and 3.3 present a description and descriptive statistics of all other time-invariant and time-variant covariates, respectively. These tables also show the variation between the two transects and between adopters and non-adopters of the borewell technology.

As time-invariant variables the following are considered: household caste, a dummy for dairy production, years of education of the household head, farm size, and the gender of the household head (Table 3.2). Caste is still an important social factor in India often defining access to resources and income level. A share of 77 percent of households in the sample pursues dairy production; the share appears to be even higher among borewell adopters (83-89 percent). Household heads received an average of 6 years of formal education, without any large differences between the two transects or adopters and non-adopters. In contrast, adopters hold on average double the area of land than non-adopters. 17 percent of participants were female household heads, which is rather low. Furthermore, the share is even lower when looking exclusively on adopters (7-15 percent). 


\section{Table 3.2}

Descriptive statistics of time-invariant variables (Subsamples: Northern vs. Southern transect; Non-adopters vs. Adopters)

\begin{tabular}{|c|c|c|c|c|c|c|c|c|c|c|}
\hline \multirow{2}{*}{ Variable } & \multirow{2}{*}{ Variable description } & \multicolumn{3}{|c|}{ Both transects } & \multicolumn{3}{|c|}{ Northern transect } & \multicolumn{3}{|c|}{ Southern transect } \\
\hline & & 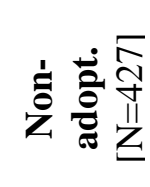 & 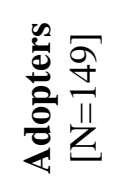 & 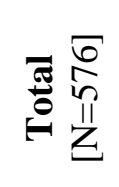 & 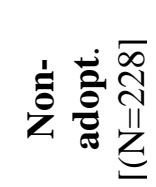 & 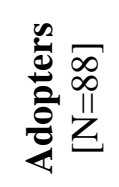 & 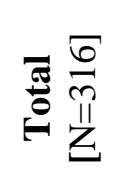 & 光䓂命 & 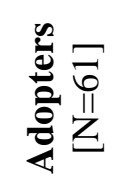 & 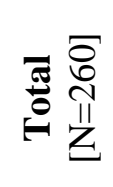 \\
\hline Caste & Factor variable & & & & & & & & & \\
\hline General & & 0.48 & 0.56 & 0.50 & 0.45 & 0.48 & 0.46 & 0.52 & 0.67 & 0.56 \\
\hline Scheduled Castes & & 0.18 & 0.11 & 0.17 & 0.17 & 0.11 & 0.15 & 0.20 & 0.12 & 0.18 \\
\hline Scheduled Tribes & & 0.07 & 0.04 & 0.06 & 0.08 & 0.06 & 0.07 & 0.07 & 0.02 & 0.05 \\
\hline Other Backward & & 0.22 & 0.26 & 0.23 & 0.26 & 0.33 & 0.28 & 0.18 & 0.15 & 0.17 \\
\hline Class & & & & & & & & & & \\
\hline Other & & 0.04 & 0.03 & 0.04 & 0.05 & 0.02 & 0.04 & 0.03 & 0.05 & 0.04 \\
\hline Dairy & $\begin{array}{l}\text { Dummy variable (1: } \\
\text { Dairy production) }\end{array}$ & 0.74 & 0.87 & 0.77 & 0.73 & 0.89 & 0.77 & 0.76 & 0.83 & 0.78 \\
\hline Education & $\begin{array}{l}\text { Years of education } \\
\text { (household head) }\end{array}$ & $\begin{array}{l}5.96 \\
(4.83)\end{array}$ & $\begin{array}{l}6.5 \\
(4.91)\end{array}$ & $\begin{array}{l}6.1 \\
(4.85)\end{array}$ & $\begin{array}{l}6.51 \\
(4.7)\end{array}$ & $\begin{array}{l}6.63 \\
(4.69)\end{array}$ & $\begin{array}{l}6.54 \\
(4.69)\end{array}$ & $\begin{array}{l}5.32 \\
(4.91)\end{array}$ & $\begin{array}{l}6.33 \\
(5.23)\end{array}$ & $\begin{array}{l}5.56 \\
(5.0)\end{array}$ \\
\hline Farm size & $\begin{array}{l}\text { Acres under } \\
\text { management }\end{array}$ & $\begin{array}{l}2.5 \\
(5.33)\end{array}$ & $\begin{array}{l}5.77 \\
(12.92 \\
)\end{array}$ & $\begin{array}{l}3.35 \\
(8.13)\end{array}$ & $\begin{array}{l}2.38 \\
(5.68)\end{array}$ & $\begin{array}{l}5.37 \\
(7.61)\end{array}$ & $\begin{array}{l}3.21 \\
(6.41)\end{array}$ & $\begin{array}{l}2.64 \\
(4.9)\end{array}$ & $\begin{array}{l}6.36 \\
(18.09)\end{array}$ & $\begin{array}{l}3.51 \\
(9.83)\end{array}$ \\
\hline Gender & $\begin{array}{l}\text { Dummy variables } \\
\text { (1:Female household } \\
\text { head) }\end{array}$ & 0.19 & 0.10 & 0.17 & 0.21 & 0.07 & 0.17 & 0.16 & 0.15 & 0.16 \\
\hline
\end{tabular}

Source: Survey data.

Note: Std. Deviation in parentheses. For dummy and factor variables percentages are given. Statistics were derived based on variable values in 2016 for non-adopters, and variable values at the time of adoption for adopters. 


\section{Table 3.3}

Descriptive statistics of time-variant variables (Subsamples: Northern vs. Southern transect; Non-adopters vs. Adopters)

\begin{tabular}{|c|c|c|c|c|c|c|c|c|c|c|}
\hline \multirow[b]{2}{*}{ Variable } & \multirow{2}{*}{ Variable description } & \multicolumn{3}{|c|}{ Both transects } & \multicolumn{3}{|c|}{ Northern transect } & \multicolumn{3}{|c|}{ Southern transect } \\
\hline & & 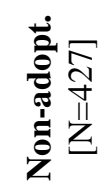 & 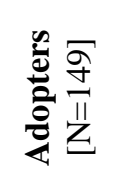 & 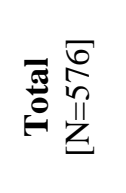 & 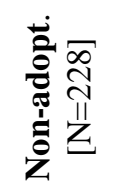 & 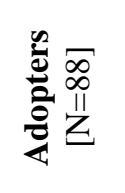 & $\begin{array}{l}\bar{\sigma} \frac{\sigma}{\pi} \\
\stackrel{\pi}{\underline{\pi}}\end{array}$ & 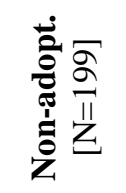 & 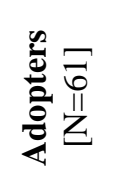 & 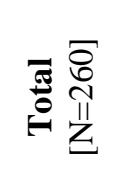 \\
\hline Age $(\mathrm{t})$ & $\begin{array}{l}\text { Age household head } \\
\text { (years) }\end{array}$ & $\begin{array}{l}50.2 \\
(13.3)\end{array}$ & $\begin{array}{l}43.85 \\
(13.68)\end{array}$ & $\begin{array}{l}48.56 \\
(13.67)\end{array}$ & $\begin{array}{l}49.42 \\
(13.47)\end{array}$ & $\begin{array}{l}43.94 \\
(13.13)\end{array}$ & $\begin{array}{l}47.9 \\
(13.58)\end{array}$ & $\begin{array}{l}51.1 \\
(13.07)\end{array}$ & $\begin{array}{l}43.7 \\
(14.55)\end{array}$ & $\begin{array}{l}49.37 \\
(13.76)\end{array}$ \\
\hline Experience (t) & $\begin{array}{l}\text { Years of farming } \\
\text { experience (household } \\
\text { head) }\end{array}$ & $\begin{array}{l}27.72 \\
(13.9)\end{array}$ & $\begin{array}{l}30.2 \\
(14.35)\end{array}$ & $\begin{array}{l}28.36 \\
(14.05)\end{array}$ & $\begin{array}{l}26.83 \\
(13.64)\end{array}$ & $\begin{array}{l}30.24 \\
(13.4)\end{array}$ & $\begin{array}{l}27.78 \\
(13.64)\end{array}$ & $\begin{array}{l}28.73 \\
(14.16)\end{array}$ & $\begin{array}{l}30.13 \\
(15.73)\end{array}$ & $\begin{array}{l}29.06 \\
(14.53)\end{array}$ \\
\hline Durable assets $(\mathrm{t})$ & $\begin{array}{l}\text { Number of durable assets } \\
\text { available to household } \\
\text { (SEC) }\end{array}$ & $\begin{array}{l}2.81 \\
(1.25)\end{array}$ & $\begin{array}{l}1.44 \\
(1.53)\end{array}$ & $\begin{array}{l}2.46 \\
(1.45)\end{array}$ & $\begin{array}{l}2.85 \\
(1.23)\end{array}$ & $\begin{array}{l}1.24 \\
(1.46)\end{array}$ & $\begin{array}{l}2.4 \\
(1.49)\end{array}$ & $\begin{array}{l}2.77 \\
(1.26)\end{array}$ & $\begin{array}{l}1.74 \\
(1.6)\end{array}$ & $\begin{array}{l}2.53 \\
(1.41)\end{array}$ \\
\hline Transport equipment $(\mathrm{t})$ & $\begin{array}{l}\text { Amount of transport } \\
\text { equipment available to } \\
\text { household (SEC) }\end{array}$ & $\begin{array}{l}0.76 \\
(0.58)\end{array}$ & $\begin{array}{l}0.36 \\
(0.56)\end{array}$ & $\begin{array}{l}0.66 \\
(0.6)\end{array}$ & $\begin{array}{l}0.83 \\
(0.57)\end{array}$ & $\begin{array}{l}0.43 \\
(0.58)\end{array}$ & $\begin{array}{l}0.72 \\
(0.6)\end{array}$ & $\begin{array}{l}0.69 \\
(0.57)\end{array}$ & $\begin{array}{l}0.26 \\
(0.51)\end{array}$ & $\begin{array}{l}0.59 \\
(0.59)\end{array}$ \\
\hline $\begin{array}{l}\text { Off-farm employment } \\
\text { (t) }\end{array}$ & $\begin{array}{l}\text { Dummy variable (1: at } \\
\text { least one member } \\
\text { involved in off-farm } \\
\text { employment) }\end{array}$ & 0.59 & 0.21 & 0.49 & 0.63 & 0.11 & 0.49 & 0.54 & 0.35 & 0.50 \\
\hline Peer effect $(t)$ & $\begin{array}{l}\text { Number of adopted } \\
\text { borewells on village level } \\
\text { in } t-1\end{array}$ & $\begin{array}{l}3.83 \\
(3.24)\end{array}$ & $\begin{array}{l}2.49 \\
(2.69)\end{array}$ & $\begin{array}{l}3.48 \\
(3.16)\end{array}$ & $\begin{array}{l}4.04 \\
(3.55)\end{array}$ & $\begin{array}{l}2.51 \\
(2.64)\end{array}$ & $\begin{array}{l}3.48 \\
(3.16)\end{array}$ & $\begin{array}{l}3.6 \\
(2.83)\end{array}$ & $\begin{array}{l}2.46 \\
(2.78)\end{array}$ & $\begin{array}{l}3.33 \\
(2.86)\end{array}$ \\
\hline
\end{tabular}

Source: Survey data.

Note: Std. Deviation in parentheses. For dummy and factor variables percentages are given. Statistics were derived based on variable values in 2016 for non-adopters, and variable values at the time of adoption for adopters. 
Time-variant variables included in the model are age of the household head, years of experience as a farmer, the number of durable assets available to the farmer, the amount of transport equipment available, a dummy for off-farm employment and the number of adopted borewells in the village at $t$ - 1 . Table 3.3 shows that adopters are on average 5 to 10 years younger than non-adopters. However, adopters seem to have slightly more farming experience than non-adopters. Living standard and purchasing power can also effect farmers' decision to adopt technologies (Cameron, 1999). In India the New Socio-Economic Classification (SEC) System is a common tool to classify households according to their socio-economic status, particularly when comparing rural and urban households (MRSI, Market Research Society of India, 2011). The SEC is based on two variables, namely the education of the household head and a count of durables out of a list of 11 items. The items include transport equipment, such as a car or two wheelers, and other durable assets like TVs, laundry machines or air conditioners. Since the education variable is time-invariant the number of assets can change during the years. Hence, the SEC components are considered separately (durable assets and transport equipment). One could argue that the actual asset value would be an even better indicator of wealth. However, since the study relies on recall data and includes durable assets and transport equipment as time-variant, this means reported prices would have to be discounted, which would likely lead to a larger bias than using the count of assets. In addition, considering transport equipment and durable assets in a time-variant way allows to establish temporal causality and, thus, to prevent potential endogeneity between the asset variable and farmers' adoption decision. The same holds for the dummy of off-farm employment. Abdulai \& Huffman (2005) show that the number of technology adopters in a village at $t-1$ is a useful way to capture social learning and interaction among farmers. Farmers observe their neighbors' experiences with the borewell technology and include them in their own optimization decision. This can include production-related information (e.g. yields) but also technical information, for example the depth of water tables which is generally unknown in the area. Next to quantifying the effect of social interaction, the variable also ensures that the location effect based on household coordinates is not biased by endogenous or small-scale local spatial patterns.

\subsubsection{Model specification and the use of P-Splines}

To accommodate more flexible non-linear effects in the duration model, the linear predictor $x_{i}^{\prime} \beta$ in equation (8) is extended to an additive predictor $\eta_{i}$ (Kneib \& Fahrmeir, 2007). By 
transforming $g_{0}(t)=\log \left(\lambda_{0}(t)\right)$, the following semiparametric hazard rate model is specified:

$\lambda_{i}(t)=\exp \left(\eta_{i}(t)\right)$

with

$\eta_{i}(t)=g_{0}(t)+x_{i}^{\prime} \beta+u_{i}(t)^{\prime} \gamma+f_{1 D}\left(u_{i}(t)\right)+f_{2 D}\left(s_{i}\right)+b_{v_{i}}$

Thus, the additive predictor consists of the log-baseline hazard $g_{0}(t)$, linear effects $\beta$ of timeinvariant covariates $x_{i}$, linear effects $\gamma$ of time-variant covariates $u_{i}(t)$, potential non-linear effects of continuous and time-variant covariates $f_{1 D}\left(u_{i}(t)\right)$, effects of household location $s_{i}=\left(\right.$ latitude $_{i}$, longitude $\left._{i}\right)$, and the household and village random effects $b_{v_{i}}$.

The baseline hazard, $g_{0}(t)$, and $f_{1 D}\left(u_{i}(t)\right)$ are estimated as 1D P-Splines, i.e. nonlinear effect functions. However, explorative data analysis implied that most of the explanatory variables show simple linear relationships with the hazard rate $\lambda_{i}(t)$ and a non-linear estimate is unnecessary. The only exception is the number of borewell adopters in a village at $t-1$, which is considered in $f_{1 D}\left(u_{i}(t)\right)$ in the subsequent analysis.

The characteristic and advantage of P-Splines can be described as an optimized trade-off between the flexibility of an estimated function $f(z)$ and the smoothness of the function due to a penalty term (Fahrmeir et al., 2013). Function $f(z)$ is estimated as polynomial spline of degree $l \geq 0$. Such a spline is a piecewise construct of polynomials of degree $l$ in intervals $\left[\kappa_{j}, \kappa_{j+1}\right)$ defined by a number of knots $a=\kappa_{1}<\cdots<\kappa_{m}$. Finally, to ensure that these interval polynomials result into one smooth function $f(z)$, the condition that $f(z)$ is $(l-1)$ times continuously differentiable must hold. With higher degrees and more knots, function $f(z)$ can become quite rough and is likely overfitted and difficult to interpret. Therefore, when estimating a P-Spline, simultaneous to the polynomial spline a penalty term based on differences of neighboring coefficients is considered. This ensures that the spline is smooth but still presents enough detail. For a detailed introduction to P-Splines and smoothing approaches see e.g. Kneib, 2006; Eilers \& Marx, 2010; Fahrmeir et al., 2013.

The concept of P-Splines can be transferred to spatial effects. Considering the GPS coordinates $s_{i}$ as bivariate (latitude, longitude) and continuous variable, a 2D non-linear effect of household location $\left(f_{2 D}\left(s_{i}\right)\right)$ on the borewell adoption rate can be estimated. Such $2 \mathrm{D}$ effects are referred to as smooth surfaces. Comparable to the 1D P-Splines, smoothness is achieved by a penalty term based on differences in coefficients of neighboring observations. 
Because smooth surfaces are spatially explicit they can be mapped and areas with particularly large or small effects of household location on adoption rates can be identified. The 1D PSplines are estimated with three degrees of freedom and 20 knots. The 2D P-Splines are specified with ten knots and a two-dimensional first order random walk penalty.

Traditionally random effects (sometimes also referred to as frailties) are used in the duration model framework to correct for omitted variables such as small-scale local patterns (e.g. soil quality, biophysical characteristics) or time-variant variables that are very difficult to collect, especially over the time of 47 years (Therneau \& Grambsch, 2000). Examples would be crops, which have been grown in the past years, or other information concerning the agricultural management system. Therefore, random effects on household $(i)$ and village $(v)$ level $\left(b_{v_{i}}\right)$ are included ${ }^{12}$.

A mixed model approach introduced by Kneib \& Fahrmeir (2007) was used for the inferences of the additive regression model in equation (9). The model was implemented using the software Bayes $X$ and the respective R-package R2BayesX (Umlauf et al., 2015). The estimation of smoothing parameters for non-linear effects was conducted via restricted maximum likelihood (REML). This estimation approach relies on a Laplace approximation and, thus, no Markov chain Monte Carlo (MCMC) simulation techniques as in a fully Bayesian approach was necessary. In this way, the smoothing parameters could be estimated from the data in advance, given priors for the other regression parameters. The result was an empirical Bayesian approach (Kneib \& Fahrmeir, 2007). The REML approach became fairly standard in recent years and several studies show results are very similar to the ones of the fully Bayesian inference (Kneib, 2006). Furthermore, one can avoid mixing and convergence problems in the MCMC simulation step.

Three model specifications were estimated as a robustness check in order to differentiate between the effects of current and past rainfall. The first model (I) includes all variables in equation (9), i.e. both the current and past years' rainfall values. The second model (II) only contains the current year's rainfall variables and the third model (III) only the past year's values. To compare the model fit, the Akaike information criterion (AIC) and the loglikelihood of estimates are presented.

\footnotetext{
${ }^{12}$ The model displayed in equation (9) is large and its estimation computational intense. As a result, estimations household random effects did not converge. However, estimations of reduced model specifications imply that household random effects do not improve model fit or contribute to coefficient estimates (Appendix 3.6). Consequently, household random effects were excluded in all subsequent estimations.
} 


\subsection{Results and Discussion}

Tables 3.4 and 3.5 show the estimated linear effects of models I-III for the northern and southern transect. The linear effects are presented as percentage changes of the adoption hazard rate (AHR), a convenient transformation of estimated coefficients since the hazard rate is modeled as exponential function of the additive predictor $\eta_{i}(t)$. Estimated nonlinear effects of borewell adopters in the village (1D P-Spline) and household location (2D P-Spline) are displayed in Fig. 3.2 and 3.3 respectively. These figures only show results from model I for the northern transect and model III for the southern transect. These are the model specification that yield the lowest AIC values (Tables 3.4 and 3.5) and are supported by likelihood ratio tests (10 percent significance level). However, estimated effects-linear as well as nonlinear-are robust through all model specifications and, thus, we can regard effects presented in Fig. 3.2 and 3.3 as statistically significant patterns. This is also supported by rather small differences among the AIC and log-likelihood values of the three model specifications for the respective transect.

Fig. 3.2 shows the estimated 2D effect (smooth surface) of household location on the AHR. The scale at the bottom of Fig. 3.2 represents direct coefficient estimates and, thus, is an exponential scale. Transforming them comparable with the linear effects in Tables 3.3 and 3.4 (e.g. $\left.\left(e^{\widehat{\beta}}-1\right) \times 100\right)$ ), an absolute coefficient magnitude of 2 (the margins of the scale) implies a 639 percent change in the adoption rate whereas a coefficient of 1 results in a 122 percent change. Furthermore, red areas imply an acceleration of the AHR whereas blue areas signal decelerating effects. Since the color shades in the northern transect are generally darker than in the southern transect, the urban influence appears to be more heterogeneous in the north. Households located in the southern part of the northern transect are likely to adopt borewells up to 6.39 times faster than the average household in the sample. This is in line with the conceptual framework. In terms of equation (6), the right-hand side decreases for households located closer to the city as market access increases and transport costs decrease. However, there is also an area in the northeast of the transect, where the household location has strong accelerating effects on the AHR. Though rather far away from Bangalore, this area is located right around a road, which connects households to the secondary town of Chikballapur (road intersection in the northeast corner of the map) and thus provides these households with access to markets. In the southern transect, there is one red area in the east of the transect, close to Bangalore and right next to a large highway (road in north-south orientation in Fig. 3.2). 


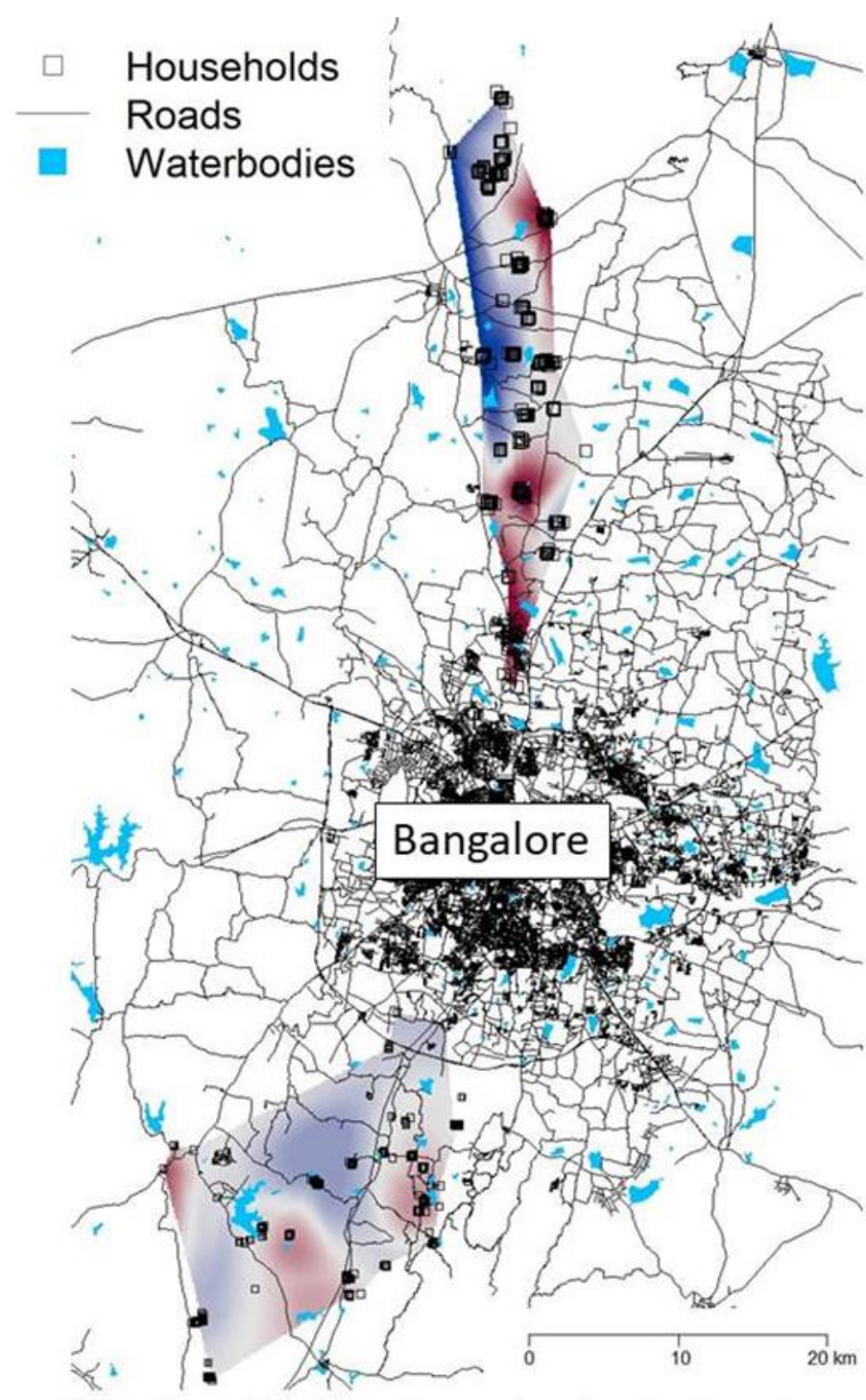

Effect of household location on the adoption hazard rate

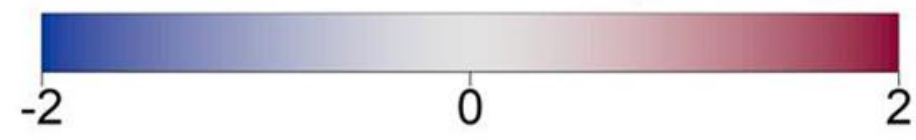

Source: Own survey data

Note: The scale presents direct coefficient estimates and is an exponential scale. For percentage changes transform by $\left(e^{\text {coefficient }}-1\right) \times 100$, e.g. an absolute coefficient magnitude of 2 implies a 639 percent change in the adoption rate.

Fig. 3.2 Estimated smooth effect surfaces of household location (values are original coefficients; Northern transect: $N=7,641$, model specification I; Southern transect: $\mathrm{N}=6,563$, model specification III) 
Furthermore, there are two red areas located in the southern part of the transect. Comparable with the northern transect, there are three secondary towns located close to these areas (Bidadi, Ramanagara, and Kanakapura) and connected by highways. Interestingly, there is a break between these two red areas just next to a larger water reservoir. This might suggest that water demand is covered by sources which are cheaper to establish in this area. Pumping water from the reservoir saves the installation costs needed for drilling a borewell and, thus, could explain negative effects on the AHR. Finally, differences in the effect patterns and magnitude between the two transects as well as their fragmentation support the assumption that effects of market access in a complex rural-urban interface are nonlinear and polycentric and, thus, require a 2D representation. In contrast, 1D measure of market access (e.g. distance) will be of limited use because they assume that urban influences spread in uniform and concentric rings around an urban center.

Concerning the effects of the rainfall variables on the AHR, the effects are very similar in both transects (Tables 3.4 and 3.5). Adoption rates decelerate with an increasing amount of total rainfall in the current $(t)$ or preceding time period $(t-1)$ as well as with the pre-monsoon rainfall in period $t-1$. The effects range from -0.2 to -0.9 percent per additional millimeter of rain. According to the conceptual framework in section 3 (in particular equation (6)) the value of waiting increases when the amount of rainfall increases. The farmer has then less need for a second water source and sticks to the old production system for another year. When there is less rain, the farmer expects a larger output difference between the two production systems and is more likely to adopt the borewell now rather than in the next year. However, we also observed an accelerating effect of increasing pre-monsoon rainfall in both transects in year $t$ as well as with the southwest monsoon in year $t$-1, effect sizes between 0.2 and 0.8 per additional millimeter of rain. A year with more monsoon rain usually generates higher agricultural output as the monsoon season is the principal growing season. Thus, the accelerated AHR might result from extra agricultural income and capital for the next season or the desire to keep up with a previous successful season. This explains the positive lagged effect of monsoon rainfalls but an explanation of the contemporaneous effect of pre-monsoon rainfalls is less clear. First of all, the effect is only statistically significant in model I and, thus, not robust (compare to model II in Tables 3.4 and 3.5). Additionally, we observe borewell adoption on a yearly basis and since the pre-monsoon occurs early in the year (March to May) a time-lag in the adoption decision-making might be lost due to the level of aggregation. After observing this effect in both transects, it seems that the households overall response to 
rainfall. They observe and take some time for their decision to adopt a borewell. This is consistent with the literature, which states that farmers try to hedge against production risks (Koundouri et al., 2006).

Table 3.4

Estimation results for linear effects on adoption hazard rate, Northern Transect

\begin{tabular}{|c|c|c|c|}
\hline & \multicolumn{3}{|c|}{$\begin{array}{c}\text { Percentage change } \\
\left(\left(e^{\text {coefficient }}-1\right) \times 100\right)\end{array}$} \\
\hline & Model I & Model II & Model III \\
\hline Intercept & $-99.981(0.001)$ & $-99.997(<0.001)$ & $-99.997(<0.001)$ \\
\hline \multicolumn{4}{|l|}{ Time-invariant } \\
\hline \multicolumn{4}{|l|}{ variables } \\
\hline \multicolumn{4}{|l|}{ Caste } \\
\hline Scheduled Castes & $-39.86(0.264)$ & $-42.161(0.25)$ & $-40.566(0.272)$ \\
\hline Scheduled Tribes & $-0.995(0.986)$ & $15.639(0.798)$ & $-0.19(0.997)$ \\
\hline Other Backward Class & $-12.733(0.622)$ & $-15.541(0.549)$ & $-14.717(0.569)$ \\
\hline Other & $-57.975(0.262)$ & $-61.349(0.232)$ & $-58.355(0.264)$ \\
\hline \multicolumn{4}{|l|}{ Dairy } \\
\hline Yes & $135.773(0.026)$ & $140.873(0.025)$ & $133.474(0.028)$ \\
\hline Education (years) & $0.19(0.95)$ & $0.05(0.987)$ & $-0.27(0.931)$ \\
\hline Farm size (ha) & $2.01(0.145)$ & $2.624(0.069)$ & $2.204(0.122)$ \\
\hline \multicolumn{2}{|l|}{ Gender } & $-79336(0002)$ & $-78,437(0.002)$ \\
\hline \multicolumn{4}{|l|}{ Time-variant variables } \\
\hline Age (years) & $-3.382(0.004)$ & $-3.488(0.004)$ & $-3.642(0.002)$ \\
\hline Experience (years) & $5.201(<0.001)$ & $4.917(<0.001)$ & $5.096(<0.001)$ \\
\hline Durable assets (count) & $-34.111(<0.001)$ & $-36.479(<0.001)$ & $-37.412(<0.001)$ \\
\hline $\begin{array}{l}\text { Transport equipment } \\
\text { (count) }\end{array}$ & $52.791(0.103)$ & $39.612(0.201)$ & $45.659(0.154)$ \\
\hline \multicolumn{4}{|l|}{ Off-farm employment } \\
\hline Yes & $-82.464(<0.001)$ & $-83.815(<0.001)$ & $-83.778(<0.001)$ \\
\hline \multicolumn{4}{|l|}{ Year t } \\
\hline 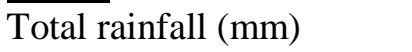 & $-0.389(<0.001)$ & $0.11(0.086)$ & \\
\hline Pre-monsoon (mm) & $0.823(0.012)$ & $0.21(0.276)$ & \\
\hline Southwest monsoon $(\mathrm{mm})$ & $0.05(0.5612)$ & $-0.06(0.462)$ & \\
\hline \multicolumn{4}{|l|}{ Year t-1 } \\
\hline Total rainfall (mm) & $-0.21(0.043)$ & & $-0.05(0.512)$ \\
\hline Pre-monsoon (mm) & $-0.886(<0.001)$ & & $-0.638(0.002)$ \\
\hline Southwest monsoon $(\mathrm{mm})$ & $0.491(<0.001)$ & & $0.2(0.011)$ \\
\hline AIC & $1,073.16$ & $1,086.18$ & $1,078.5$ \\
\hline Log-likelihood & -493.128 & -499.096 & -496.663 \\
\hline $\mathrm{N}$ & 7,641 & 7,641 & 7,641 \\
\hline
\end{tabular}

Source: Own Survey data and rainfall data from Department of Agrometerology, UASB.

Note: Exact p-values are given in parentheses. $\mathrm{N}$ refers to the number of observations of the augmented data set, not to the number of households. 
Table 3.5

Estimation results for linear effects on adoption hazard rate, Southern Transect

\begin{tabular}{|c|c|c|c|}
\hline & \multicolumn{3}{|c|}{$\begin{array}{c}\text { Percentage change } \\
\left(\left(e^{\text {coefficient }}-1\right) \times 100\right)\end{array}$} \\
\hline & Model I & Model II & Model III \\
\hline Intercept & $-99.991(0.004)$ & $-99.996(<0.001)$ & $-99.993(<0.001)$ \\
\hline \multicolumn{4}{|l|}{ Time-invariant } \\
\hline \multicolumn{3}{|l|}{ Caste } & \\
\hline Scheduled Castes & $-66.915(0.026)$ & $-67.044(0.029)$ & $-67.851(0.023)$ \\
\hline Scheduled Tribes & $-89.816(0.031)$ & $-91.084(0.023)$ & $-90.672(0.025)$ \\
\hline Other Backward Class & $-43.17(0.159)$ & $-48.149(0.109)$ & $-45.382(0.135)$ \\
\hline Other & $-55.974(0.243)$ & $-58.996(0.206)$ & $-56.308(0.239)$ \\
\hline \multicolumn{4}{|l|}{ Dairy } \\
\hline Yes & $49.616(0.293)$ & $53.71(0.264)$ & $51.907(0.276)$ \\
\hline Education (years) & $4.645(0.176)$ & $3.884(0.264)$ & $4.362(0.206)$ \\
\hline Farm size (ha) & $2.881(<0.001)$ & $2.747(<0.001)$ & $2.819(<0.001)$ \\
\hline Female & $-10.031(0.798)$ & $-12.392(0.753)$ & $-12.383(0.751)$ \\
\hline \multicolumn{4}{|l|}{ Time-variant variables } \\
\hline Age (years) & $-6.471(<0.001)$ & $-7.42(<0.001)$ & $-6.919(<0.001)$ \\
\hline Experience (years) & $8.937(<0.001)$ & $9.221(<0.001)$ & $9.09(<0.001)$ \\
\hline Durable assets (count) & $1.725(0.887)$ & $-3.806(0.741)$ & $-2.244(0.846)$ \\
\hline $\begin{array}{l}\text { Transport equipment } \\
\text { (count) }\end{array}$ & $-48.737(0.056)$ & $-54.674(0.023)$ & $-52.365(0.032)$ \\
\hline \multicolumn{4}{|l|}{ Off-farm employment } \\
\hline Yes & $17.257(0.594)$ & $6.396(0.837)$ & $14.176(0.658)$ \\
\hline \multicolumn{4}{|l|}{ Year $t$} \\
\hline$\overline{\text { Total rainfall (mm) }}$ & $-0.21(0.084)$ & $0.05(0.581)$ & \\
\hline Pre-monsoon (mm) & $0.713(0.061)$ & $-0.05(0.826)$ & \\
\hline Southwest monsoon $(\mathrm{mm})$ & $0.06(0.593)$ & $-0.03(0.75)$ & \\
\hline \multicolumn{4}{|l|}{ Year t-1 } \\
\hline Total rainfall (mm) & $-0.28(0.026)$ & & $-0.14(0.13)$ \\
\hline Pre-monsoon (mm) & $-0.509(0.076)$ & & $-0.419(0.071)$ \\
\hline Southwest monsoon(mm) & $0.491(<0.001)$ & & $0.260(0.006)$ \\
\hline AIC & 824.33 & 832.684 & 823.005 \\
\hline Log-likelihood & -376.895 & -382.16 & -378.444 \\
\hline $\mathrm{N}$ & 6,563 & 6,563 & 6,563 \\
\hline
\end{tabular}

Source: Own survey data and rainfall data from Department of Agrometerology, UASB.

Note: Exact p-values are given in parentheses. $\mathrm{N}$ refers to the number of observations of the augmented data set, not to the number of households. 
Differences between the transects become more evident when looking at the effects of the control variables in Tables 3.4 and 3.5 and Fig. 3.3. Only the effects of age and experience are similar. Increasing age reduces the AHR, in the northern transect by about 3.5 percent and on the southern transect around 7 percent. In contrast, farming experience increases the AHR by 5 percent in the northern and 9 percent in the southern transect.

Turning to variables describing agricultural management and income composition of the household, dairy production has a large accelerating effect and off-farm employment a large decelerating effect on the AHR in the northern transect. Dairy production requires a lot of water for the animals to drink and wash them but also to grow fodder crops. In addition, dairy production is profitable and might lead to extra income that can be invested in the borewell adoption. ${ }^{13}$ Off-farm employment can generally have two effects on agricultural production. Either additional income is invested in agricultural production (e.g. in form of technology adoption) (Barrett et al., 2001; De Janvry et al., 2005), or the relevance of the agricultural production for the income of the household decreases (Huang et al., 2009). A number of studies show that smallholders - if they have access to a labor market-will diversify their income sources (Fafchamps \& Shilpi, 2003; Deichmann et al., 2009; Imai et al., 2015). Moreover, literature shows that higher management demands of new technologies and the opportunity costs of skilled labor further decreases technology adoption (Pannell et al., 2006). At least in the northern transect, it appears that the latter negative effect (82-84 percent, table 3.4) of off-farm employment is the case. Neither dairy production nor off-farm employment show significant coefficients in the southern transect. However, farm size is a highly statistically significant factor for borewell adoption (in the northern transect only significant in model II). With every additional acre the AHR increases by 3 percent everything else equal.

Furthermore, transport equipment and durable assets were included as measures of the living standard of a household. In the northern transect only durable assets show significant effects, whereas in the southern transect only transport equipment yields significant effects. However, both of them are showing negative signs and comparable magnitudes. Since both of them are measures of living standard, they are likely to signal the same effect. Furthermore, correlation between the two measures explains the insignificant coefficient of the respective other variable (see Appendix 3.5). Accordingly, these results imply that wealthier households are less likely to adopt borewell technology. This is somehow counterintuitive as it could be

${ }^{13}$ Unfortunately, no time-variant information on dairy production is available. Hence, results might suffer from potential endogeneity and we rather observe correlation than causality. 
assumed that wealthier families have better access to financial resources needed to invest in borewell technology. One explanation of this effect could be that wealthier families are less and less dependent on agricultural production. Comparable with the effect of off-farm employment, income diversification decreases the borewell adoption rate. Table 3.3 shows that about 50 percent of the sample has at least one household member in the off-farm sector and off-farm employment is positively correlated with both wealth indicators (Appendix 3.5). If farming is no longer the main income source, the need to modernize production systems and adopt groundwater lifting technology might decrease.

Furthermore, measures of social status and interaction produce different effects as well. For caste only significant negative effects of scheduled castes and scheduled tribes in the southern transect were found. These present the castes that generally hold the lowest social status. Thus, when belonging to these groups in the southern transect, a household's adoption rate is reduced by 67 or 90 percent respectively. While not finding any significant effects for caste in the northern transect, gender has a statistically significant negative effect on the AHR (not significant in the southern transect). If the household head is female the adoption rate of the household is 75 to 79 percent lower in the northern transect. These results imply different social structures between the two transects. Since the share of households in the different castes are very similar in both transects (Table 3.1), caste boundaries are more relevant in the southern transect. Lower caste households have less and later access to groundwater lifting technology. However, same holds for female-headed households in the northern transect. As a consequence, already disadvantaged households will be more vulnerable to water shortage.

The number of borewell adopters in a village shows statistically significant effects in both transects (Fig. 3.3). Up to a number of six adopters per village in $t$-1 (sample population), we observe strong accelerating effects on the AHR (about 700 percent, the y-axis in Fig. 3.3 presents coefficient estimates) in the northern transect (Fig. 3.3a). In the southern transect, the effect is lower (by about 100 percent) and lasts up to 4 adopters in the sample per village. Hence, there is a positive effect on technology diffusion due to social interaction. Interestingly, effects change at higher numbers of adopters. In the northern transect effects become even significantly negative, i.e. if there are more than 9 adopters, the adoption probability of remaining non-adopters decreases. Potential reason might be that wells are shared among neighbors. Since water extraction is unregulated, water prices are close to zero once the well is drilled. Consequently, even if farmers have to pay their neighbors a fee to use their well, it might still be cheaper than drilling one for themselves. However, no household in 
the sample reported such agreements. Another explanation could be that with more wells and unregulated water extraction groundwater tables are likely to fall. Observing the drop in water availability in already existing wells might prevent further adoption as farmers are less optimistic that their own drilling will be successful.

\section{a) Northern transect}

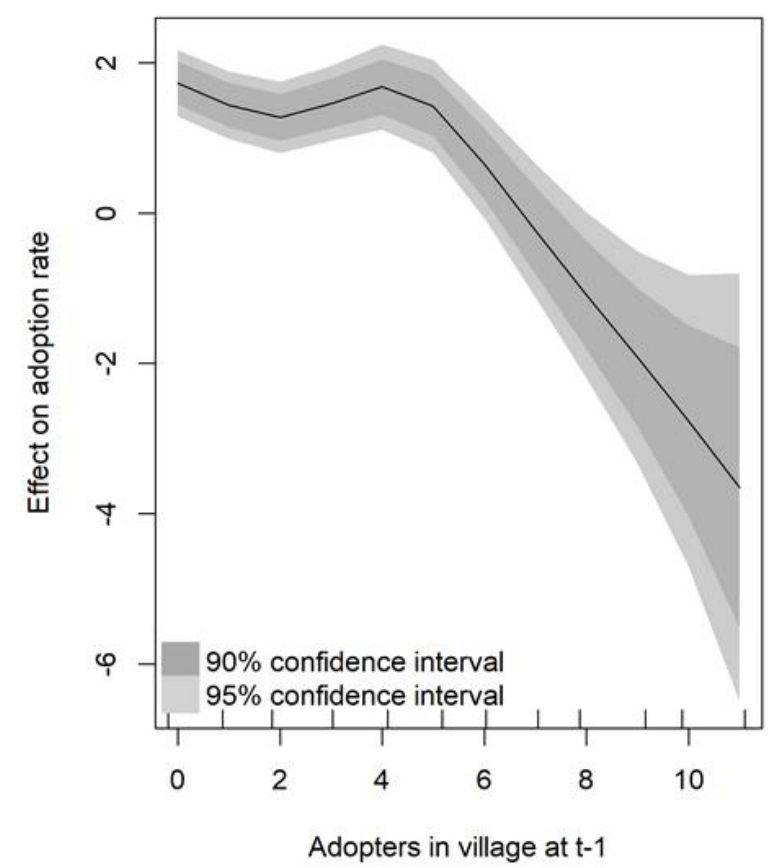

b) Southern transect

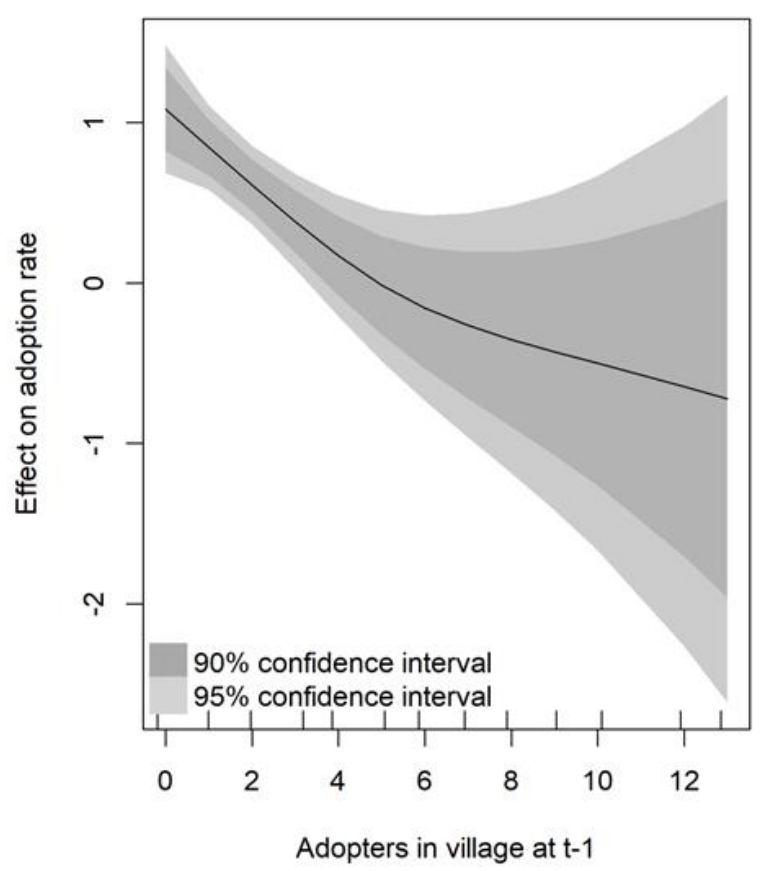

Source: Own survey data

Note: The scale presents direct coefficient estimates and is an exponential scale. For percentage changes transform by $\left(e^{\text {coefficient }}-1\right) \times 100$, e.g. an absolute coefficient magnitude of 2 implies a 639 percent change in the adoption rate.

Fig. 3.3 Estimated non-linear effect of number of adopters in village at $t-1$ on borewell adoption rate (values are original coefficients; Northern transect: $N=7,641$, model specification I; Southern transect: $\mathrm{N}=6,563$, model specification III)

\subsection{Conclusions}

The analysis aims at understanding both the effect of households' location as a measure of urban influence and market access, and the effect of changing climate conditions on borewell adoption behavior in the rural-urban interface of Bangalore. Duration models were applied with semiparametric predictors to accommodate for complex and polycentric urbanization patterns (e.g. secondary towns) and three rainfall variables were used to obtain nuanced insights into the effect of weather changes. 
The results show that household location matters. Both, proximity to Bangalore and proximity to secondary towns increase the borewell adoption rate. This supports the assumption that urbanization effects are polycentric and that empirical strategies using 2D splines are a useful instrument to quantify them. Moreover, adoption rates are further accelerated by social interaction within villages. The study finds that the number of adopters in a village increases the adoption probability of remaining non-adopters. Only if adoption shares are already high, will the effects decrease and even turn negative in the northern transect. Considering changing climate conditions, the study finds that the amount of rainfall affects decisions in two ways. First, a decelerating effect with the amount total rainfall in year $t$ as well as in the lagged time period $t-1$ was observed. Hence, dry spells accelerate the adoption of borewell technology. Second, an accelerating effect with the amount of rainfall during the southwest monsoon in period $t-1$ was observed. As the monsoon season is the most important growing period, the adoption rate also depends on the household's additional income.

Based on these results, the following policy implications are proposed. First, groundwater extraction should be regulated to at least some degree, for example via access rights. Not only better access to the technology but also social learning drives adoption rates and, thus, can quickly lead to local over-exploitation of aquifers. Consequently, over-exploitation is not an evenly distributed phenomenon but is often locally concentrated. Second, the management and number of aboveground water reservoirs should be increased. In the southern transect, lower adoption rates around such as water bodies were found, so that they can at least reduce the adoption speed. In that light, sustainable water management practices such as water efficient irrigation technologies (e.g. drip irrigation) could be promoted more strongly. Third, in policy programs promoting borewell adoption, vulnerable and already disadvantaged groups should be explicitly targeted. The study finds that for example female headed or lower caste households have statistically significantly lower adoption rates.

Nevertheless, there is room for further research. These estimation results show that a household's income composition affects decision making in the context of urban growth and drought pressure. Urban centers provide opportunities for off-farm employment, and increasing water insecurity might encourage farm households to pursue off-farm opportunities. This means, farmers' decision-making might not only rely on the maximization of agricultural production but rather on the maximization of overall household utility. This aspect could be an interesting addition to models explaining technology adoption decisions. 


\section{References}

Abdulai, A., \& Huffman, W. E. (2005). The Diffusion of New Agricultural Technologies: The Case of Crossbred-Cow Technology in Tanzania. American Journal of Agricultural Economics, 87, 645-659.

Alcon, F., Miguel, M. D. de, \& Burton, M. (2011). Duration analysis of adoption of drip irrigation technology in southeastern Spain. Technol. Forecast. Soc., 78, 991-1001.

Barrett, C. B., Bezuneh, M., \& Aboud, A. (2001). Income diversification, poverty traps and policy shocks in Côte d'Ivoire and Kenya. Food Policy, 26, 367-384.

Cameron, L. A. (1999). The Importance of Learning in the Adoption of High-Yielding Variety Seeds. American Journal of Agricultural Economics, 81, 83-94.

Caswell, M., \& Zilberman, D. (1985). The Choices of Irrigation Technologies in California. American Journal of Agricultural Economics, 67, 224.

Caswell, M. F., \& Zilberman, D. (1986). The Effects of Well Depth and Land Quality on the Choice of Irrigation Technology. American Journal of Agricultural Economics, 68, 798.

Chamberlin, J., \& Jayne, T. S. (2013). Unpacking the Meaning of 'Market Access': Evidence from Rural Kenya. World Dev., 41, 245-264.

Cox, D. R. (1972). Regression Models and Life-Tables. J. Roy. Stat. Soc. B. Met., 34, 187220.

Dadi, L., Burton, M., \& Ozanne, A. (2004). Duration Analysis of Technological Adoption in Ethiopian Agriculture. J. Agric. Econ., 55, 613-631.

Damania, R., Berg, C., Russ, J., Federico Barra, A., Nash, J., \& Ali, R. (2017). Agricultural Technology Choice and Transport. American Journal of Agricultural Economics, 99, 265284.

Deichmann, U., Shilpi, F., \& Vakis, R. (2009). Urban Proximity, Agricultural Potential and Rural Non-farm Employment: Evidence from Bangladesh. World Dev., 37, 645-660.

De Janvry, A., Sadoulet, E., \& Zhu, N. (2005). The role of non-farm incomes in reducing rural poverty and inequality in China.

Dixit, A. K., \& Pindyck, R. S. (1994). Investment under uncertainty. Princeton, NJ: Princeton Univ. Press.

Eilers, P. H. C., \& Marx, B. D. (2010). Splines, knots, and penalties. Wiley Interdisciplinary Reviews: Computational Statistics, 2, 637-653.

Euler, M., Schwarze, S., Siregar, H., \& Qaim, M. (2016). Oil Palm Expansion among Smallholder Farmers in Sumatra, Indonesia. J. Agric. Econ., 67, 658-676. 
Fafchamps, M., \& Shilpi, F. (2003). The spatial division of labour in Nepal. J. Dev. Stud., 39, 23-66.

Fahrmeir, L., Kneib, T., Lang, S., \& Marx, B. (2013). Regression: Models, Methods and Applications. Dordrecht: Springer.

Feder, G., Just, R. E., \& Zilberman, D. (1985). Adoption of Agricultural Innovations in Developing Countries: A Survey. Econ. Dev. Cult. Change, 33, 255-298.

Genius, M., Koundouri, P., Nauges, C., \& Tzouvelekas, V. (2014). Information Transmission in Irrigation Technology Adoption and Diffusion: Social Learning, Extension Services, and Spatial Effects. American Journal of Agricultural Economics, 96, 328-344.

Hoffmann, E., Jose, M., Nölke, N., \& Möckel, T. (2017). Construction and Use of a Simple Index of Urbanisation in the Rural-Urban Interface of Bangalore, India. SustainabilityBasel, 9, 2146.

Huang, J., Wu, Y., \& Rozelle, S. (2009). Moving off the farm and intensifying agricultural production in Shandong: A case study of rural labor market linkages in China. Agr. Econ., 40, 203-218.

Imai, K. S., Gaiha, R., \& Thapa, G. (2015). Does non-farm sector employment reduce rural poverty and vulnerability? Evidence from Vietnam and India. J. Asian Econ., 36, 47-61.

Irwin, E., \& Bockstael, N. (2004). Endogenous Spatial Externalities: Empirical Evidence and Implications for the Evolution of Exurban Residential Land Use Patterns. In L. Anselin, R. J. G. M. Florax, \& S. J. Rey (Eds.), Advances in Spatial Econometrics: Methodology, Tools and Applications (pp. 359-380). Berlin, Heidelberg: Springer Berlin Heidelberg.

Kajisa, K., Palanisami, K., \& Sakurai, T. (2007). Effects on poverty and equity of the decline in collective tank irrigation management in Tamil Nadu, India. Agr. Econ., 36, 347-362.

Key, N., Sadoulet, E., \& Janvry, A. de (2000). Transactions Costs and Agricultural Household Supply Response. American Journal of Agricultural Economics, 82, 245-259.

Kneib, T. (2006). Mixed model-based inference in geoadditive hazard regression for intervalcensored survival times. Computation. Stat. Data An., 51, 777-792.

Kneib, T., \& Fahrmeir, L. (2007). A Mixed Model Approach for Geoadditive Hazard Regression. Scand. J. Stat., 34, 207-228.

Koundouri, P., Nauges, C., \& Tzouvelekas, V. (2006). Technology Adoption under Production Uncertainty: Theory and Application to Irrigation Technology. American Journal of Agricultural Economics, 88, 657-670. 
Moore, D. F. (2016). Applied Survival Analysis Using R. Cham: Springer International Publishing.

MRSI, Market Research Society of India (2011). Socio-Economic Classification 2011. The SEC System.

Pannell, D. J., Marshall, G. R., Barr, N., Curtis, A., Vanclay, F., \& Wilkinson, R. (2006). Understanding and promoting adoption of conservation practices by rural landholders. Aust. J. Exp. Agr., 46, 1407-1424.

Sampson, G. S., \& Perry, E. D. (2019). The Role of Peer Effects in Natural Resource Appropriation - The Case of Groundwater. American Journal of Agricultural Economics, $101,154-171$.

Shah, E. (2003). Social designs: Tank irrigation technology and agrarian transformation in Karnataka, South India. Wageningen: Shah.

Shah, T. (2007). The groundwater economy of South Asia: An assessment of size, significance and socio-ecological impacts. In M. Giordano, \& K. G. Villholth (Eds.), The agricultural groundwater revolution: Opportunities and threats to development (pp. 736). Wallingford: CABI.

Shah, T. (2014). Groundwater governance and irrigated agriculture. TEC Background Papers, 69.

Siebert, S., Burke, J., Faures, J. M., Frenken, K., Hoogeveen, J., Döll, P., \& Portmann, F. T. (2010). Groundwater use for irrigation - a global inventory. Hydrology and Earth System Sciences, 14, 1863-1880.

Srinivasa Rao, C., Lal, R., Prasad, J. V.N.S., Gopinath, K. A., Singh, R., Jakkula, V. S., Sahrawat, K. L., Venkateswarlu, B., Sikka, A. K., \& Virmani, S. M. (2015). Potential and Challenges of Rainfed Farming in India. In D. L. Sparks (Ed.), Advances in Agronomy (pp. 113-181). Burlington: Elsevier Science.

Srinivasan, V., Penny, G., Lele, S., Thomas, B. K., \& Thompson, S. (2017). Proximate and underlying drivers of socio-hydrologic change in the upper Arkavathy watershed, India. Hydrology and Earth System Sciences Discussions, 1-28.

Srinivasan, V., Thompson, S., Madhyastha, K., Penny, G., Jeremiah, K., \& Lele, S. (2015). Why is the Arkavathy River drying? A multiple-hypothesis approach in a data-scarce region. Hydrology and Earth System Sciences, 19, 1905-1917. 
Sunding, D., \& Zilberman, D. (2001). Chapter 4 The agricultural innovation process: Research and technology adoption in a changing agricultural sector. In Handbook of Agricultural Economics Agricultural Production (pp. 207-261): Elsevier.

Taylor, R., \& Zilberman, D. (2017). Diffusion of Drip Irrigation: The Case of California. Appl. Econ. Perspect. P., 78, 16-40.

Therneau, T. M., \& Grambsch, P. M. (2000). Modeling Survival Data: Extending the Cox Model. Statistics for biology and health. New York, NY: Springer New York.

Umlauf, N., Adler, D., Kneib, T., Lang, S., \& Zeileis, A. (2015). Structured Additive Regression Models: An R Interface to BayesX. J. Stat. Softw., 63.

Vandercasteelen, J., Beyene, S. T., Minten, B., \& Swinnen, J. (2017). Cities and agricultural transformation in Africa: Evidence from Ethiopia. World Development, 105, 383-399. 


\section{Appendix}

\section{Appendix 3.1 Derivation of equation (6)}

$$
\begin{aligned}
& V(T, l) \geq V(T+1, l) \\
& \Leftrightarrow \sum_{h=0}^{\infty} A_{1}(T+h, l) \delta(h)-C(T, l)-\sum_{h=0}^{\infty} A_{0}(T+h, l) \delta(h) \geq \\
& A_{0}(T, l)+\sum_{h=1}^{\infty} A_{1}(T+h, l) \delta(h)-C(T+1, l) \delta(1)-A_{1}(T, l)-\sum_{h=1}^{\infty} A_{0}(T+h, l) \delta(h) \\
& \Leftrightarrow A_{1}(T, l)-A_{0}(T, l)-C(T, l) \geq A_{0}(T, l)-A_{1}(T, l)-C(T+1, l) \delta(1) \\
& \Leftrightarrow A_{1}(T, l)-A_{0}(T, l) \geq \frac{1}{2}[C(T, l)-C(T+1, l) \delta(1)] \\
& \Leftrightarrow p(T, l) q_{1}(T)-a_{1} c(T, l)-p(T, l) q_{0}(T)-a_{0} c(T, l) \geq \frac{1}{2}[C(T, l)-C(T+1, l) \delta(1)] \\
& \Leftrightarrow p(T, l)\left(q_{1}(T)-q_{0}(T)\right)-c(T, l)\left(a_{1}-a_{0}\right) \geq \frac{1}{2}[C(T, l)-C(T+1, l) \delta(1)] \\
& \Leftrightarrow p(T, l)\left(q_{1}(T)-q_{0}(T)\right) \geq \frac{1}{2}[C(T, l)-C(T+1, l) \delta(1)]+c(T, l)\left(a_{1}-a_{0}\right) \\
& \Leftrightarrow q_{1}(T)-q_{0}(T) \geq \frac{C(T, l)-C(T+1, l) \delta(1)}{2 p(T, l)}+\frac{c(T, l)\left(a_{1}-a_{0}\right)}{p(T, l)}
\end{aligned}
$$




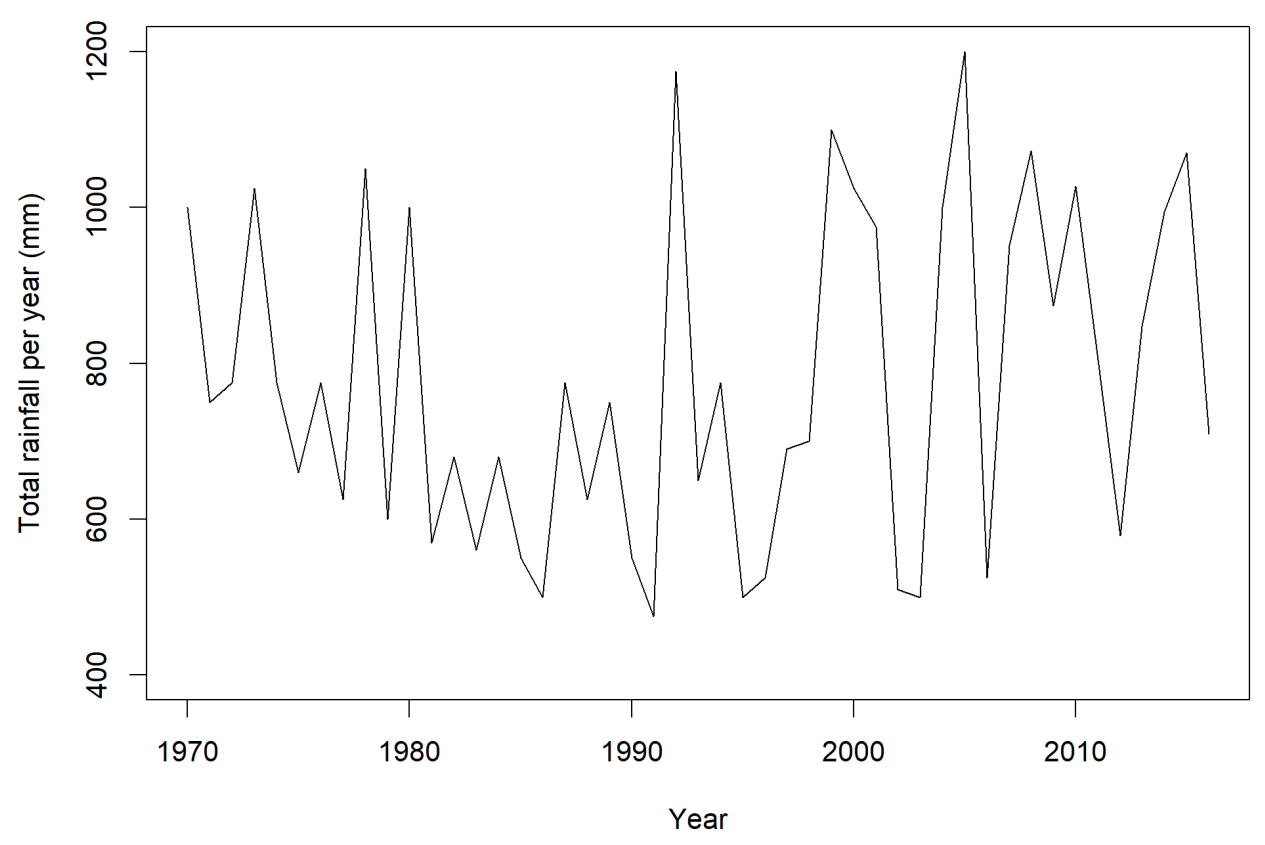

Source: Rainfall data (Department of Agrometerology, UASB).

Appendix 3.2 Total rainfall in the Bengaluru urban district, 1970-2016 


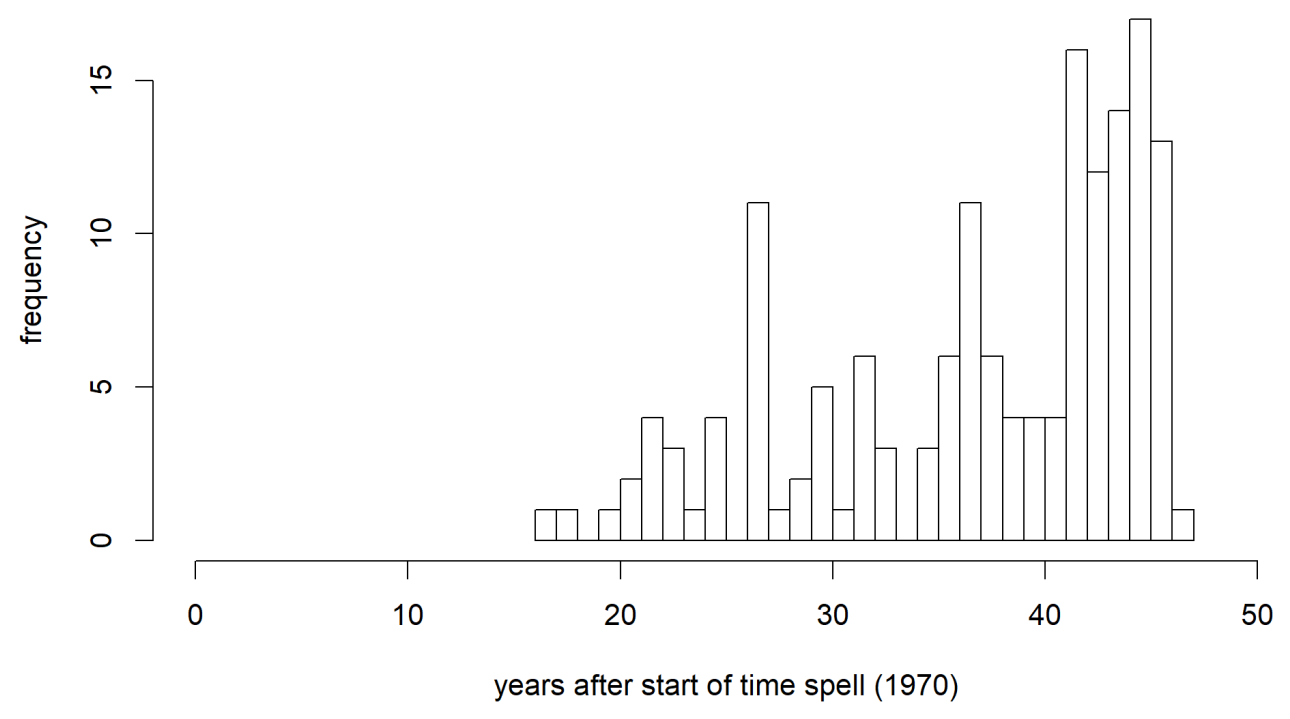

Source: Survey data.

Appendix 3.3 Response frequency of when borewell was adopted ( $N=148$, households) 


\section{Northern transect}

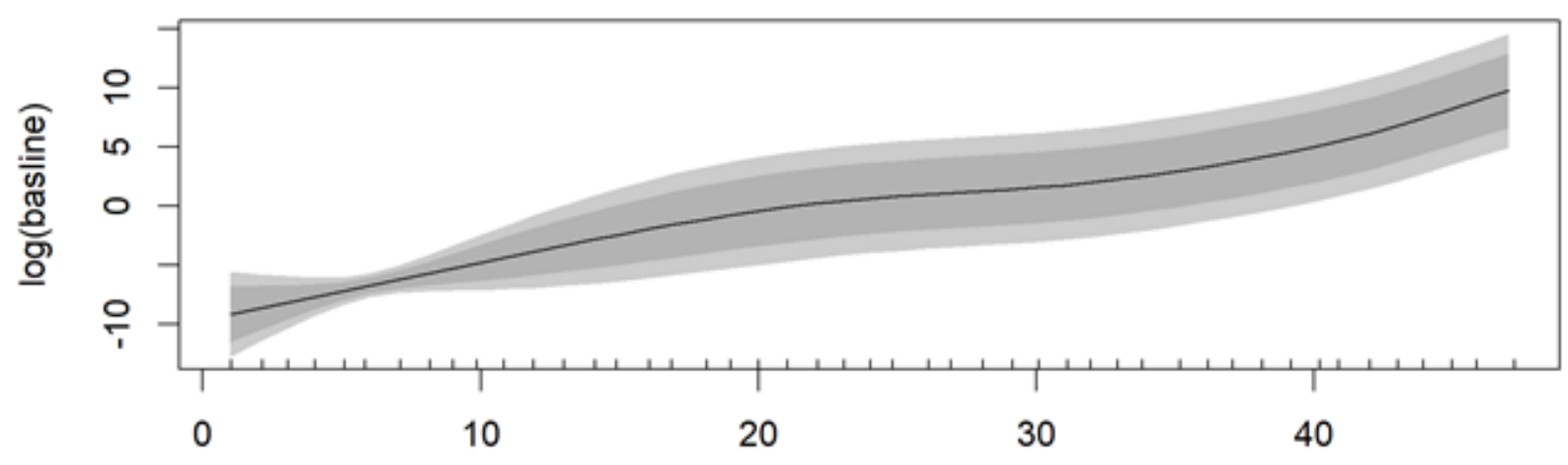

years after start of time spell (1970)

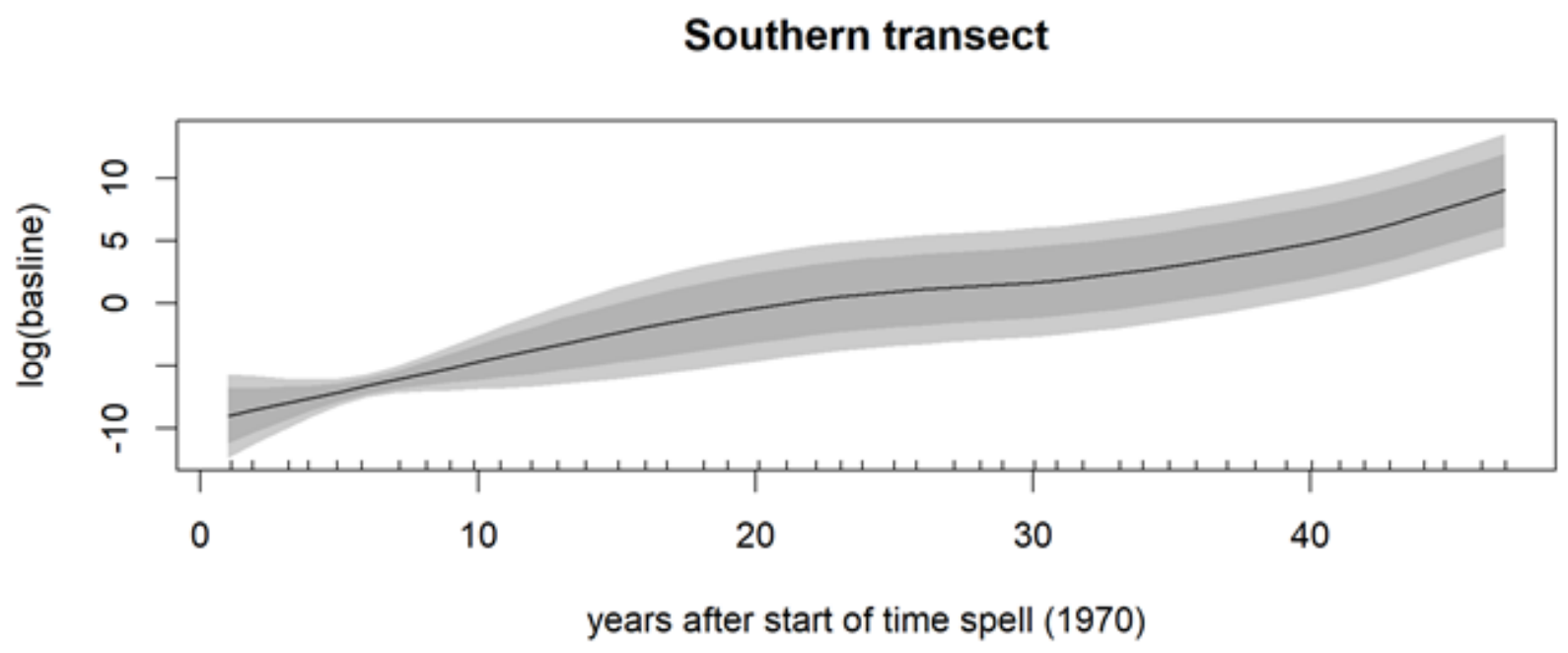

Source: Own survey data and rainfall data from Department of Agrometerology, UASB.

Appendix 3.4 Estimated log-baseline of Spatial Model I (P-Spline), Northern and Southern transect (Northern transect: $N=7,641$; Southern transect: $N=6,563$ ) 
Appendix 3.5

Correlation among off-farm employment and assets owned by households

\begin{tabular}{llll}
\hline & $\begin{array}{l}\text { Off-farm } \\
\text { employment } \\
\text { (dummy) }\end{array}$ & $\begin{array}{l}\text { Durable assets } \\
\text { (count) }\end{array}$ & $\begin{array}{l}\text { Transport equipment } \\
\text { (count) }\end{array}$ \\
\hline $\begin{array}{l}\text { Off-farm } \\
\text { employment } \\
\text { (dummy) }\end{array}$ & 1.00 & & \\
$\begin{array}{l}\text { Durable assets } \\
\text { (count) }\end{array}$ & $\begin{array}{l}0.219 \\
(<0.001)\end{array}$ & 1.00 & \\
$\begin{array}{l}\text { Transport equipment } \\
\text { (count) }\end{array}$ & $\begin{array}{l}0.14 \\
(<0.001)\end{array}$ & 0.552 & 1.00 \\
\hline
\end{tabular}

Source: Own survey data. 
Appendix 3.6

AIC and log-likelihood values of estimations ${ }^{\text {a) }}$ with different random effects included

\begin{tabular}{lll}
\hline Random effects included & AIC & Log-likelihood
\end{tabular}

\section{Northern transect}

$\begin{array}{lll}\text { None } & 1147.69 & -547.74 \\ \text { Household } & 1147.69 & -547.74 \\ \text { Village } & 1141.8 & -542.23\end{array}$

\section{Southern transect}

$\begin{array}{lll}\text { None } & 830.843 & -388.866 \\ \text { Household } & 830.843 & -388.866 \\ \text { Village } & 835.726 & -393.958\end{array}$

Source: Own survey data.

Note: Estimated coefficients and standard errors of models without and with household random effects are equal up to the third decimal place, ${ }^{\text {a) }}$ A reduced model was estimated, i.e. the model in equation (9) without 1D P-

Splines and without weather variables. 


\title{
4. Farmers' decision-making and pollination services: A spatial autoregressive analysis
}

Linda Steinhübel, Arne Wenzel, Prashant Hulamani, Stephan von Cramon-Taubadel, Nicole M. Mason

Under review in Agriculture, Ecosystems \& Environment

\begin{abstract}
Ecosystem services provided by pollinators are essential for the agricultural production of smallholders, especially in low-income countries. However, increased adoption of modern inputs such as chemical fertilizers and pesticides threaten these services. Thus, understanding how farmers' use of modern management practices affects wild pollinator communities is crucial for the design and promotion of sustainable agricultural practices. We provide empirical evidence on the effects of chemical fertilizer and pesticide use on the abundance and species richness of wild bees, a key pollinator, on a sample of 131 agricultural plots in the rural-urban interface of Bangalore, India. To accommodate spatial scaling due to pollinator mobility, we apply spatial Durbin models in our empirical analysis allowing for spatial correlation and spatial spillovers. We find that pesticide use in particular has a negative effect on bee abundance, which spills over to neighboring plots up to a distance of four kilometers. In addition, our results show that bee richness decreases with continuing intensive plot management. These results suggest that strategies to protect pollination services by wild bee communities could include support for cooperative behavior among famers to handle externalities of pesticide use and rotation of intensive and extensive agricultural management systems.
\end{abstract}

Key words: Agricultural management, India, pollination services, spatial autoregressive regression 


\subsection{Introduction}

The importance of ecosystem services and in particular pollinator services for agricultural production and food security has been repeatedly emphasized in the literature (Kleijn et al., 2015; Tscharntke et al., 2012). The interest in the topic particularly increased with the socalled "pollinator crisis", the fast decline of pollinator populations on a global scale. Even though most staple crops do not rely on animal pollinations, many fruits and vegetable crops do (Klein et al., 2007). The latter are often crucial for smallholders in low-income countries to commercialize their production systems and, thus, to improve their income and living standards by participating in national and international agricultural value chains (Chamberlin \& Jayne, 2013). However, such commercialized production systems are frequently characterized by greater use of chemical fertilizers and pesticides. These can harm pollinator populations, with negative implications for the economic performance of production systems (Klein et al., 2007; Allsopp et al., 2008). Therefore, it is essential to understand the interaction of agricultural management decisions and pollinator services, particularly in low-income countries where farmers primarily rely on wild pollinator populations (Kennedy et al., 2013), and where the services provided by these populations have been studied much less than in high-income countries.

This problem has ecological as well as economic facets and several studies have called for increased interdisciplinary analysis of the topic (Bennett et al., 2015; Collins et al., 2011; Vanbergen \& Initiative, 2013; Zhang et al., 2007). Nevertheless, the majority of studies so far have originated in ecological research. In this literature, management decisions are often considered at the landscape scale in an aggregate fashion, e.g., home gardens versus natural forest (Blitzer et al., 2012; Motzke et al., 2016; Tscharntke \& Brandl, 2004; Tscharntke et al., 2005). Since the traditional ecological area of reference is the habitat, this aggregation is intuitive because ecological and anthropogenic boundaries do not necessarily match, i.e. pollinators can move between agricultural plots. Thus, several articles make a strong case for case studies on larger scales and demonstrate the importance of fragmented landscapes in defining local pollinator services to account for pollinator mobility and dispersal ranges (Kremen et al., 2007; Tscharntke et al., 2005; Tscharntke et al., 2012; Tscharntke \& Brandl, 2004). Empirical evidence suggests that the landscape scale is indeed useful to explain the composition of pollinator communities but not necessarily with consistent results. Zou et al. (2017), for example, find that landscape fragmentation enhances pollinator abundance but 
decreases pollinator diversity in China. Motzke et al. (2016) and Ricketts (2004) show that proximity of natural habitat supports pollination services.

However, from an economic and policy perspective the landscape scale is of limited use because decision-making typically takes place at the household or farm level. In this regard, Bockstael (1996) refers to the "confusion between public and private decisions, and between exogenous and endogenous effects" (p. 1170). What this means is that only considering the landscape scale implies the assumption that it is possible to manage the landscape in an overall or public fashion. But this is not how land use change happens in economic understanding. Even if there are public initiatives that aim at influencing landscape structure, they are normally implemented to influence individual decision-making at the local scale. Therefore, to derive conclusions that are policy-relevant, an analytical framework is required that can account for the effects of household- or farm-level decision-making on pollinator communities, as well as their spillover effects at larger scales.

Consequently, the objective of this paper is to present an empirical strategy to model the interactions between specific agricultural management practices and pollinator populations. A key feature of this strategy is that it accounts for spatial spillovers, which allows us to measure whether and over what range management practices on one plot affect pollinator abundance and richness ${ }^{14}$ on neighboring and nearby plots. We explicitly incorporate both plot and landscape scales in our empirical analysis and consider the spatial scaling problems inherent to mobile agents such as insect pollinators. To capture spatial interactions at different scales (i.e., to estimate the dispersal ranges of pollinator communities and the extent of spillovers due to agricultural management practices), we apply spatial econometric techniques, namely a spatial Durbin model (Hoef et al., 2018).

We illustrate the advantages of this empirical approach with primary data on the abundance and richness of bees collected on 131 plots in the rural-urban interface of Bangalore, India. This enables us to also contribute to the still small body of literature on pollinator communities in low-income and tropical countries. Our results can contribute to improve extension and policy measures to manage the use of agricultural inputs that significantly reduce pollinator abundance and richness, and that spill over to neighboring plots. Furthermore, knowledge about the dispersal range of pollinator populations can support

\footnotetext{
${ }^{14}$ These are standard proxies of pollination services in the literature (see e.g. Kremen et al. (2002); Kremen et al. (2004); Holzschuh et al. (2007)). Abundance refers to the number of bee individuals counted per plot whereas richness describes the number of bee species.
} 
measures and landscape management on a larger scale - e.g., the maximum distance between high-quality habitats that still allow pollinator communities to recover.

\subsection{Data}

\subsubsection{Study area}

Our empirical analysis is based on combined field data on bees captured in pan traps on 131 agricultural plots and a panel survey on agricultural management. All plots are located in two geographic areas that extend from urban Bangalore roughly $40 \mathrm{~km}$ into the surrounding ruralurban interface, one to the north and the other roughly to the southwest. We refer to these areas, which are mapped in Fig. 4.1, as the research transects. Although it is under the heavy influence of the rapidly growing city of Bangalore (the last official census in 2011 recorded 9.6 million inhabitants and yearly growth rates of about 8 percent on average (Directorate of Census Operations Karnataka, 2011)), the rural-urban interface is dominated by smallholder agriculture leading to a highly fragmented agricultural land use pattern. Bangalore and several satellite towns offer a variety of marketing possibilities to farmers and connect them to local, national, and even international agricultural markets. Better infrastructure and urban expansion also improves farmers' access to input markets, especially for chemical fertilizers and pesticides. As a consequence, an increasing number of smallholders commercialize and intensify their production systems. Particularly common is the shift from subsistence, staple crop production to high-input fruit and vegetable production. Therefore, the agricultural production systems in the rural-urban interface of Bangalore represent perfectly the dilemma mentioned in the introduction, i.e. smallholders shift to more pollinator-dependent production systems and simultaneously increase the use of potentially pollinator-harming inputs. 


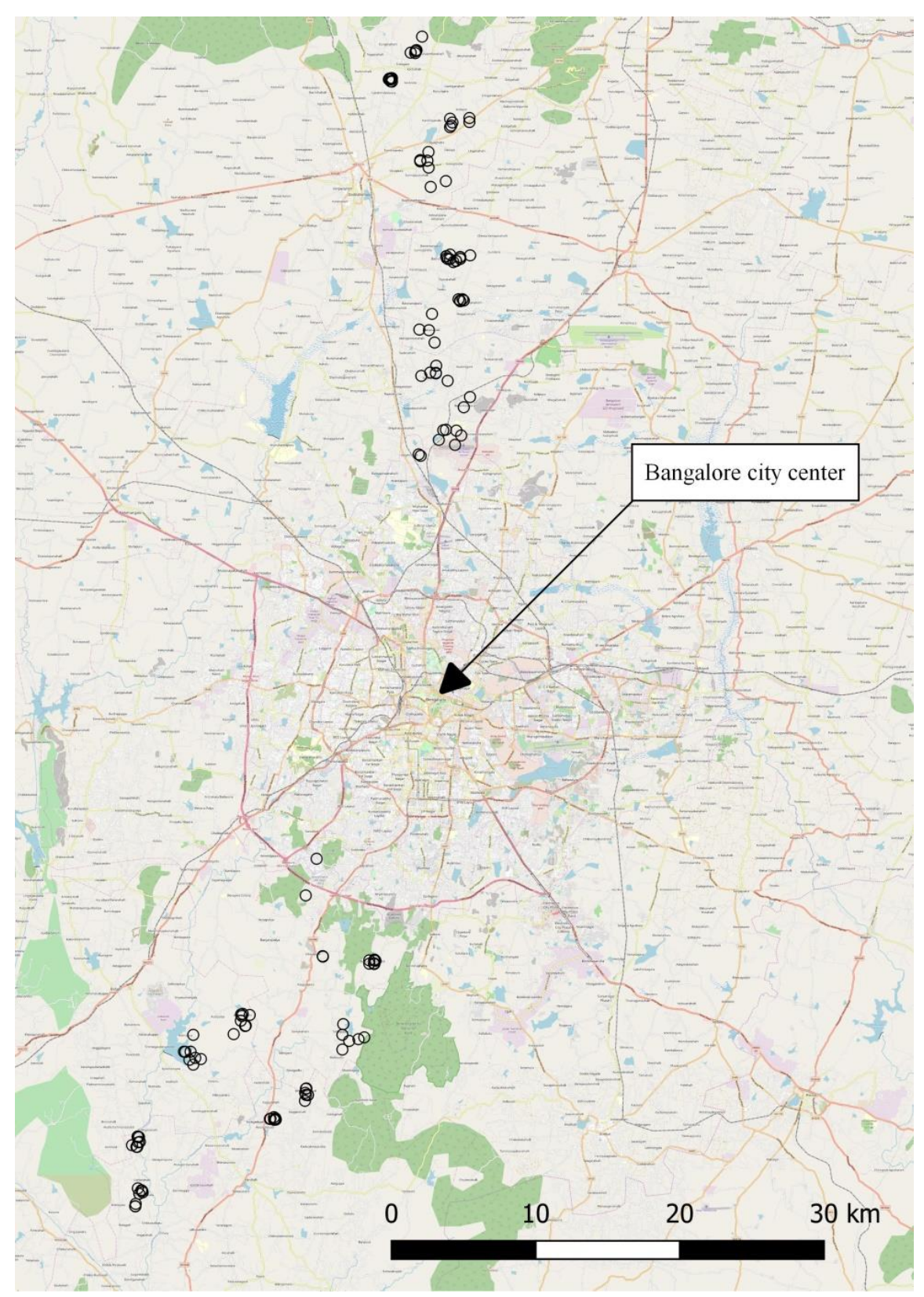

Fig. 4.1 Location of sampled plots (excluding three outliers with maximum distance to Bangalore of $70 \mathrm{~km})$.

\subsubsection{Survey design}

Pan traps were placed on 131 plots farmed by households that represent a subsample of a larger sample of 1,275 farm households, which were visited for a detailed baseline socioeconomic survey in the period from December 2016 to May 2017. During this baseline survey, data on agricultural management in the agricultural year 2016/2017 and recall data for the years 2012 to 2015 was collected. To capture potential spatial heterogeneity induced by 
the urban center of Bangalore, the selection of the 1,275 farm households followed a stratified random sample approach. Based on the Survey Stratification Index (SSI) introduced by Hoffmann et al. (2017), all villages in the two research transects were classified into three strata (rural, peri-urban, urban). In each stratum, ten villages were randomly selected (60 villages in total). Preschool teachers provided us with household lists in the selected villages so that we could randomly draw 20 households on average (weighted by village size) per village. These households were interviewed from December 2016 to May 2017. To select the 131 plots on which pan traps were placed, we drew a random subsample of the 1,275 households. Of the 40 villages located in the peri-urban and rural strata, ${ }^{15}$ we randomly selected 24 villages, twelve in each transect. In these villages all households that managed agricultural land in 2016 according to the first survey $(\mathrm{N}=131)$ were visited in the second survey round.

On each of these 131 sampled households' farms, we randomly selected one agricultural plot and installed four pan traps. These $500 \mathrm{ml}$ bowls were sprayed with yellow UV-bright color and filled with unscented soapy water. To ensure we captured the maximum possible number of pollinators, all four pan traps were positioned at the margins of the agricultural plots close to flower-rich patches. The traps were collected after 48 hours. This is a standard sampling method to record pollinator communities (Westphal et al., 2008). Unfortunately, some traps failed; they spilled or were taken away by passers-by. As a consequence, we introduce dummy variables in our later analysis to control for the number of successful traps per plot (see Fig. A4.1). Pan traps were placed in the field on sunny, windless and dry days, only. After recollection, all bees caught in the bowls were treated with $70 \%$ ethanol, pinned, and identified to species or genus level. The vast majority of all captured insects were bees alongside a few other pollinating insects (e.g. beetles, butterflies, flies, wasps). Pollinator groups can greatly differ in their ecological characteristics and thus indicators based on a variety of different pollinator families can cause inconclusive results (Gagic et al., 2015). Consequently, we decided to only consider bees in our analysis. In the remainder of this article "species" refers to the lowest taxonomic rank identified.

\footnotetext{
${ }^{15}$ Because only a few agricultural households are located in the urban stratum, we ignored these households in our subsample.
} 
We used the number of bees caught per plot as proxy for bee abundance and the number of different bee species as proxy for bee richness. ${ }^{16} \mathrm{We}$ are aware that these are only rough indicators for pollination services and that pan traps might oversample smaller species (see e.g. Baum \& Wallen, 2011); however, both are standard in the ecological literature and hence our results can easily be put in the context of previous studies (Bates et al., 2011; Clough et al., 2011).

In addition to setting out the pan traps on the 131 plots, we also conducted a second household survey of the corresponding households to collect detailed information on the recent (2017/2018) agricultural management decision on each of these plots. We recorded information on the direct neighborhood of the plots and took GPS-coordinates of plot centroids. Since the 131 pan trap plots are nested in the sample of the baseline socioeconomic survey, we also have information on the plot history back to 2012. The latter can be very important as land use patterns evolve through time and thus influence nesting and foraging possibilities for bee communities not only in space but also over time (Kremen et al., 2007).

\subsection{Methods}

\subsubsection{Conceptual framework}

We argue that spatial scaling is one of the major challenges in modeling the effect of farmers' agricultural decision-making on pollinator communities. Pollinator insects are mobile, so that their range is often larger than the size of a smallholder's plot. As a consequence, one pollinator community will be influenced by the decision-making of several farms.

In their study, Kremen et al. (2007) conceptualize the effects of land-use change, including changing agricultural systems, on so-called mobile-agent-based ecosystem services (MABES) and outline the importance and relation of processes taking place at different spatial scales. Therefore, we adapt their framework for our study to motivate our own empirical strategy (Fig. 4.2).

At the farm level, farmers make decisions on the management practices and inputs to use on the land they farm. The sum of all these individual decisions aggregate to the composition of

\footnotetext{
${ }^{16}$ We decided to control for different numbers of pan traps per plot by introducing dummies in the econometric model instead of normalizing the two bee proxies by the number of successful traps. Such a normalization would be particularly difficult for the richness proxy. Theoretically, the number of species caught should stay the same no matter how many traps were put on a plot. The case is different for the abundance measure. One could argue that four traps lead to a higher number of caught insects overall. However, Fig. A4.2 shows that this relationship does not hold. Therefore, we argue that potential systematic bias due to differences in the number of successful traps is best controlled for by including associated dummy variables in the econometric model.
} 
the landscape (Fig. 4.2, a), i.e., a mosaic of "different types of natural, semi-natural and anthropogenic habitats"(Kremen et al., 2007, p. 301). Plant and pollinator communities are sensitive to these habitats and to changes in them (Fig. 4.2, b). In addition, plant and pollinator communities interact (Fig. 4.2, c), which amplifies the effects of landscape change. For example, the disappearance of certain plants might lead to the disappearance of pollinator species that depend on them for nesting or forage. At the same time, plant species vanish if pollinator species disappear that plants rely on for reproduction. Therefore, both plant and pollinator communities define the actual value of pollination services in an area (Fig. 4.2, d). The value of pollination in terms of agricultural production may then feed back into the decision-making behavior of the farmer on the plot scale (Fig. 4.2, e). There may also be feedback from the landscape scale to the local scale. Individual farmers are likely to be influenced by landscape structures (e.g., urban centers, management practices of neighbors) independent of pollinator services (Fig. 4.2, f). An important concept of this framework is that both feedback loops e and f are channeled through either policies or economic factors back to the individual plot or household level. In that sense the circle starts at the plot scale, moves through the landscape scale, and loops back to the local scale.

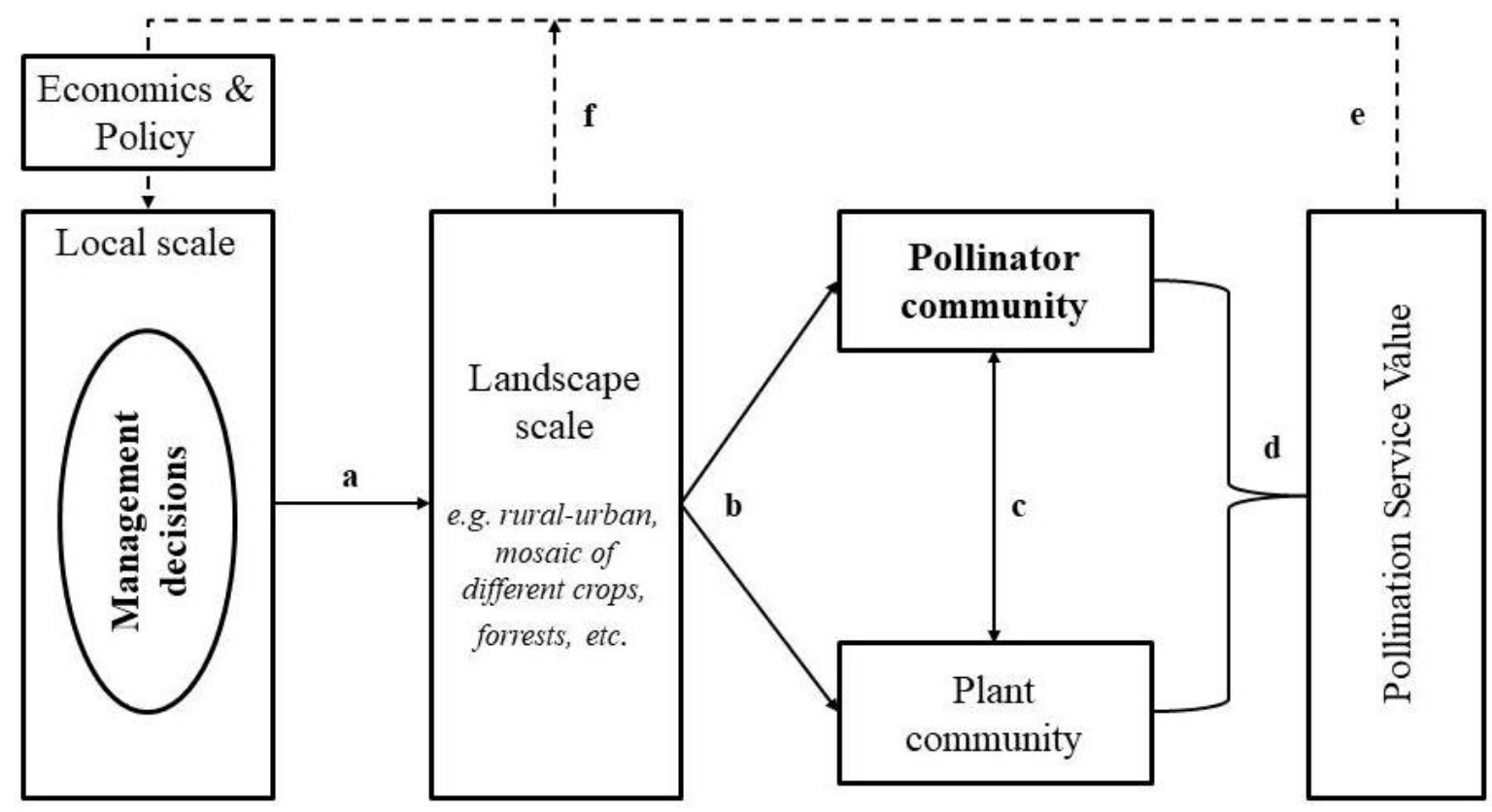

Fig. 4.2 Conceptual framework: interaction of agricultural management decisions and pollinator services (adapted from Kremen et al. (2007)). 
Moreover, the framework shows that there are ecological as well as economic aspects to the cycle of agriculture-pollinator interactions. Several economic studies analyze technology adoption and the effect of policies on agricultural decision-making (see for example Asfaw et al. (2016); Damania et al. (2017); Sharma et al. (2011)). In addition, several studies developed instruments to quantify the actual value of pollinator services (Allsopp et al., 2008; Cordier et al., 2014). Therefore, the economic literature to date has been mainly concerned with the two outer boxes of the framework in Fig. 4.2 and feedback loop e. Pollinator services are modeled as inputs in decision problems of farmers. To the extent that farmers attempt to maximize expected profit, pollinator services and the conservation of pollinators will only be incorporated into farmers' agricultural management decisions if they can see their value in the form of a market or shadow price (Narjes \& Lippert, 2019; Schmidtner et al., 2012; Wollni \& Andersson, 2014).

In contrast, ecological studies are mainly concerned with the arrows b and c in Fig. 4.2. A common aspect is land fragmentation and agricultural intensification measured by distance to or the share of natural or high-quality habitats and its effects on pollinators (see, e.g., Carvalheiro et al., 2010; Clermont et al., 2015; Krishnan et al., 2012; Motzke et al., 2016). Most of these studies show that landscape patterns are a critical and significant factor in determining pollinator composition and abundance. Proximity to high-quality habitats generally supports pollinators (Motzke et al., 2016; Ricketts, 2004), while regions with intensified agriculture threaten — in particular—wild pollinators (Kremen et al., 2002; Tuell \& Isaacs, 2010).

While we acknowledge the importance of larger landscape patterns, we argue that it is equally important to pay attention to the effects of farmers' decision-making at the plot level on pollinator communities because this is the level at which specific agricultural management decisions that affect pollinators are taken and implemented. As emphasized by the framework in Fig. 4.2 the usual starting point is the local household level. Therefore, an understanding of the interaction of plot level managements and pollinator communities is essential for informed policy making.

To model the effect of local decision-making on pollinators subject to landscape scale variation, there are two conceptual challenges that have to be considered in an empirical model. First, observed bee abundance and richness might be spatially correlated. Previous studies show that pollinators can have dispersal ranges of up to six kilometers (Beekman \& Ratnieks, 2000; Dyer \& Seeley, 1991). Therefore, observations within this range might be 
defined by the same pollinator community resulting in endogeneity and spatial clustering of observations. Models that do not control or at least test for spatial correlation run the risk of generating biased parameter estimates as the assumption of independent error terms is violated (Hoef et al., 2018; Lichstein et al., 2002). Second, agricultural management decisions on all plots within its dispersal range affect a bee population. Additionally, farmers' choices of agricultural practices are influenced by the decisions of their neighbors. These spillovers and simultaneity produces another spatial pattern that is not fully determined by exogenous forces and, thus, needs to be controlled for (see for example Wollni \& Andersson (2014) or Läpple et al. (2017)).

\subsubsection{Empirical model}

To incorporate spatial correlation and spillovers, classical linear models can be extended by including spatially lagged dependent and independent variables and spatially lagged error terms (Elhorst, 2010; Kelejian \& Prucha, 1999, 2010; LeSage \& Pace, 2009). Since including all three spatial effects likely leads to an over-parameterization and estimation inefficiency (Elhorst, 2010), a central question is which effects should be included in empirical analysis to represent the data generating process most appropriately? Recent spatial econometrics literature argues that the spatial Durbin model, which includes spatial lags of the dependent and independent variables, should be favored over other models. It is most robust against bias in coefficient estimates when the true data-generating process results from another model specification, and it does not need any a priori assumption about the scale of spatial spillovers. For more details see e.g. Elhorst (2010) and LeSage \& Pace (2009). Accordingly, we estimated a spatial Durbin model in our empirical model, which takes the following form:

$$
Y=\rho W Y+\alpha \iota_{N}+X \beta+X W \theta+\varepsilon
$$

Here $\boldsymbol{Y}$ denotes the dependent variable, either bee abundance or bee richness. In addition to a constant, $\boldsymbol{\alpha} \boldsymbol{\iota}_{\boldsymbol{N}}$, and standard linear effects, $\boldsymbol{X} \boldsymbol{\beta}$, this model allows for spatial dependence in the dependent variable $\boldsymbol{Y}$ and in a set of explanatory variables $\boldsymbol{X}$ by introducing the spatial weight matrix $\boldsymbol{W}$. The matrix $\boldsymbol{W}$ is of dimension $N \times N$ and non-negative. It is composed of known scalars that represent a priori assumptions on the spatial interdependence between observations $i$ and $j$ where $i, j \in\{1, \ldots, N\}$ (Lee, 2004). The main diagonal consists of zeros, i.e. if $i=j$. The error term $\varepsilon$ is assumed to be i.i.d. and normally distributed. Even though both terms $\boldsymbol{\rho} \boldsymbol{W} \boldsymbol{Y}$ and $\boldsymbol{X} \boldsymbol{W} \boldsymbol{\theta}$ represent interactions between observations, technically speaking 
the spatial parameter $\boldsymbol{\rho}$ is a autoregressive coefficient whereas $\boldsymbol{\theta}$ can be estimated as fixed effects (Elhorst, 2010). $\boldsymbol{W Y}$ is endogenous and captures the spillover of bee abundance or richness between plots, i.e. the mobility range of bee communities. In contrast, $\boldsymbol{X W}$ is exogenous and captures the spillover of explanatory variables on neighboring plots on bee abundance or richness. Since spillovers of agricultural decision-making is the focus of this study, dummy variables for chemical fertilizer and pesticide use are included in $\boldsymbol{X} \boldsymbol{W}$.

A standard procedure to construct $\boldsymbol{W}$ is to assume that the strength of spatial interdependence is proportional to the inverse distance between observations (LeSage \& Pace, 2009). In addition, it is assumed that beyond a certain distance no interdependence exists, i.e. the weight in $\boldsymbol{W}$ equals zero. Previous studies indicate different mobility ranges of bees up to a maximum of 6 kilometers (Zurbuchen et al., 2010). Therefore, we set up six different $\boldsymbol{W}$ matrices with distance cut-offs from one to six kilometers in one kilometer steps. We estimated the model (equation 1) with each of these six matrices and retained the model that yields the best model fit according to the Akaike information criterion (AIC). To satisfy assumptions in the asymptotic theory of the estimators for the spatial parameters $\boldsymbol{\rho}$ and $\boldsymbol{\theta}$ and thus to guarantee estimability of the model in equation $1, \boldsymbol{W}$ has to be normalized. For more details see e.g. Kelejian \& Prucha (2010). We chose spectral normalization, which means all entries in $\boldsymbol{W}$ are divided by the largest absolute eigenvalue of the matrix.

Table 4.1 shows the explanatory variables in the linear effects $\boldsymbol{X} \boldsymbol{\beta}$. We included variables at the landscape, as well as plot scale to capture as many factors that affect bee abundance and richness as possible. At the landscape scale, we calculated the distance of each plot from Bangalore city center based on its GPS-coordinates. This variable allows us to control for exogenous spatial heterogeneity induced by the rural-urban gradient. In addition, we include a dummy for the Southern transect to control for any effect due to the different research areas. Based on satellite images, we estimated the built-up area of every village, i.e. the area covered by infrastructure in a $1 \mathrm{~km}$-radius around the village center (for details see Hoffmann et al. (2017)). Built-up area is an indicator of habitat availability, and buildings can also represent physical barriers to bee dispersal. Finally, we collected information of the direct neighborhood of every plot. Thus, we were able to create several dummies describing the land use pattern in the vicinity of the plots on which the pan traps were placed. 
Table 4.1

Descriptive statistics of explanatory variables.

\begin{tabular}{lcccc}
\hline Variable & Mean & Std. Dev. & Min & Max \\
\hline Dependent variables & & & & \\
Bee abundance (number of bees per plot) & 4.68 & 4.44 & 0 & 22 \\
Bee richness (number of bee species per plot) & 2.78 & 2.35 & 0 & 11 \\
& & & & \\
Explanatory variables & & & & \\
Landscape scale & 3.18 & 9.57 & 16.32 & 67.48 \\
Distance to Bangalore (km) & 0.46 & 0.50 & 0 & 1 \\
Southern transect (dummy) & 1.12 & 5.41 & 0.80 & 25.59 \\
Village build-up area (percentage) & 0.85 & 0.35 & 0 & 1 \\
Agricultural plot in direct neighborhood (dummy) & 0.49 & 0.50 & 0 & 1 \\
Fallow plot in direct neighborhood (dummy) & 0.10 & 0.30 & 0 & 1 \\
Forest in direct neighborhood (dummy) & 0.27 & 0.44 & 0 & 1 \\
Building in direct neighborhood (dummy) & 0.37 & 0.49 & 0 & 1 \\
Road in direct neighborhood (dummy) & 0.11 & 0.32 & 0 & 1
\end{tabular}

\section{Local / Plot scale}

Successful pan traps (number)

Clouds at time of pan trap placement (Okta scale)

Temperature at time of pan trap placement $\left({ }^{\circ} \mathrm{C}\right)$

Wind at time of pan trap placement (Beaufort scale)

Plot status at time of pan trap placement

$$
\text { 0: Not harvested }
$$

1: Fallow or already harvested

$\begin{array}{llll}0.02 & 0.12 & 0 & 1 \\ 0.11 & 0.31 & 0 & 1 \\ 0.26 & 0.44 & 0 & 1 \\ 0.62 & 0.49 & 0 & 1 \\ 2.63 & 0.51 & 2 & 4 \\ 26.96 & 1.13 & 23 & 29 \\ 2.16 & 0.37 & 2 & 3\end{array}$

Flower crop (dummy)

$\begin{array}{llll}0.52 & 0.50 & 0 & 1 \\ 0.48 & 0.50 & 0 & 1 \\ 0.04 & 0.19 & 0 & 1 \\ 0.08 & 0.27 & 0 & 1 \\ 0.78 & 0.42 & 0 & 1 \\ 0.05 & 0.21 & 0 & 1 \\ 0.60 & 0.49 & 0 & 1 \\ 0.81 & 0.39 & 0 & 1 \\ 1.08 & 1.53 & 0 & 5 \\ 3.25 & 1.35 & 0 & 5\end{array}$

Fruit crop (dummy)

Staple crop (dummy)

Trees (dummy)

Vegetable crop (dummy)

$3.41 \quad 2.41$

$\begin{array}{ll}3.41 & 2.41 \\ 0.78 & 0.42\end{array}$

$0.37 \quad 0.49$

$0.25 \quad 0.44$

$3.90 \quad 2.00$

\begin{tabular}{|c|c|}
\hline 0 & \\
\hline 0 & \\
\hline $\begin{array}{l}0 \\
0\end{array}$ & \\
\hline & \\
\hline
\end{tabular}

Chemical fertilizer since 2012 (years) 
Table 4.1 continued

\begin{tabular}{|c|c|c|c|c|c|}
\hline Variable & & Mean & Std. Dev. & Min & Max \\
\hline Irrigation since 2012 (years) & & 1.58 & 2.26 & 0 & 5 \\
\hline Pesticide use since 2012 (years) & & 0.34 & 1.18 & 0 & 5 \\
\hline Plot size (acre) & & 1.34 & 1.37 & 0 & 10 \\
\hline \multicolumn{6}{|l|}{ Slope } \\
\hline & 1: Flat & 0.22 & 0.42 & 0 & 1 \\
\hline & 2: Moderate & 0.57 & 0.50 & 0 & 1 \\
\hline & 3: Steep & 0.21 & 0.41 & 0 & 1 \\
\hline \multicolumn{6}{|l|}{ Soil quality } \\
\hline & 1: Poor & 0.06 & 0.24 & 0 & 1 \\
\hline & 2: Middle & 0.45 & 0.50 & 0 & 1 \\
\hline & 3: Very good & 0.49 & 0.50 & 0 & 1 \\
\hline
\end{tabular}

At the plot level, we included several variables that are related to the pan traps and their placement and might therefore influence our measures of abundance and richness. These variables are the number of successful pan traps per plot and meteorological variables such as cloud cover, temperature, and wind conditions when the pan traps were in place. Since the cropping systems in the Bangalore area are very diverse, we also control for different crops. On the 131 pan trap plots, 32 different crops were grown. This crop diversity creates two main issues. First, different crops serve pollinator communities in different ways and certain management practices might be strongly correlated with certain crops. Second, different crops have different growing schedules. As a consequence, some plots had already been harvested when the pan traps were placed, while others were at different stages of development. We use different variables to test and control for these issues. We introduce a dummy variable indicating whether the plot was already harvested. In addition, we control for functional groups of crops, namely flowers, fruits, staples, trees, and vegetables on the plots. We also created a dummy variable indicating whether crops classify as forage crops for pollinators. Thus, this variable represents the forage quality of the plot in the current season. Furthermore, we used the recall data from the baseline survey to measure the number of years since 2012 with bee forage crops on each plot. Finally, we estimated the number of flowers of the focal crop on the plot when the pan traps were in place and the number of flowers in direct proximity ( $2 \mathrm{~m}$ radius) to the pan traps.

To evaluate the effects of farmers' agricultural input and management decision-making on bee communities, we included dummy variables on the use of chemical fertilizers, irrigation, and pesticides. These are standard indicators in the literature to quantify agricultural intensification (see e.g. Asfaw et al., 2016; Sharma et al., 2011.). Similar to the forage crops, we also included variables that count the number of years since 2012 in which these practices 
had been used. Other factors relevant for agricultural management such as plot size, slope, and soil quality were also included in the data set.

Given the 131 observations of our data set, estimating a model that includes all of the explanatory variables described above could lead to over-parameterization and estimation inefficiencies. Therefore, we use the AIC to exclude explanatory variables that do not contribute to the model fit. In addition, we have to account for correlation among certain explanatory variables. Table A4.1 shows strong correlation between the irrigation and pesticide dummies. To avoid multicollinearity one of the two variables should be excluded. Since pesticide use is of primary interest for our research objectives and is more likely to have a direct effect on pollinator communities (Goulson et al., 2015), we exclude the irrigation dummy from further analysis. Furthermore, we also observe strong positive correlation among the past use of pesticides, chemical fertilizer, and irrigation (Table A4.1). Based on the model choice criterion (AIC) we keep the number of irrigated years in the model. However, considering the strong correlation with the other two variables on plot history, past irrigation should be rather understood as a general indicator of agricultural intensification.

\subsubsection{Estimation strategy and interpretation of effects}

We estimate the parameters of the spatial Durbin model via maximum likelihood (Elhorst, 2010; LeSage \& Pace, 2009). All estimations were conducted in Stata, which provides an updated and very flexible package for spatial econometric models in its new version Stata 15 (StataCorp, 2017).

Equation 1 represents the structural form of the spatial Durbin model. In order to estimate all parameters, the model is transformed into its reduced form.

$$
Y=(I-\rho W)^{-1} \alpha \iota_{N}+(I-\rho W)^{-1}(X \beta+W X \theta)+(I-\rho W)^{-1} \varepsilon
$$

This is necessary because $\boldsymbol{W} \boldsymbol{Y}$ is endogenous, i.e. $y_{i}$ affects $y_{j}$ and vice versa. Equation 2 also shows that the interpretation of parameters is more complex than in a simple linear regression. The second term on the right-hand side implies that the dependent variable observed on one plot is affected by changes in explanatory variables on the same plot and also by changes in explanatory variables on other plots. As a consequence, changes at one point in space can propagate through the entire system. Therefore, LeSage \& Pace (2009) propose calculating mean direct, indirect, and total impacts based on the actual partial derivatives $\partial \boldsymbol{Y} / \partial \boldsymbol{X}$ instead of interpreting estimated $\boldsymbol{\beta}$-coefficients themselves. Equation 3 shows the derivation of partial 
derivatives $\partial \boldsymbol{Y} / \partial \boldsymbol{X}$ for an explanatory variable $x_{k}$. The main diagonal represents the direct impacts, i.e. the change in $y$ on plot $i$ if $x_{k}$ changes on plot $i$. Off-diagonal elements represent indirect impacts, i.e. the effect of $x_{k}$ observed on a neighboring plot $j$ on bee abundance or richness at plot $i$.

$$
\left[\frac{\partial \boldsymbol{Y}}{\partial x_{1 k}} \cdot \frac{\partial \boldsymbol{Y}}{\partial x_{N k}}\right]=\left[\begin{array}{ccc}
\frac{\partial y_{1}}{\partial x_{1 k}} & \cdot & \frac{\partial y_{1}}{\partial x_{N k}} \\
\cdot & \cdot & \cdot \cdot \\
\frac{\partial y_{N}}{\partial x_{1 k}} & \cdot & \frac{\partial y_{N}}{\partial x_{N k}}
\end{array}\right]=(I-\rho W)^{-1}\left[\begin{array}{cccc}
\beta_{k} & w_{12} \theta_{k} & \cdot & w_{1 N} \theta_{k} \\
w_{21} \theta_{k} & \beta_{k} & \cdot & w_{2 N} \theta_{k} \\
\cdot & \cdot & \cdot & \cdot \\
w_{N 1} \theta_{k} & w_{N 2} \theta_{k} & \cdot & \beta_{k}
\end{array}\right]
$$

Equation 3 also implies that every observation has its own set of direct and indirect impacts due to the weights assigned in $\boldsymbol{W}$. However, to present specific estimates of impact for every observation in the sample is impractical. Therefore, the general approach is to calculate the mean overall direct and indirect impacts (Elhorst, 2010). In addition, a mean total impact is presented, which is the sum of direct and indirect impacts and, thus, represents the overall effect of explanatory variable $x_{k}$ on $y$.

\subsection{Results}

Overall, we caught 696 bee individuals and identified 31 species belonging to three different families (Apidaea, Halictidae and Megachile). The most abundant species were Apis florea, Lasioglossum sp. 1 and Apis cerana (160, 83 and 79 individuals respectively). These findings are comparable to other studies of tropical agricultural bee communities (Hass et al., 2018; Hoehn et al., 2008). Species accumulation curves indicate that our sampling effort was adequate to detect the majority of bee species present in the rural-urban interface of Bangalore (Table A4.2 and Fig. A4.3).

Estimations with a $\boldsymbol{W}$-matrix that assumes a four kilometer cut-off resulted in the best model fit based on the $\mathrm{AIC}^{17}$. Accordingly, we only present the results of this model in the following. Table 4.2 shows the estimates of the spatial parameters $\boldsymbol{\rho}$ and $\boldsymbol{\theta}$. Tables 4.3 and 4.4 present direct, indirect, and total impacts of explanatory variables on bee abundance and richness, respectively. Effects are quite similar in both the abundance and the richness models ${ }^{18}$ but the levels of statistical significance are generally higher in the abundance model.

\footnotetext{
17 Differences among AICs are rather small. Thus, the spillover distance should be understood as an approximation in the following analysis. Note that coefficients of the explanatory variables are robust to the different cut-offs in $\boldsymbol{W}$.

${ }^{18}$ Correlation between bee abundance and richness in our data set is 91.9 percent and highly statistically significant.
} 


\section{Table 4.2}

Estimates of spatial parameters $(\mathrm{N}=131, W$ matrix with $4 \mathrm{~km}$ cut-off).

\begin{tabular}{lll}
\hline Spatial parameter & Abundance & Richness \\
\hline Pesticide use $(\boldsymbol{\theta})$ & $-4.701^{*}(0.096)$ & \\
Abundance or Richness respectively $(\boldsymbol{\rho})$ & $0.365^{* *}(0.013)$ & $0.292^{* *}(0.023)$ \\
\hline
\end{tabular}

Note: asterisks indicate significance levels $* \mathrm{p}<0.1 ; * * \mathrm{p}<0.05 ; * * * \mathrm{p}<0.01 ; \mathrm{p}$-values in parentheses.

\subsubsection{Spatial parameters}

For bee abundance the best model fit is achieved when spatial lags are included in the dependent variable and in the explanatory variable "pesticide use". Spatial lags in chemical fertilizer use were omitted in exchange for a better model fit. In contrast, bee richness is best explained when a spatial lag is included for the dependent variable but for none of the explanatory variables. Table 4.2 shows that in both models the estimate of the spatial autoregressive parameter $\boldsymbol{\rho}$ is highly significant and positive. This is a clear sign of spatial correlation in the observations of bee abundance and richness within a four kilometer radius. Assuming that the correlation results from bee mobility, the average dispersal range of bee communities in our research area is approximately four kilometers.

Furthermore, we observe significant negative spillovers from pesticide use on neighboring plots, $\boldsymbol{\theta}$, on bee abundance. The lack of such spillovers in the model of bee richness suggests that pesticide spillovers affect bee abundance but not the composition of bee communities as such.

\subsubsection{Effects of agricultural management practices on bee abundance and richness}

In both models dummies for farmers' adoption decisions for chemical fertilizer and pesticide use are included, as is total number of years of irrigation since 2012. In the bee abundance model, all three variables show significant negative total impacts (Table 4.3, third column). The magnitude of total impacts for chemical fertilizer and pesticide are particularly large. Given the average of 4.68 caught bees per plot in our data set (Table 4.1), effects of -2.089 and -3.621 for the use of chemical fertilizer and pesticides respectively imply a strong negative influence of such practices on bee abundance. Furthermore, pesticide use appears to have a stronger overall influence on bee abundance than chemical fertilizer use; the latter effect is only about two-thirds the size of the former ceteris paribus (c.p.). The effect of past irrigation is also statistically significant but smaller in magnitude (-0.309). Comparing direct 
and indirect impacts, chemical fertilizer use and past irrigation yield stronger direct than indirect impacts in terms of magnitude and significance. In contrast, the magnitude and significance of indirect impacts are higher for pesticide use than for direct impacts. These results imply that pesticides have effects that spill over to other plots, whereas the effects of chemical fertilizers and irrigation are more spatially concentrated. This coincides with the choice of spatial parameters presented in section 4.4.1, which also emphasizes the importance of spatial spillovers in pesticide use for bee abundance.

The picture is different for the model on bee richness (Table 4.4). Even though irrigation, pesticide use and chemical fertilizer use have negative effects in this model as well, only the direct and total impact of past irrigation is statistically significant. Assuming 2.78 bee species per plot on average (Table 4.1), every additional year with an intensified management system c.p. leads to 0.24 fewer observed species. Overall, agricultural practices and their spillovers do not have strong effects on bee richness. In addition to rather high $p$-values, direct and indirect impacts of chemical fertilizer and pesticide use show low magnitudes (Table 4.4, columns 1 and 2).

These results imply some significant differences in the dynamics of how agricultural management decisions affect bee communities. While bee abundance is more determined by present management practices, past plot management appears to be primarily important for the composition of the bee community.

\subsubsection{Other determinants of bee abundance and richness}

Several other explanatory variables have statistically significant effects on bee abundance and richness. Village build-up and the dummy for agricultural plots in the direct neighborhood are two landscape scale factors that show significantly negative direct impacts on bee abundance (Table 4.3). The latter variable is likely related to negative spillovers of management practices discussed in section 4.4.2. The negative effect of village build-up might be explained by physical barriers to bee dispersal (e.g. buildings, roads, etc.). The effect is also significantly negative in the model of bee richness but its magnitude is fairly small. On the plot level, soil quality has a highly significant positive direct (and total) impact on bee abundance as well as richness. 


\section{Table 4.3}

Direct, indirect, and total impacts on bee abundance ( $N=131, W$ matrix with $4 \mathrm{~km}$ cut-off).

\begin{tabular}{|c|c|c|c|c|}
\hline \multirow[b]{2}{*}{ Variable } & & \multicolumn{3}{|c|}{$d y / d x$} \\
\hline & & Direct impacts & Indirect impacts & Total impacts \\
\hline \multicolumn{5}{|l|}{ Landscape scale } \\
\hline Village build-up area (percentage) & & $-0.205 * * *(0.003)$ & $-0.032 *(0.055)$ & $-0.237 * * *(0.002)$ \\
\hline Agricultural plot in direct neighborhood (dummy) & & $-2.407 * *(0.02)$ & $-0.377(0.147)$ & $-2.784 * *(0.024)$ \\
\hline Road in direct neighborhood (dummy) & & $-0.832(0.233)$ & $-0.13(0.319)$ & $-0.962(0.237)$ \\
\hline \multicolumn{5}{|l|}{ Local / Plot scale } \\
\hline \multicolumn{5}{|l|}{ Successful pan traps (number) (ref. four traps) } \\
\hline & 1 & $-0.48(0.862)$ & $-0.075(0.863)$ & $-0.555(0.862)$ \\
\hline & 2 & $0.984(0.374)$ & $0.154(0.42)$ & $1.139(0.375)$ \\
\hline & 3 & $2.452 * * *(0.002)$ & $0.384 *(0.075)$ & $2.836 * * *(0.002)$ \\
\hline Fruit crop (dummy) & & $0.581(0.654)$ & $0.091(0.663)$ & $0.672(0.654)$ \\
\hline Chemical fertilizer (count) & & $-1.806^{* *}(0.029)$ & $-0.283(0.168)$ & $-2.089 * *(0.034)$ \\
\hline Pesticides (dummy) & & $-1.383(0.111)$ & $-2.238 *(0.086)$ & $-3.621 * *(0.023)$ \\
\hline Irrigation since 2012 (years) & & $-0.381 * *(0.014)$ & $-0.06(0.109)$ & $-0.441 * *(0.014)$ \\
\hline \multicolumn{5}{|l|}{ Slope (ref. flat) } \\
\hline & 2: Moderate & $1.313(0.125)$ & $0.206(0.229)$ & $1.518(0.128)$ \\
\hline & 3: Steep & $0.746(0.468)$ & $0.117(0.506)$ & $0.862(0.47)$ \\
\hline \multicolumn{5}{|l|}{ Soil quality (ref. poor) } \\
\hline & 2: Middle & $3.813 * *(0.013)$ & $0.598(0.135)$ & $4.41 * *(0.016)$ \\
\hline & 3: Very good & $4.541 * * *(0.003)$ & $0.712(0.107)$ & $5.253 * * *(0.004)$ \\
\hline
\end{tabular}

Note: asterisks indicate significance levels $* \mathrm{p}<0.1 ; * * \mathrm{p}<0.05$; $* * * \mathrm{p}<0.01 ; \mathrm{p}$-values in parentheses 


\section{Table 4.4}

Direct, indirect, and total impacts on bee richness ( $N=131, W$ matrix with $4 \mathrm{~km}$ cut-off).

\begin{tabular}{|c|c|c|c|}
\hline \multirow{2}{*}{ Variable } & \multicolumn{3}{|c|}{$\mathrm{dy} / \mathrm{dx}$} \\
\hline & Direct impacts & Indirect impacts & Total impacts \\
\hline \multicolumn{4}{|l|}{ Landscape scale } \\
\hline Village build-up area (percentage) & $-0.067 *(0.73)$ & $-0.008(0.137)$ & $-0.075^{*}(0.068)$ \\
\hline Agricultural plot in direct neighborhood (dummy) & $-0.8775(0.163)$ & $-0.093(0.262)$ & $-0.867(0.164)$ \\
\hline Successful pan traps (number) (ref. four traps) & & & \\
\hline 1 & $0.636(0.654)$ & $0.076(0.66)$ & $0.712(0.654)$ \\
\hline 2 & $0.76(0.189)$ & $0.091(0.277)$ & $0.851(0.19)$ \\
\hline 3 & $0.798 *(0.05)$ & $0.095(0.153)$ & $0.893 * *(0.049)$ \\
\hline \multicolumn{4}{|l|}{ Flowers present in focal crop 2018 (number, logarithmic } \\
\hline Irrigation since 2012 (years) & $-0.215 * * *(0.008)$ & $-0.026(0.108)$ & $-0.24 * * *(0.008)$ \\
\hline Plot size (acre) & $0.187(0.154)$ & $0.022(0.268)$ & $0.209(0.158)$ \\
\hline \multicolumn{4}{|l|}{ Slope (ref. flat) } \\
\hline 2: Moderate & $0.836 *(0.066)$ & $0.1(0.187)$ & $0.936 *(0.068)$ \\
\hline 3: Steep & $0.699(0.202)$ & $0.084(0.296)$ & $0.783(0.204)$ \\
\hline \multicolumn{4}{|l|}{ Soil quality (ref. poor) } \\
\hline 2: Middle & $1.753 * *(0.032)$ & $0.209(0.152)$ & $1.962 * *(0.033)$ \\
\hline 3: Very good & $2.034 * *(0.015)$ & $0.243(0.125)$ & $2.277 * *(0.015)$ \\
\hline
\end{tabular}

Note: asterisks indicate significance levels $* \mathrm{p}<0.1 ; * * \mathrm{p}<0.05$; $* * * \mathrm{p}<0.01$; $\mathrm{p}$-values in parentheses 


\subsection{Discussion}

The strong significance of the positive spillovers in bee abundance and richness indicated by the spatial parameter $\boldsymbol{\rho}$ (Table 4.2) supports our assumption that observations of mobile pollinators are spatially correlated. Therefore, appropriate empirical models have to be chosen to avoid estimation biases. This is in line with methodological studies by Hoef et al. (2018), Lichstein et al. (2002), and Kissling \& Carl (2007), who emphasize that ecological data often show spatial patterns and, thus, violate the assumptions of traditional linear models such as independent error terms.

In addition to the methodological advantages of our modeling approach, our results also provide insights about the dispersal range of bee communities. Since the spatial weight matrix with a four kilometer cut-off yielded the best model fits, we can assume that this is roughly the average dispersal range of wild bee communities in the rural-urban interface of Bangalore. This estimate appears plausible in the context of the pollinator literature. The maximum dispersal or forage ranges (we use the two terms interchangeably) of some bee species are as high as six kilometers (Beekman \& Ratnieks, 2000; Hagler et al., 2011; Pasquet et al., 2008); however, many species fall below that (Beil et al., 2008; Gathmann \& Tscharntke, 2002; Zurbuchen et al., 2010). The distance a bee can fly to find forage depends to a large degree on species' characteristics such as body size or wing length (Greenleaf et al., 2007). Particularly in fragmented landscapes, access to sufficient forage resources can become a limiting factor to bee populations. Zurbuchen et al. (2010), for example, argue that increasing travel distances to find forage can decrease the development of brood cells by female bees. Thus, knowledge of forage ranges is essential for the understanding and management of pollination services. However, land fragmentation does not only refer to agricultural land use change but also physical infrastructure such as buildings and roads. These can impede biodiversity and ecosystem services due to changes in physical parameters (e.g. temperature) or reduction of habitat size and connectivity (Faeth et al., 2011; Pickett et al., 2011; Steffan-Dewenter, 2003; Turrini \& Knop, 2015). This aspect is captured in our results in the negative direct impact of village build-up on bee abundance and richness (Table 4.3 and 4.4), though more significant for the abundance indicator.

In terms of agricultural management, many studies highlight the negative effects of agricultural intensification on biodiversity and ecosystem services, including pollination (Matson, 1997; Tilman et al., 2002; Winfree et al., 2009). This matches our results since we find that chemical fertilizers, pesticides, and intensive past plot management have negative 
effects on both bee abundance and richness. However, effects differ between these two dependent variables.

Bee abundance is more prone to spatial spillovers, particularly of pesticide use (Tables 4.2 and Table 4.3, column 2). Several studies analyze the effect of pesticides on bee abundance, but results are not consistent. Whereas Tuell \& Isaacs (2010) find significant negative effects, Kremen et al. (2004) and Shuler et al. (2005) do not find any interactions. However, these studies do not consider spatial scaling, which has been shown to be an important factor determining effects on bee abundance; several studies have demonstrate that surrounding plots and distance to natural habitats influence bee abundance (Holzschuh et al., 2007; Krishnan et al., 2012; Motzke et al., 2016). This coincides with the significant negative effect of agricultural plots in the direct neighborhood of the experimental plots on bee abundance in our study. The negative significant spillovers of pesticide use suggest comparable dynamics. In addition, the spillover of pesticide use shows another advantage of our modeling approach. Because pesticide use is measured at the plot level, we can directly relate it to farmers' decision-making and resulting externalities. Even if a farmer wanted to reduce pesticide use to protect pollination services, he might still face decreased pollination rates due to pesticide use by neighbors. In the worst case, this farmer could end up with only pests and no pollinators on his/her plot. At the other extreme a free-riding problem can arise. If only one farmer applies pesticides while all others avoid them, then the farmer who applies pesticides faces lower pest rates and can also benefit from intact pollination services. Thus, our results show that cooperative behavior among smallholders is necessary to guarantee pollination services for all farmers. In game theory this is referred to as prisoner's dilemma (Rapoport, 1989).

In contrast, the negative impacts of chemical fertilizers and intensive past plot management appear to be limited to the plot level and do not show any significant spillovers. Particularly bee richness, compared with abundance, appears to be primarly responsive to a plot history of intensified agriculture (indicated by past irrigation in Table 4.4). Several authors have emphasized the importance of time in determining pollinators' access to species-specific forage and nesting resources (Kremen et al., 2007; Potts et al., 2003; Tuell \& Isaacs, 2010). Bee diversity (richness) can only be established and maintained if such resources are consistently available over a number of seasons. Soil quality can also support the availability of sufficient and high-quality forage (e.g. nectar, pollen) (Baude et al., 2011; Burkle \& Irwin, 2009; Burkle \& Irwin, 2010; Muñoz et al., 2005). This explains the significant positive effect of soil quality in both models (Tables 4.3 and 4.4). 
Whereas a sufficient number of pollinators (abundance) is necessary to guarantee a full pollination service (Kremen et al., 2002), other studies highlight the importance of bee richness for a complete fruit set referring to specialized plant-pollinator relationships (Klein et al., 2003). Both abundance and richness are common indicators of pollination services in the literature (Gabriel \& Tscharntke, 2007; Kremen et al., 2004; Krishnan et al., 2012) and, thus, effects on both indicators have to be taken into consideration in evaluating effects of farmers' decision-making on pollination services.

\subsection{Conclusions and policy implications}

The goal of this study is to evaluate the effects of agricultural management practices on bee abundance and richness in an interdisciplinary fashion. Thus, we consider both ecological factors identified mostly on the landscape scale in the literature with local plot-level decisions on agricultural intensification. The latter is measured as farmers' decisions to use chemical fertilizers and pesticides. To handle spatial scaling in our empirical analysis we apply a spatial Durbin model that allows for spatial correlation and spatial spillovers. Furthermore, we include plot- and landscape-level exogenous explanatory variables in our analysis as well as variables on the history of plot management.

Our results show strong spatial correlation among observations within a four kilometer radius. This distance can be interpreted as the approximate average dispersal range of bee communities in our study area. Furthermore, we find that bee abundance is significantly negatively affected by the adoption of chemical fertilizers and pesticides, and by a history of intensive plot management. Particularly, pesticide use has a large negative impact on bee abundance that spills over to neighboring plots. In contrast, the effects of chemical fertilizers and past plot management are local. Our results also imply that the intensive past management of agricultural plots is the primary determinant of decreasing bee richness. Thus, the response of bee populations to agricultural management practices in the rural-urban interface of Bangalore has spatial as well as temporal components. We argue that more empirical studies should include these two dimensions in an explicit fashion and that our empirical approach is a suitable way to do so.

Because our results refer directly to farmers' decision-making, we can identify types of behavior which can contribute to wild pollinator conservation and, thus, are relevant for extension services or policy programs. First, the existence of negative spillovers from pesticide use call for cooperative approaches among farmers to avoid free-riding or prisoners' dilemma problems. Therefore, extension services that promote knowledge distribution and 
pollinator conservation need to be inclusive, i.e. all farmers in a village should participate. Second, past plot history is important to conserve bee abundance and richness. Thus, rotation of intensive and extensive management practices might help to maintain sufficient forage and nesting opportunities for different bee species. In addition, sustainable practices to maintain and improve soil quality could help to provide bee communities with high-quality forage.

Finally, we recommend larger samples for future studies that increase the statistical validity and precision of the estimates. Furthermore, data from other regions with fewer cultivated crops might reduce the correlation among variables and allow for even more specific conclusions concerning the effects of different agricultural practices and parameters. 


\section{References}

Allsopp, M. H., Lange, W. J. de, \& Veldtman, R. (2008). Valuing insect pollination services with cost of replacement. PloS one, 3, e3128.

Asfaw, S., Di Battista, F., \& Lipper, L. (2016). Agricultural Technology Adoption under Climate Change in the Sahel: Micro-evidence from Niger. Journal of African Economies, $25,637-669$.

Bates, A. J., Sadler, J. P., Fairbrass, A. J., Falk, S. J., Hale, J. D., \& Matthews, T. J. (2011). Changing bee and hoverfly pollinator assemblages along an urban-rural gradient. PloS one, 6, e23459.

Baude, M., Leloup, J., Suchail, S., Allard, B., Benest, D., Mériguet, J., Nunan, N., Dajoz, I., \& Raynaud, X. (2011). Litter inputs and plant interactions affect nectar sugar content. Journal of Ecology, 99, 828-837.

Baum, K. A., \& Wallen, K. E. (2011). Potential Bias in Pan Trapping as a Function of Floral Abundance. Journal of the Kansas Entomological Society, 84, 155-159.

Beekman, M., \& Ratnieks, F. L. W. (2000). Long-range foraging by the honey-bee, Apis mellifera L. Functional Ecology, 14, 490-496.

Beil, M., Horn, H., \& Schwabe, A. (2008). Analysis of pollen loads in a wild bee community (Hymenoptera: Apidae) - a method for elucidating habitat use and foraging distances. Apidologie, 39, 456-467.

Bennett, E. M., Cramer, W., Begossi, A., Cundill, G., Díaz, S., Egoh, B. N., Geijzendorffer, I. R., Krug, C. B., Lavorel, S., Lazos, E., Lebel, L., Martín-López, B., Meyfroidt, P., Mooney, H. A., Nel, J. L., Pascual, U., Payet, K., Harguindeguy, N. P., Peterson, G. D., Prieur-Richard, A.-H., Reyers, B., Roebeling, P., Seppelt, R., Solan, M., Tschakert, P., Tscharntke, T., Turner, B. L., Verburg, P. H., Viglizzo, E. F., White, P. C. L., \& Woodward, G. (2015). Linking biodiversity, ecosystem services, and human well-being: three challenges for designing research for sustainability. Current Opinion in Environmental Sustainability, 14, 76-85.

Blitzer, E. J., Dormann, C. F., Holzschuh, A., Klein, A.-M., Rand, T. A., \& Tscharntke, T. (2012). Spillover of functionally important organisms between managed and natural habitats. Agriculture, Ecosystems \& Environment, 146, 34-43.

Bockstael, N. E. (1996). Modeling Economics and Ecology: The Importance of a Spatial Perspective. American Journal of Agricultural Economics, 78, 1168. 
Burkle, L., \& Irwin, R. (2009). The importance of interannual variation and bottom-up nitrogen enrichment for plant-pollinator networks. Oikos, 118, 1816-1829.

Burkle, L. A., \& Irwin, R. E. (2010). Beyond biomass: measuring the effects of communitylevel nitrogen enrichment on floral traits, pollinator visitation and plant reproduction. Journal of Ecology, 98, 705-717.

Carvalheiro, L. G., Seymour, C. L., Veldtman, R., \& Nicolson, S. W. (2010). Pollination services decline with distance from natural habitat even in biodiversity-rich areas. Journal of Applied Ecology, 47, 810-820.

Chamberlin, J., \& Jayne, T. S. (2013). Unpacking the Meaning of 'Market Access': Evidence from Rural Kenya. World Development, 41, 245-264.

Clermont, A., Eickermann, M., Kraus, F., Hoffmann, L., \& Beyer, M. (2015). Correlations between land covers and honey bee colony losses in a country with industrialized and rural regions. The Science of the total environment, 532, 1-13.

Clough, Y., Barkmann, J., Juhrbandt, J., Kessler, M., Wanger, T. C., Anshary, A., Buchori, D., Cicuzza, D., Darras, K., Putra, D. D., Erasmi, S., Pitopang, R., Schmidt, C., Schulze, C. H., Seidel, D., Steffan-Dewenter, I., Stenchly, K., Vidal, S., Weist, M., Wielgoss, A. C., \& Tscharntke, T. (2011). Combining high biodiversity with high yields in tropical agroforests. Proceedings of the National Academy of Sciences of the United States of America, 108, 8311-8316.

Collins, S. L., Carpenter, S. R., Swinton, S. M., Orenstein, D. E., Childers, D. L., Gragson, T. L., Grimm, N. B., Grove, J. M., Harlan, S. L., Kaye, J. P., Knapp, A. K., Kofinas, G. P., Magnuson, J. J., McDowell, W. H., Melack, J. M., Ogden, L. A., Robertson, G. P., Smith, M. D., \& Whitmer, A. C. (2011). An integrated conceptual framework for long-term social-ecological research. Frontiers in Ecology and the Environment, 9, 351-357.

Cordier, M., Pérez Agúndez, J. A., Hecq, W., \& Hamaide, B. (2014). A guiding framework for ecosystem services monetization in ecological-economic modeling. Ecosystem Services, 8, 86-96.

Damania, R., Berg, C., Russ, J., Federico Barra, A., Nash, J., \& Ali, R. (2017). Agricultural Technology Choice and Transport. American Journal of Agricultural Economics, 99, 265284.

Directorate of Census Operations Karnataka (2011). Census of India 2011: Karnataka, District Census Handbook, Bangalore. Series-30. 
Dyer, F., \& Seeley, T. (1991). Dance dialects and foraging range in three Asian honey bee species. Behavioral Ecology and Sociobiology, 28.

Elhorst, J. P. (2010). Applied Spatial Econometrics: Raising the Bar. Spatial Economic Analysis, 5, 9-28.

Faeth, S. H., Bang, C., \& Saari, S. (2011). Urban biodiversity: patterns and mechanisms. Annals of the New York Academy of Sciences, 1223, 69-81.

Gabriel, D., \& Tscharntke, T. (2007). Insect pollinated plants benefit from organic farming. Agriculture, Ecosystems \& Environment, 118, 43-48.

Gagic, V., Bartomeus, I., Jonsson, T., Taylor, A., Winqvist, C., Fischer, C., Slade, E. M., Steffan-Dewenter, I., Emmerson, M., Potts, S. G., Tscharntke, T., Weisser, W., \& Bommarco, R. (2015). Functional identity and diversity of animals predict ecosystem functioning better than species-based indices. Proceedings. Biological sciences, 282, 20142620.

Gathmann, A., \& Tscharntke, T. (2002). Foraging ranges of solitary bees. Journal of Animal Ecology, 71, 757-764.

Goulson, D., Nicholls, E., Botías, C., \& Rotheray, E. L. (2015). Bee declines driven by combined stress from parasites, pesticides, and lack of flowers. Science (New York, N.Y.), $347,1255957$.

Greenleaf, S. S., Williams, N. M., Winfree, R., \& Kremen, C. (2007). Bee foraging ranges and their relationship to body size. Oecologia, 153, 589-596.

Hagler, J. R., Mueller, S., Teuber, L. R., Machtley, S. A., \& van Deynze, A. (2011). Foraging range of honey bees, Apis mellifera, in alfalfa seed production fields. Journal of insect science (Online), 11, 144.

Hass, A. L., Liese, B., Heong, K. L., Settele, J., Tscharntke, T., \& Westphal, C. (2018). Plantpollinator interactions and bee functional diversity are driven by agroforests in ricedominated landscapes. Agriculture, Ecosystems \& Environment, 253, 140-147.

Hoef, J. M. ver, Peterson, E. E., Hooten, M. B., Hanks, E. M., \& Fortin, M.-J. (2018). Spatial autoregressive models for statistical inference from ecological data. Ecological Monographs, 88, 36-59.

Hoehn, P., Tscharntke, T., Tylianakis, J. M., \& Steffan-Dewenter, I. (2008). Functional group diversity of bee pollinators increases crop yield. Proceedings. Biological sciences, 275, 2283-2291. 
Hoffmann, E., Jose, M., Nölke, N., \& Möckel, T. (2017). Construction and Use of a Simple Index of Urbanisation in the Rural-Urban Interface of Bangalore, India. Sustainability, 9, 2146.

Holzschuh, A., Steffan-Dewenter, I., Kleijn, D., \& Tscharntke, T. (2007). Diversity of flowervisiting bees in cereal fields: effects of farming system, landscape composition and regional context. Journal of Applied Ecology, 44, 41-49.

Kelejian, H. H., \& Prucha, I. R. (1999). A Generalized Moments Estimator for the Autoregressive Parameter in a Spatial Model. International Economic Review, 40, 509533.

Kelejian, H. H., \& Prucha, I. R. (2010). Specification and Estimation of Spatial Autoregressive Models with Autoregressive and Heteroskedastic Disturbances. Journal of econometrics, 157, 53-67.

Kennedy, C. M., Lonsdorf, E., Neel, M. C., Williams, N. M., Ricketts, T. H., Winfree, R., Bommarco, R., Brittain, C., Burley, A. L., Cariveau, D., Carvalheiro, L. G., Chacoff, N. P., Cunningham, S. A., Danforth, B. N., Dudenhöffer, J.-H., Elle, E., Gaines, H. R., Garibaldi, L. A., Gratton, C., Holzschuh, A., Isaacs, R., Javorek, S. K., Jha, S., Klein, A. M., Krewenka, K., Mandelik, Y., Mayfield, M. M., Morandin, L., Neame, L. A., Otieno, M., Park, M., Potts, S. G., Rundlöf, M., Saez, A., Steffan-Dewenter, I., Taki, H., Viana, B. F., Westphal, C., Wilson, J. K., Greenleaf, S. S., \& Kremen, C. (2013). A global quantitative synthesis of local and landscape effects on wild bee pollinators in agroecosystems. Ecology letters, 16, 584-599.

Kissling, W. D., \& Carl, G. (2007). Spatial autocorrelation and the selection of simultaneous autoregressive models. Global Ecology and Biogeography, 0, 070618060123007-???

Kleijn, D., Winfree, R., Bartomeus, I., Carvalheiro, L. G., Henry, M., Isaacs, R., Klein, A.-M., Kremen, C., M'Gonigle, L. K., Rader, R., Ricketts, T. H., Williams, N. M., Lee Adamson, N., Ascher, J. S., Báldi, A., Batáry, P., Benjamin, F., Biesmeijer, J. C., Blitzer, E. J., Bommarco, R., Brand, M. R., Bretagnolle, V., Button, L., Cariveau, D. P., Chifflet, R., Colville, J. F., Danforth, B. N., Elle, E., Garratt, M. P.D., Herzog, F., Holzschuh, A., Howlett, B. G., Jauker, F., Jha, S., Knop, E., Krewenka, K. M., Le Féon, V., Mandelik, Y., May, E. A., Park, M. G., Pisanty, G., Reemer, M., Riedinger, V., Rollin, O., Rundlöf, M., Sardiñas, H. S., Scheper, J., Sciligo, A. R., Smith, H. G., Steffan-Dewenter, I., Thorp, R., Tscharntke, T., Verhulst, J., Viana, B. F., Vaissière, B. E., Veldtman, R., Ward, K. L., 
Westphal, C., \& Potts, S. G. (2015). Delivery of crop pollination services is an insufficient argument for wild pollinator conservation. Nature Communications, 6, 7414 EP -.

Klein, A.-M., Steffan-Dewenter, I., \& Tscharntke, T. (2003). Fruit set of highland coffee increases with the diversity of pollinating bees. Proceedings. Biological sciences, 270, 955-961.

Klein, A.-M., Vaissière, B. E., Cane, J. H., Steffan-Dewenter, I., Cunningham, S. A., Kremen, C., \& Tscharntke, T. (2007). Importance of pollinators in changing landscapes for world crops. Proceedings. Biological sciences, 274, 303-313.

Kremen, C., Williams, N. M., Aizen, M. A., Gemmill-Herren, B., LeBuhn, G., Minckley, R., Packer, L., Potts, S. G., Roulston, T.'a., Steffan-Dewenter, I., Vázquez, D. P., Winfree, R., Adams, L., Crone, E. E., Greenleaf, S. S., Keitt, T. H., Klein, A.-M., Regetz, J., \& Ricketts, T. H. (2007). Pollination and other ecosystem services produced by mobile organisms: a conceptual framework for the effects of land-use change. Ecology letters, 10, 299-314.

Kremen, C., Williams, N. M., Bugg, R. L., Fay, J. P., \& Thorp, R. W. (2004). The area requirements of an ecosystem service: crop pollination by native bee communities in California. Ecology letters, 7, 1109-1119.

Kremen, C., Williams, N. M., \& Thorp, R. W. (2002). Crop pollination from native bees at risk from agricultural intensification. Proceedings of the National Academy of Sciences of the United States of America, 99, 16812-16816.

Krishnan, S., Kushalappa, C. G., Shaanker, R. U., \& Ghazoul, J. (2012). Status of pollinators and their efficiency in coffee fruit set in a fragmented landscape mosaic in South India. Basic and Applied Ecology, 13, 277-285.

Läpple, D., Holloway, G., Lacombe, D. J., \& O’Donoghue, C. (2017). Sustainable technology adoption: a spatial analysis of the Irish Dairy Sector. European Review of Agricultural Economics, 44, 810-835.

Lee, L.-F. (2004). Asymptotic Distributions of Quasi-Maximum Likelihood Estimators for Spatial Autoregressive Models. Econometrica, 72, 1899-1925.

LeSage, J. P., \& Pace, R. K. (2009). Introduction to spatial econometrics. Statistics, textbooks and monographs, 196. Boca Raton: CRC Press.

Lichstein, J. W., Simons, T. R., Shriner, S. A., \& Franzreb, K. E. (2002). SPATIAL AUTOCORRELATION AND AUTOREGRESSIVE MODELS IN ECOLOGY. Ecological Monographs, 72, 445-463. 
Matson, P. A. (1997). Agricultural Intensification and Ecosystem Properties. Science, 277, 504-509.

Motzke, I., Klein, A.-M., Saleh, S., Wanger, T. C., \& Tscharntke, T. (2016). Habitat management on multiple spatial scales can enhance bee pollination and crop yield in tropical homegardens. Agriculture, Ecosystems \& Environment, 223, 144-151.

Muñoz, A. A., Celedon-Neghme, C., Cavieres, L. A., \& Arroyo, M. T. K. (2005). Bottom-up effects of nutrient availability on flower production, pollinator visitation, and seed output in a high-Andean shrub. Oecologia, 143, 126-135.

Narjes, M. E., \& Lippert, C. (2019). The Optimal Supply of Crop Pollination and Honey From Wild and Managed Bees: An Analytical Framework for Diverse Socio-Economic and Ecological Settings. Ecological Economics, 157, 278-290.

Pasquet, R. S., Peltier, A., Hufford, M. B., Oudin, E., Saulnier, J., Paul, L., Knudsen, J. T., Herren, H. R., \& Gepts, P. (2008). Long-distance pollen flow assessment through evaluation of pollinator foraging range suggests transgene escape distances. Proceedings of the National Academy of Sciences of the United States of America, 105, 13456-13461.

Pickett, S. T. A., Cadenasso, M. L., Grove, J. M., Boone, C. G., Groffman, P. M., Irwin, E., Kaushal, S. S., Marshall, V., McGrath, B. P., Nilon, C. H., Pouyat, R. V., Szlavecz, K., Troy, A., \& Warren, P. (2011). Urban ecological systems: scientific foundations and a decade of progress. Journal of environmental management, 92, 331-362.

Potts, S. G., Vulliamy, B., Dafni, A., Ne'eman, G., O'Toole, C., Roberts, S., \& Willmer, P. (2003). Response of plant-pollinator communities to fire: changes in diversity, abundance and floral reward structure. Oikos, 101, 103-112.

Rapoport, A. (1989). Prisoner's Dilemma. In J. Eatwell (Ed.), The new Palgrave: game theory (pp. 199-204). Basingstoke: Macmillan Reference.

Ricketts, T. H. (2004). Tropical Forest Fragments Enhance Pollinator Activity in Nearby Coffee Crops. Conservation Biology, 18, 1262-1271.

Schmidtner, E., Lippert, C., Engler, B., Häring, A. M., Aurbacher, J., \& Dabbert, S. (2012). Spatial distribution of organic farming in Germany: does neighbourhood matter?

European Review of Agricultural Economics, 39, 661-683.

Sharma, A., Bailey, A., \& Fraser, I. (2011). Technology Adoption and Pest Control Strategies Among UK Cereal Farmers: Evidence from Parametric and Nonparametric Count Data Models. Journal of Agricultural Economics, 62, 73-92. 
Shuler, R. E., Roulston, T. H., \& Farris, G. E. (2005). Farming practices influence wild pollinator populations on squash and pumpkin. Journal of economic entomology, 98, 790795.

StataCorp (2017). Stata: Release 15: Statistical Software. College Station, TX: StataCorp LLC.

Steffan-Dewenter, I. (2003). Importance of Habitat Area and Landscape Context for Species Richness of Bees and Wasps in Fragmented Orchard Meadows. Conservation Biology, 17, 1036-1044.

Tilman, D., Cassman, K. G., Matson, P. A., Naylor, R., \& Polasky, S. (2002). Agricultural sustainability and intensive production practices. Nature, 418, $671 \mathrm{EP}$-.

Tscharntke, T., \& Brandl, R. (2004). Plant-insect interactions in fragmented landscapes. Annual review of entomology, 49, 405-430.

Tscharntke, T., Clough, Y., Wanger, T. C., Jackson, L., Motzke, I., Perfecto, I., Vandermeer, J., \& Whitbread, A. (2012). Global food security, biodiversity conservation and the future of agricultural intensification. Biological Conservation, 151, 53-59.

Tscharntke, T., Klein, A. M., Kruess, A., Steffan-Dewenter, I., \& Thies, C. (2005). Landscape perspectives on agricultural intensification and biodiversity - ecosystem service management. Ecology letters, 8, 857-874.

Tuell, J. K., \& Isaacs, R. (2010). Community and Species-Specific Responses of Wild Bees to Insect Pest Control Programs Applied to a Pollinator-Dependent Crop. Journal of Economic Entomology, 103, 668-675.

Turrini, T., \& Knop, E. (2015). A landscape ecology approach identifies important drivers of urban biodiversity. Global change biology, 21, 1652-1667.

Vanbergen, A. J., \& Initiative, t. I. P. (2013). Threats to an ecosystem service: pressures on pollinators. Frontiers in Ecology and the Environment, 11, 251-259.

Westphal, C., Bommarco, R., Carré, G., Lamborn, E., Morison, N., Petanidou, T., Potts, S. G., Roberts, S. P. M., Szentgyörgyi, H., Tscheulin, T., Vaissière, B. E., Woyciechowski, M., Biesmeijer, J. C., Kunin, W. E., Settele, J., \& Steffan-Dewenter, I. (2008). MEASURING BEE DIVERSITY IN DIFFERENT EUROPEAN HABITATS AND BIOGEOGRAPHICAL REGIONS. Ecological Monographs, 78, 653-671.

Winfree, R., Aguilar, R., Vázquez, D. P., LeBuhn, G., \& Aizen, M. A. (2009). A metaanalysis of bees' responses to anthropogenic disturbance. Ecology, 90, 2068-2076. 
Wollni, M., \& Andersson, C. (2014). Spatial patterns of organic agriculture adoption: Evidence from Honduras. Ecological Economics, 97, 120-128.

Zhang, W., Ricketts, T. H., Kremen, C., Carney, K., \& Swinton, S. M. (2007). Ecosystem services and dis-services to agriculture. Ecological Economics, 64, 253-260.

Zou, Y., Bianchi, F. J.J.A., Jauker, F., Xiao, H., Chen, J., Cresswell, J., Luo, S., Huang, J., Deng, X., Hou, L., \& van der Werf, W. (2017). Landscape effects on pollinator communities and pollination services in small-holder agroecosystems. Agriculture, Ecosystems \& Environment, 246, 109-116.

Zurbuchen, A., Landert, L., Klaiber, J., Müller, A., Hein, S., \& Dorn, S. (2010). Maximum foraging ranges in solitary bees: only few individuals have the capability to cover long foraging distances. Biological Conservation, 143, 669-676. 


\section{Appendix}

Table A4.1

Correlation among different measures of agricultural management practices.

\begin{tabular}{lllllll}
\hline & $\begin{array}{l}\text { Chemical } \\
\text { fertilizer } \\
\text { (dummy) }\end{array}$ & $\begin{array}{l}\text { Pesticides } \\
\text { (dummy) }\end{array}$ & $\begin{array}{l}\text { Irrigation } \\
\text { (dummy) }\end{array}$ & $\begin{array}{l}\text { Chemical } \\
\text { fertilizer } \\
\text { (years } \\
\text { since } \\
2012)\end{array}$ & $\begin{array}{l}\text { Pesticides } \\
\text { (years } \\
\text { since } \\
2012)\end{array}$ & $\begin{array}{l}\text { Irrigation } \\
\text { (years } \\
\text { since }\end{array}$ \\
2012)
\end{tabular}

Note: asterisks indicate significance levels $* \mathrm{p}<0.1 ; * * \mathrm{p}<0.05 ; * * * \mathrm{p}<0.01 ; \mathrm{p}$-values in parentheses 
Table A4.2

Total number of individuals per bee species sorted by family.

\begin{tabular}{|c|c|c|c|}
\hline Family & Species & Author & Abundance \\
\hline \multirow[t]{12}{*}{ Apidae } & Amegilla sp. 1 & & 3 \\
\hline & Amegilla sp. 2 & & 3 \\
\hline & Apis cerana & Fabricius & 79 \\
\hline & Apis dorsata & Fabricius & 16 \\
\hline & Apis florea & Fabricius & 160 \\
\hline & Ceratina binghami & Cockerell & 58 \\
\hline & Ceratina heiroglyphica & Smith & 6 \\
\hline & Ceratina heiroglyphica & Smith & 34 \\
\hline & Ceratina smaragdina & Smith & 9 \\
\hline & Ceratina unimaculata & Smith & 11 \\
\hline & Xylocopa latipes & Drury & 1 \\
\hline & Xylocopa sp. 1 & & 1 \\
\hline \multirow[t]{16}{*}{ Halictidae } & Austronomia sp. 1 & & 2 \\
\hline & Hoplonomia sp. 1 & & 1 \\
\hline & Lasioglossum sp.1 & & 83 \\
\hline & Lasioglossum sp.2 & & 39 \\
\hline & Lasioglossum sp.3 & & 58 \\
\hline & Lasioglossum sp.4 & & 22 \\
\hline & Lasioglossum sp.5 & & 22 \\
\hline & Lasioglossum sp.6 & & 15 \\
\hline & Lasioglossum sp.7 & & 6 \\
\hline & Leuconomia sp. 1 & & 1 \\
\hline & Nomia westwoodi & Gribodo & 2 \\
\hline & Pachynomia sp. 1 & & 2 \\
\hline & Seladonia sp. 1 & & 29 \\
\hline & Seladonia sp. 2 & & 17 \\
\hline & Sphecodes sp. 1 & & 9 \\
\hline & Sphecodes sp. 2 & & 3 \\
\hline \multirow[t]{3}{*}{ Megachilidae } & Coelioxys confusa & Smith & 1 \\
\hline & Megachile disjuncta & Fabricius & 1 \\
\hline & Megachile lanata & Fabricius & 2 \\
\hline
\end{tabular}




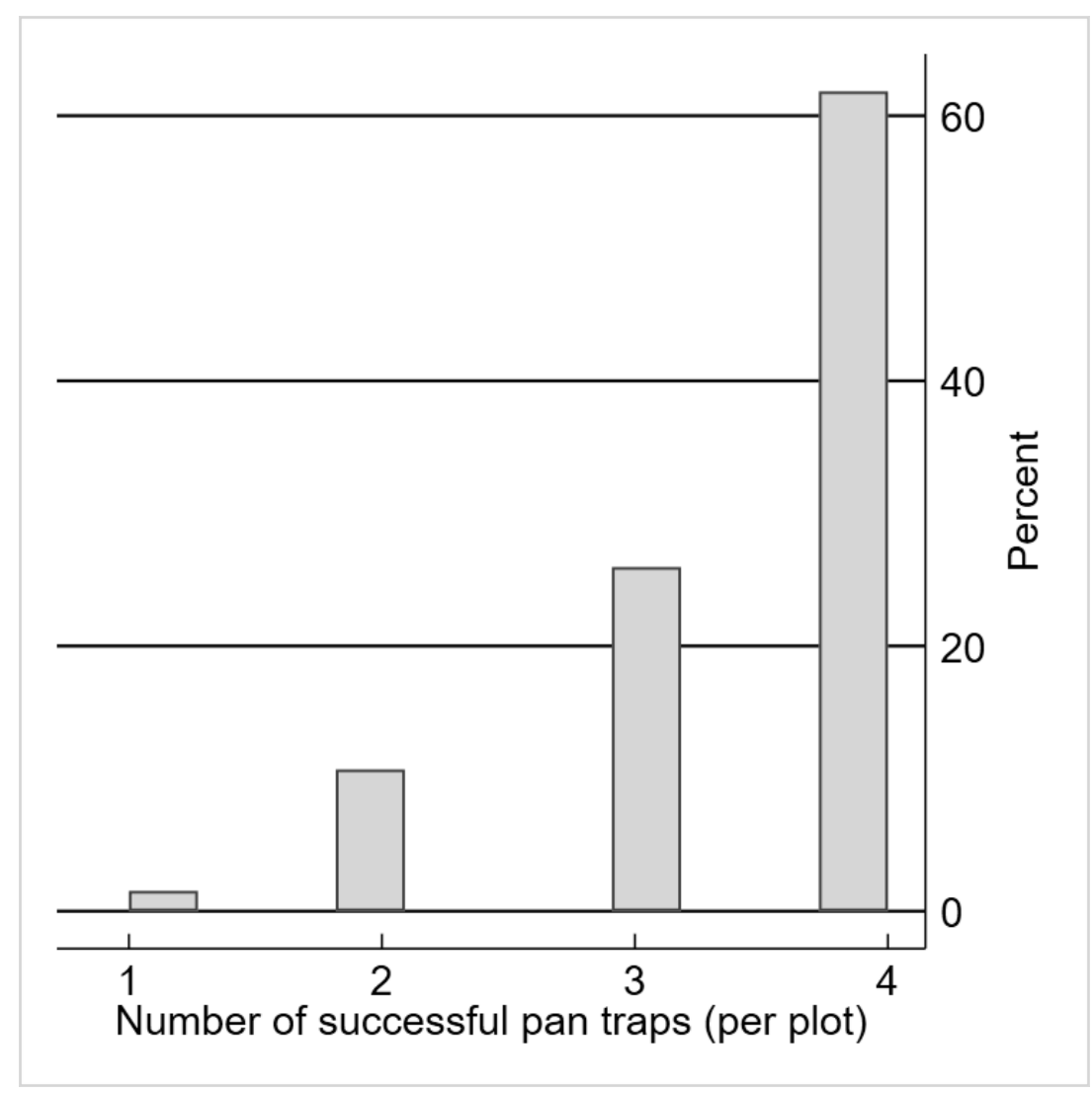

Fig. A4.1 Histogram of successful pan traps per plot. 


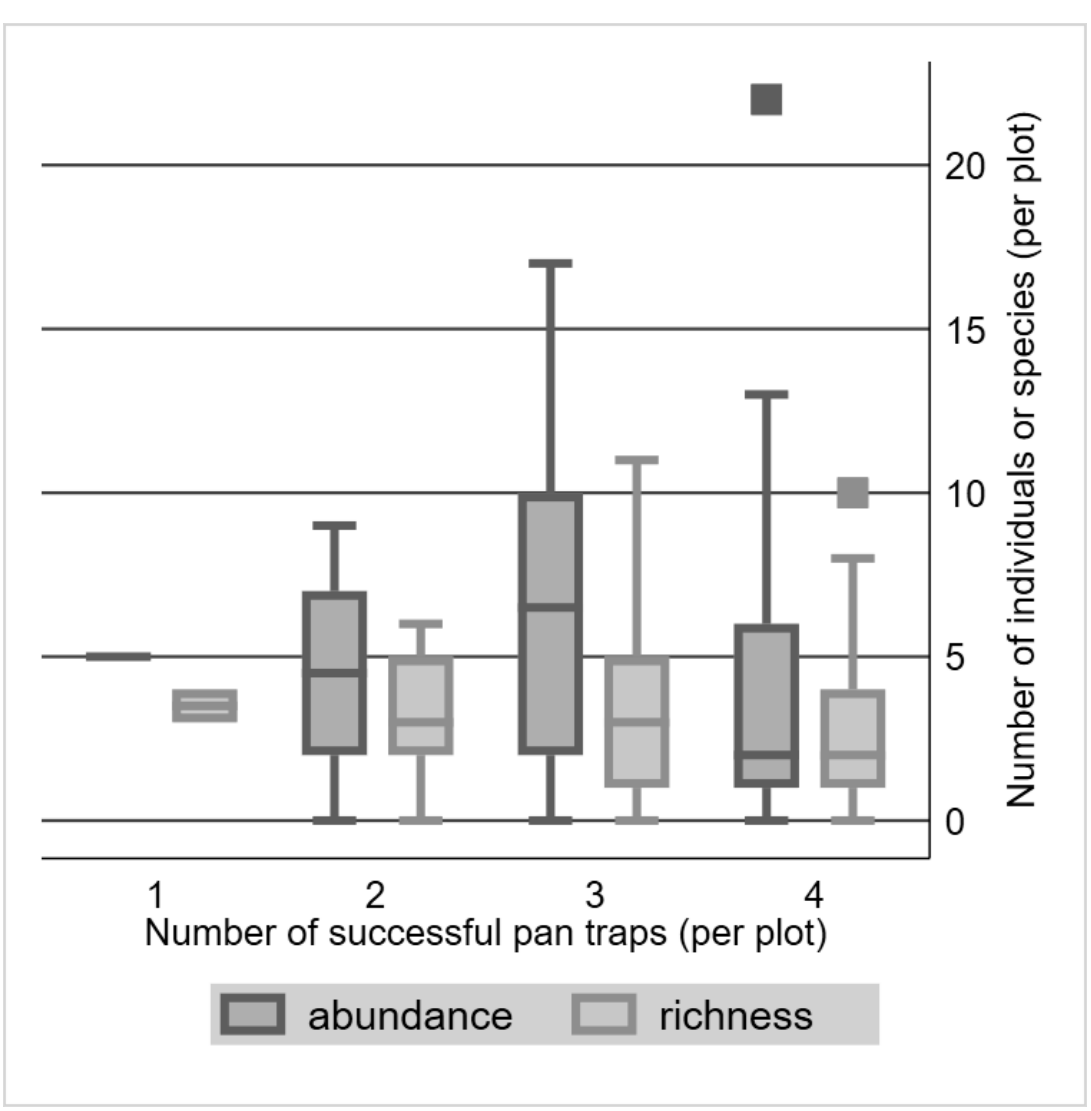

Fig. A4.2 Distribution of bee abundance and richness over the number of successful pan traps. 


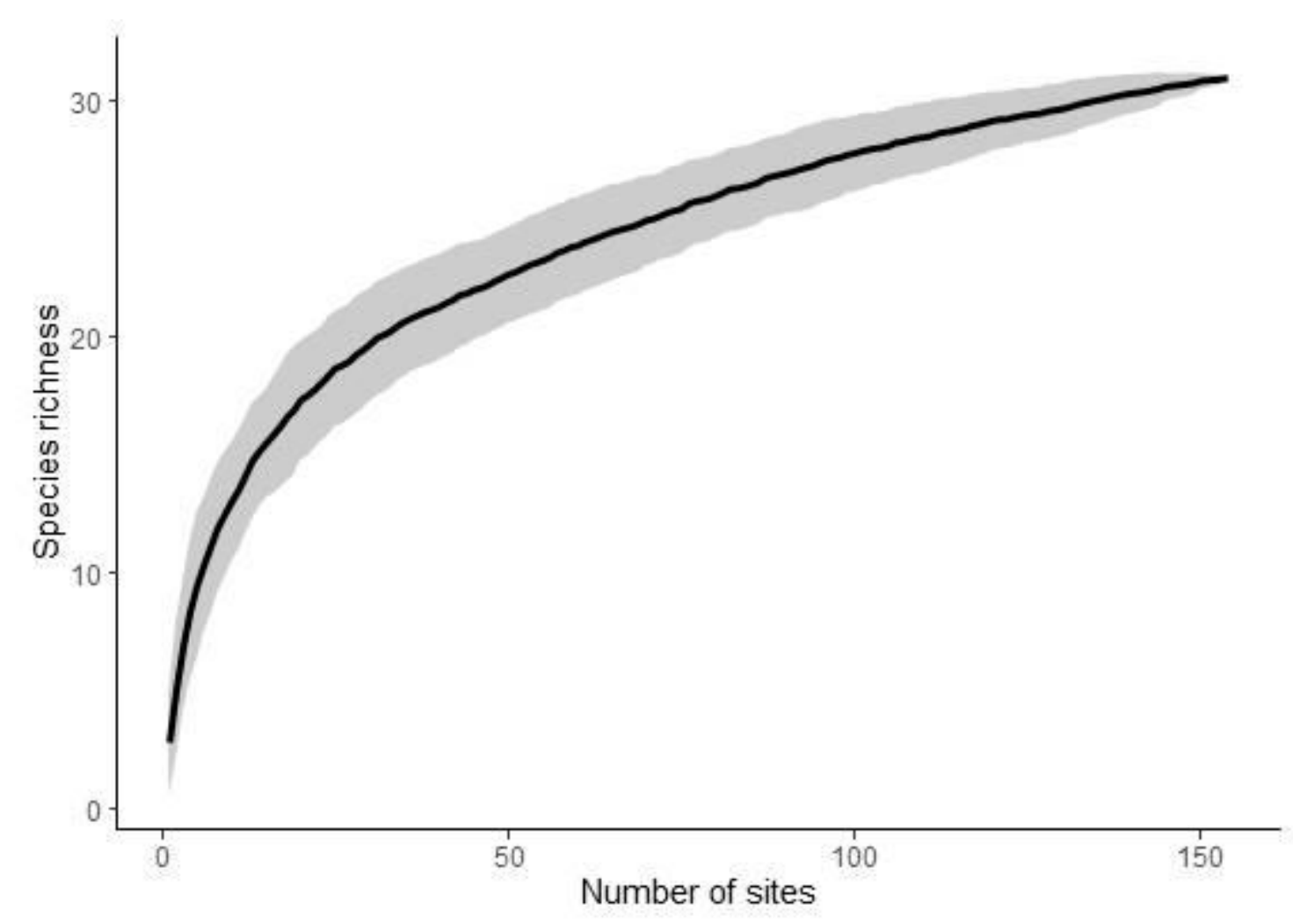

Fig. A4.3 Species accumulation curve of bees, mean values (lines) and standard deviations (polygon) from 100 permutations of 154 sampled sites are shown. 


\section{Conclusions, limitations, and future research potential}

In the introduction (Chapter 1) two research questions were defined outlining the focus of this dissertation. Accordingly, the three studies in Chapters 2 to 4 address effects of urban centers on agricultural management systems and consequences of agricultural change for natural resources and environmental services. The empirical work in all three studies is based on primary data from two research transects in the rural-urban interface of Bangalore in South India. Data were collected in two socio-economic surveys from December 2016 to May 2017 and February to March 2018, and in pan trap experiments.

This dissertation focuses particularly on effects of rapidly growing urban centers and megacities such as Bangalore. This type of urbanization is predicted to dominate future urbanization trends and presents new challenges to modeling urbanization effects on agricultural systems (United Nations, Department of Economic and Social Affairs, Population Division, 2019). The setup of larger urban agglomerations is often polycentric, i.e. a larger city with several satellite towns (Marull et al., 2015). Additionally, such regions are characterized by well-functioning industrial and service sectors (Hall \& Pain, 2009). Consequently, effects of such urban centers on farming households are complex because they provide access to multiple market centers and off-farm employment. In previous studies urbanization effects on agricultural systems have been measured by one-dimensional variables such as distance or travel time to the next urban center (Chamberlin \& Jayne, 2013; Vandercasteelen et al., 2017). This definition relies on the concept of transportation costs, which are assumed to be proportional to the distance to a city or equivalent proxies (Damania et al., 2017). The closer a farm is located to a city the higher the degree of agricultural intensification due to lower transportation costs and, thus, lower net input and high net output prices (Vandercasteelen et al., 2017). However, what happens when smallholder farmers have access to more than one market or when some household members are employed in the offfarm-sector? To account for this increasing complexity and interaction of multiple urban influences, more complex theoretical and empirical models are necessary.

This is the point of departure for the first two studies presented in this dissertation. In both studies two-dimensional Penalized (P-) Splines are applied to model urbanization effects in a spatially explicit way (Fahrmeir et al., 2013). The goal is to present a more flexible alternative to the usually used one-dimensional proxies. 
The first study "Somewhere in between towns, markets and jobs - Opportunity costs of agricultural intensification in the rural-urban interface" addresses two research questions: First, it is interested in farmers' management decisions when they have access to more than one urban center, i.e. in a polycentric urbanization setting. Second, we investigate the effect of households' income diversification on agricultural management decisions. The number of adopted modern inputs represents the degree of agricultural intensification. Urbanization effects are estimated by two-dimensional P-Splines based on household and village coordinates in the rural-urban interface of Bangalore. In a conceptual framework, we are able to show that households' choices concerning labor allocation between off-farm employment in the city and labor-intensive modern agricultural management lead to complex and likely nonlinear patterns. The patterns are defined by the ratio of net wage and net output price as functions of household location. That means wages as well as output prices depend on the access to urban centers, i.e. transportation costs. The empirical analysis supports the hypothesis of complex spatial patterns. The estimated two-dimensional P-Splines differ significantly between the two research transects. Effect sizes are five times higher in the northern than in the southern transect, and effect patterns differ as well. In the northern transect proximity to a satellite town appears to increase the adoption of modern inputs, whereas proximity to Bangalore has a negative effect. In the southern transect, proximity to a highway has an increasing effect on modern input adoption.

The second study "Digging deep and running dry - the adoption of borewell technology in the face of climate change and urbanization" examines how urbanization and changing weather patterns influence farmers' decisions to adopt groundwater lifting technology. On the one hand, the adoption of such a technology is an indicator of the modernization of agricultural systems. On the other hand, it is also interesting in the context of natural resource management. Water is scare in the Bangalore area and access to groundwater is often a prerequisite for commercialized agriculture and income generation for many farm households (Alcon et al., 2011). Therefore, sustainable management of groundwater is essential to the long-term wellbeing of smallholders. This becomes especially important since weather and monsoon rains have become increasingly unreliable in the course of climate change (Shah, 2007). To incorporate urbanization and weather changes in the analysis, we estimate a duration model with structured additive predictor including a two-dimensional P-Spline for 
household coordinates (Kneib, 2006; Fahrmeir et al., 2013). The dependent variable of a duration model represents the probability that an event - in the present case the adoption of a borewell-takes place in a given time period (Therneau \& Grambsch, 2000). It is thus a dynamic model and time-variant weather data (rainfalls) can be included. The results of the empirical analysis show that proximity to Bangalore, as well as to satellite towns increases the likelihood of borewell adoption. Furthermore, we observe a higher probability of borewell adoption when rainfalls decrease. In contrast, high monsoon rains increase the likelihood of borewell adoption in the subsequent year. One explanation could be additional capital from a year with sufficient monsoon rains or the wish to secure another good harvest. Moreover, we find some evidence of technology spillover among farmers in the same village. The more farmers in a village adopted the borewell technology the higher becomes the likelihood of non-adopters to build a borewell in the next period. ${ }^{19}$ Thus, increased probability of borewell adoption due to urban centers or droughts might be further amplified by social learning and information spillovers.

The results of the first two studies confirm that modeling two-dimensional urbanization effects has several advantages. Particularly, the first study demonstrates that the adoption of modern inputs is not affected in a uniform and concentric gradient around Bangalore. To account for such differences, spatially explicit modeling is inevitable since one-dimensional measures such as distance to a city will only represent blurred and aggregate effects. Furthermore, the importance of satellite towns becomes visible in both studies. These towns appear to have an equal, if not stronger, positive effect on agricultural intensification. Therefore, polycentric setups of metropolitan regions have to be considered in the analysis of urban effects on agricultural management systems. Effects by satellite towns contribute to overall nonlinear effect patterns and thus underline the case for spatially explicit modeling approaches. A flexible representation of urbanization effect is also necessary because there is a multitude of urban influences. We show that urbanization effects very likely result from an interplay of antagonistic forces and can only be understood in a relative concept. The particular case outlined in the first study refers to household choices concerning labor allocation into off-farm employment or labor-intensive modern agriculture. This shows that nonlinear and nonconcentric effect patterns cannot only result from polycentric urbanization patterns but also from antagonistic incentives for farm households.

\footnotetext{
19 Only in the northern transect this effect turns negative once a higher number of farmers adopted the technology. That might be a sign that water aquifers are already overexploited and wells start to fall try.
} 
Despite the strong case that the first two studies make for spatially explicit modeling of urbanization effects on agricultural management systems, there are several limitations and additional research potentials that must be addressed. First, both studies rely on crosssectional data. With such data it is difficult to establish causality among variables. Urbanization and agricultural change are developments that both evolve over time. The simultaneity of these processes makes it hard to establish cause-effect-relationships in crosssectional data analysis without making strict or unrealistic assumptions. In the first study, we address the issue by considering only variable inputs for the construction of the dependent variable. Variable inputs can be adjusted every growing seasons and represent short-term responses to farmers' circumstances. Therefore, the status of urbanization at the time of decision-making is assumed to be a static and exogenous factor. In the second study, we try to overcome the limitation by using a dynamic modeling approach (duration model). The borewell technology - unlike variable inputs - is a long-term management decision and has a lasting effect on agricultural management systems. In addition, the second study shows that there are other time-dependent developments such as weather changes influencing management decisions that are neglected in cross-sectional analysis as well. Therefore, to obtain a comprehensive understanding of cause and effect relations between urbanization processes and agricultural change, panel data sets are indispensible.

Moreover, the research transects which build the foundation of the empirical analysis of this dissertation, where designed under the impression of monocentric urbanization patterns around Bangalore. Consequently, detected urbanization effects by satellite towns or road infrastructure are somewhat arbitrary. Future studies should foresee polycentricity and plan research areas accordingly. That means, instead of several transects connected to one city, a larger coherent area including several towns of different structures, e.g. industrial vs. nonindustrial or large vs. small, should be chosen. In addition, the Bangalore area is characterized by diverse cropping patterns; in our sample, more than 70 crops were recorded. This crop diversity makes it difficult to draw general conclusions on effects of urban centers on agricultural systems because the different cropping systems already differ substantially by construction. Therefore, future studies - particularly if only cross-sectional data is availableshould focus on areas with one dominant or similar cropping systems.

Another limitation lies in the modeling of simultaneous household decision-making concerning off- and on-farm labor allocation. In this dissertation we estimate one-equation 
models with proxies of agricultural management decisions (input adoption) as dependent variable. Nevertheless, the conceptual framework developed in the first study implies that households simultaneously optimize their decisions subject to farm output prices and wage rates in the off-farm sector. In our household sample, the majority of off-farm employment refers to salary employment, which is generally a long-term decision. Therefore, in Chapter 2, we treat off-farm employment as exogenous variable using the same argument as with urbanization, i.e. decisions concerning variable inputs can be assumed to be more recent than decisions concerning off-farm employment. In the second study, we treat off-farm employment as time-variant variable, so that temporal causality can be established. However, in regions where seasonal and casual labor is more common such assumptions may not hold. Therefore, simultaneous equation models or estimation approaches with instrumental variables might be required.

Finally, some suggestions for future research building on the findings presented in Chapters 2 and 3: A full formal derivation of the conceptual framework would present an interesting objective for future research. Additionally, simultaneous estimation models might present a suitable empirical tool to investigate then formalized hypotheses. If employment for each adult household member is recorded, a variable could be created representing the share of household time allocated into the off-farm sector. With a simultaneous equation model, allowing interdependence between this variable and an intensification indicator (e.g. number of adopted modern inputs), the decision-making problem described in the conceptual framework could be directly estimated. Particularly interesting would be to connect such an equation system with the estimation of geosplines keeping up the flexible approach of estimating urbanization effects presented in Chapters 2 and 3. If panel data on the share of households' time allocated to either agricultural production or off-farm employment were available, it would also be possible to observe changes in the contribution of agricultural production to a household's income over time. Such changes can have implications for food and nutrition status of smallholder households, i.e. households might consume less own produce but purchase more in food markets when the importance of own agricultural production decreases, and for households' living standards in general. In addition, a disaggregation of effects of different kinds of off-farm employment should be investigated. Skilled and unskilled labor is likely to have very different consequences for the living standards of smallholder households. A good understanding of these developments is, thus, crucial for extension services and policy programs. 
Furthermore, the second study shows that social learning and information spillover contribute to speeding up technology adoption. Thus, modeling social networks in a more explicit way presents an interesting research objective. Adhering to the focus on spatial analysis, a comparison of geographic and social distance between households and resulting effects on information transfer and adoption decisions comes to mind. Every exogenous variable can be used to construct weight matrices in the fashion presented in Chapter 4. Especially in developing countries tribal affiliation, age or comparable factors define social networks (Jackson, 2011; Jackson \& Yariv, 2011). However, a majority of studies exclusively consider geographic distance to setup weight matrices and describe diffusion processes (Schmidtner et al., 2012; Wollni \& Andersson, 2014). By applying recently developed spatial econometric models allowing for several weight matrices (Prucha et al., 2016; Bhattacharjee et al., 2018), the adequacy of different geographic and social distance measures could be directly tested and compared within the same model specification. Determining which and to which extent different distance measures affect technology adoption, would allow for a more nuanced understanding of technology diffusion processes and programs promoting the adoption of certain technologies could be targeted more effectively. In the Indian context, good examples for social distance measures would be caste or the age of farmers. Caste is still an important factor structuring Indian society; the same holds for age hierarchies.

The second study already hints at consequences of agricultural change for natural resources and environmental services, and negative feedbacks threatening the agricultural production and wellbeing of smallholders. In this context, the third study of this dissertation 'Farmers' decision-making and pollination services: A spatial autoregressive analysis" analyzes the effect of agricultural intensification on bee communities in the rural-urban interface of Bangalore. More specifically, we model the effect of farmers' decisions to use chemical fertilizers and pesticides on bee abundance and species richness. The Bangalore area is famous for its fruit and vegetable production, which largely depends on wild pollination (Directorate of Census Operations Karnataka, 2011; Kennedy et al., 2013). In contrast to management systems in the northern hemisphere, where a lack of wild pollinators can be compensated by managed bee colonies, this is less common in the agricultural production in developing countries (Kennedy et al., 2013). Therefore, the use of agricultural practices threatening pollinator communities will eventually have devastating consequences for 
smallholder agricultural production. It is, thus, essential to identify harmful management practices and investigate the way they affect pollinator communities. Only then can appropriate policy measures be designed and implemented. The majority of recent studies treat this issue at the landscape scale, which appears to be useful to explain the status of pollinator populations, which can have large dispersal ranges (Beekman \& Ratnieks, 2000). Nevertheless, such a perspective does not allow for conclusions concerning individual decision-making at the plot level (Bockstael, 1996). This is however important because the plot or household level is normally the target of policy measures. To close this gap, the goal of the study in Chapter 4 is to connect the economic concept of decision-making on the plot level and ecological indicators of abundance and richness generally attributed to the landscape scale. Durbin models, a spatial econometric model specified by spatial lags in dependent and independent variables, are applied (LeSage \& Pace, 2009). Moreover, explanatory variables on the plot and landscape scale are included, as well as information on the history of plot management.

For both bee indicators we find strong spatial correlation among observations in a 4-kilometer radius. This can be interpreted as the mean dispersal range of bee populations in the area. Despite the dispersal range, effects differ between the indictors of abundance and species richness. Bee abundance significantly decreases with the use of chemical fertilizers and pesticides as well as with intensive past plot management. Furthermore, pesticide use shows a strong negative spillover on bee abundance on neighboring plots. In contrast, bee richness is primarily affected by intensive past plot management that leads to significant negative effects. Consequently, spatial as well as temporal factors influence bee populations in the Bangalore area. Based on these results we deduce two main policy implications: First, considering the negative spillovers of pesticide use, extension services should target groups of neighboring farmers to avoid free-riding or a prisoner's dilemma. Second, continuous intensive plot management should be avoided. A coordinated rotation between intensive and extensive management systems could create more forage and nesting opportunities for pollinators.

By connecting economic and ecological concepts, the study presented in Chapter 4 addresses a gap in and contributes to the existing literature. However, there are some limitations that should be mentioned. The empirical analysis relies on a sample of 131 plots. Future studies should aim at larger samples to increase the statistical validity of estimates. In addition, comparable with the first two studies, the analysis would greatly benefit from a panel data set. 
The consideration of recall data on past plot management was an attempt to control for some temporal factors influencing pollinator communities. However, panel data on the pollinator indicators, abundance and richness, would allow to more appropriately control for timedependent factors.

Finally, some suggestions for future research: Bees are only one (though important) group of pollinators and environmental services providers. However, many other agents are crucial for agricultural production. These include other pollinator species (e.g. flies or beetles), birds, or soil organisms. The proposed spatial method presents a useful tool of analysis to overcome spatial scaling and resulting correlation, especially in the case of mobile agents. It would also be interesting to quantify the negative economic spillovers of pesticide use (i.e. reductions in revenues and profits). Several studies have quantified the contribution of pollination services to agricultural output in monetary terms (Allsopp et al., 2008; Cordier et al., 2014). If such a concept could be transferred to the production losses/gains farmers experience when their neighbors use/do not use pesticides, the value of policies and extension services could be quantified as well. To be more precise, if the actual contribution of pollinator services for the production of particular crops could be estimated in ecological experiments, simulations of production loss due to pesticide use in the area based on calculated spillovers in Chapter 4 are conceivable. By changing parameters such as the number or location/clustering of pesticide users, different scenarios could be tested and compared to assess consequences of different land use systems for pollinator communities. 


\section{References}

Alcon, F., Miguel, M. D. de, \& Burton, M. (2011). Duration analysis of adoption of drip irrigation technology in southeastern Spain. Technol. Forecast. Soc., 78, 991-1001.

Allsopp, M. H., Lange, W. J. de, \& Veldtman, R. (2008). Valuing insect pollination services with cost of replacement. PloS one, 3, e3128.

Beekman, M., \& Ratnieks, F. L. W. (2000). Long-range foraging by the honey-bee, Apis mellifera L. Functional Ecology, 14, 490-496.

Bhattacharjee, A., Holly, S., \& Mur, J. (2018). Contemporary developments in the theory and practice of spatial econometrics. Spatial Economic Analysis, 13, 139-147.

Bockstael, N. E. (1996). Modeling Economics and Ecology: The Importance of a Spatial Perspective. American Journal of Agricultural Economics, 78, 1168.

Chamberlin, J., \& Jayne, T. S. (2013). Unpacking the Meaning of 'Market Access': Evidence from Rural Kenya. World Dev., 41, 245-264.

Cordier, M., Pérez Agúndez, J. A., Hecq, W., \& Hamaide, B. (2014). A guiding framework for ecosystem services monetization in ecological-economic modeling. Ecosystem Services, 8, 86-96.

Damania, R., Berg, C., Russ, J., Federico Barra, A., Nash, J., \& Ali, R. (2017). Agricultural Technology Choice and Transport. American Journal of Agricultural Economics, 99, 265284.

Directorate of Census Operations Karnataka (2011). Census of India 2011: Karnataka, District Census Handbook, Bangalore. Series-30.

Fahrmeir, L., Kneib, T., Lang, S., \& Marx, B. (2013). Regression: Models, Methods and Applications. Dordrecht: Springer.

Hall, P., \& Pain, K. (Eds.) (2009). The polycentric metropolis: Learning from mega-city regions in Europe. (Paperback ed.). London: Earthscan.

Jackson, M. O. (2011). An Overview of Social Networks and Economic Applications. In J. Benhabib, A. Bisin, \& M. O. Jackson (Eds.), Handbook of social economics (pp. 511585). San Diego, London: North Holland.

Jackson, M. O., \& Yariv, L. (2011). Diffusion, Strategic Interaction, and Social Structure. In J. Benhabib, A. Bisin, \& M. O. Jackson (Eds.), Handbook of social economics (pp. 645678). San Diego, London: North Holland.

Kennedy, C. M., Lonsdorf, E., Neel, M. C., Williams, N. M., Ricketts, T. H., Winfree, R., Bommarco, R., Brittain, C., Burley, A. L., Cariveau, D., Carvalheiro, L. G., Chacoff, N. 
P., Cunningham, S. A., Danforth, B. N., Dudenhöffer, J.-H., Elle, E., Gaines, H. R., Garibaldi, L. A., Gratton, C., Holzschuh, A., Isaacs, R., Javorek, S. K., Jha, S., Klein, A. M., Krewenka, K., Mandelik, Y., Mayfield, M. M., Morandin, L., Neame, L. A., Otieno, M., Park, M., Potts, S. G., Rundlöf, M., Saez, A., Steffan-Dewenter, I., Taki, H., Viana, B. F., Westphal, C., Wilson, J. K., Greenleaf, S. S., \& Kremen, C. (2013). A global quantitative synthesis of local and landscape effects on wild bee pollinators in agroecosystems. Ecology letters, 16, 584-599.

Kneib, T. (2006). Mixed model-based inference in geoadditive hazard regression for intervalcensored survival times. Computation. Stat. Data An., 51, 777-792.

LeSage, J. P., \& Pace, R. K. (2009). Introduction to spatial econometrics. Statistics, textbooks and monographs, 196. Boca Raton: CRC Press.

Marull, J., Font, C., \& Boix, R. (2015). Modelling urban networks at mega-regional scale: Are increasingly complex urban systems sustainable? Land Use Policy, 43, 15-27.

Prucha, I. R., Drukker, D. M., \& Egger, P. H. (2016). Simultaneous equations models with higher-order spatial or social network interactions.

Schmidtner, E., Lippert, C., Engler, B., Häring, A. M., Aurbacher, J., \& Dabbert, S. (2012). Spatial distribution of organic farming in Germany: does neighbourhood matter? European Review of Agricultural Economics, 39, 661-683.

Shah, T. (2007). The groundwater economy of South Asia: An assessment of size, significance and socio-ecological impacts. In M. Giordano, \& K. G. Villholth (Eds.), The agricultural groundwater revolution: Opportunities and threats to development (pp. 736). Wallingford: CABI.

Therneau, T. M., \& Grambsch, P. M. (2000). Modeling Survival Data: Extending the Cox Model. Statistics for biology and health. New York, NY: Springer New York.

United Nations, Department of Economic and Social Affairs, Population Division (2019). World Urbanization Prospects 2018: Highlights.

Vandercasteelen, J., Beyene, S. T., Minten, B., \& Swinnen, J. (2017). Cities and agricultural transformation in Africa: Evidence from Ethiopia. World Development, 105, 383-399.

Wollni, M., \& Andersson, C. (2014). Spatial patterns of organic agriculture adoption: Evidence from Honduras. Ecol. Econ., 97, 120-128. 


\section{List of publications}

Published papers in peer-reviewed journals:

Vogel, S., Märker, M., Rellini, I., Hoelzmann, P., Wulf, S., Robinson, M., Steinhübel, L., Di Maio, G., Imperatore, C., Kastenmeier, P., Liebmann, L., Esposito, D. \& Seiler, F. (2016). From a stratigraphic sequence to a landscape evolution model: Late Pleistocene and Holocene volcanism, soil formation and land use in the shade of Mount Vesuvius (Italy). Quaternary international, 394, 155-179.

Papers under review in peer-reviewed journals:

Steinhübel, L. \& von Cramon-Taubadel, S. "Somewhere in between towns, markets, and jobs - Opportunity costs of agricultural intensification in the rural-urban interface", submitted and under review at The Journal of Development Studies since August 28, 2019.

Steinhübel, L., Wegmann, J. \& Mußhoff, O. "Digging deep and running dry - the adoption of borewell technology in the face of climate change and urbanization", submitted to the journal Agricultural Economics January 4, 2019, currently under review after a first round of revisions.

Steinhübel, L., Wenzel, A., Hulamani, P., von Cramon-Taubadel, S. \& Mason, N. M. "Farmers' decision-making and pollination services: A spatial autoregressive analysis", submitted and under review at the journal Agriculture, Environment \& Ecosystems since May $15,2019$.

\section{Conference presentations:}

Steinhübel, L. (2018). Somewhere in between towns, markets, and neighbors - Agricultural transition in the rural-urban interface of Bangalore, India. $30^{\text {th }}$ International Conference of Agricultural Economists (ICAE), July 28 - August 2, 2018, Vancouver, Canada. 
Steinhübel, L. (2018). Somewhere in between towns, markets, and neighbors - Agricultural transition in the rural-urban interface of Bangalore, India. XII World Conference of the Spatial Econometrics Association, June 11-12, 2018, Vienna, Austria.

Steinhübel. L., Prehn, S., Brümmer, B., Pies, I. \& Will, M. G. (2017). The impact of index funds on grain futures markets revisited. XV Congress of the European Association of Agricultural Economists (EAAE), August 29 - September 1, 2017, Parma, Italy. 


\section{Declaration of own contribution}

Hereafter, I declare the parts I contributed to the three studies presented in this dissertation.

In the first study "Somewhere in between towns, markets, and job - Opportunity costs of agricultural intensification in the rural-urban interface", a collaboration with Prof. Dr. Stephan von Cramon-Taubadel, I was responsible for the following parts: preparation and implementation of socio-economic survey in collaboration with other graduate students from the DFG Research Group 2432 "Social-ecological systems in the Indian rural-urban interface: Functions, scales, and dynamics of transition" from December 2016 to May 2017 (particularly responsible for the questionnaire part on agricultural production), development of conceptual framework in collaboration with Prof. Dr. Stephan von Cramon-Taubadel, statistical analysis and interpretation of results, writing in collaboration with Prof. Dr. Stephan von CramonTaubadel.

In the second study "Digging deep and running dry - the adoption of borewell technology in the face of climate change and urbanization", a collaboration with Johannes Wegmann and Prof. Dr. Oliver Mußhoff, I was responsible for the following parts: preparation and implementation of socio-economic survey (see first study) in collaboration with Johannes Wegmann and other graduate students from the DFG Research Group 2432, development of conceptual framework, statistical analysis, interpretation of results and writing in collaboration with Johannes Wegmann, lead in the revision requested by the journal Agricultural Economics.

In the third study "Farmers' decision-making and pollination services: A spatial autoregressive analysis", a collaboration with Arne Wenzel, Prashant Hulamani, Prof. Dr. Stephan von Cramon-Taubadel, and Associate Professor Nicole M. Mason, I was responsible for the following parts: development of research idea in collaboration with Arne Wenzel and Prof. Dr. Stephan von Cramon-Taubadel, preparation of socio-economic questionnaire, coordination of survey and pan trap experiments with Arne Wenzel and Prashant Hulamani, implementation of socio-economic survey between February and March 2018 supported by Anjali Purushotham (graduate student in FOR2432), development of conceptual framework, econometric analysis, lead in interpretation of results and writing supported by Arne Wenzel, Prof. Stephan von Cramon-Taubadel, and Nicole M. Mason. 


\section{Affidavit}

I hereby declare on oath that:

1. This work has not already been submitted in the same or a similar form to other examination offices.

2. I have not applied for a doctoral degree at any other university.

Göttingen, September 12, 2019

(Signature)

I hereby declare on oath that this dissertation was written independently and without undue assistance.

Göttingen, September 12, 2019

(Signature) 